\title{
How to better measure hedonic residential property price indexes
}




\section{WP/16/213}

\section{IMF Working Paper}

\section{How to better measure hedonic residential property price indexes}

by Mick Silver

IMF Working Papers describe research in progress by the author(s) and are published to elicit comments and to encourage debate. The views expressed in IMF Working Papers are those of the author(s) and do not necessarily represent the views of the IMF, its Executive Board, or IMF management.

I N T ER N A T I O N A L MONETAR Y FUND 


\title{
IMF Working Paper
}

\author{
Statistics Department
How to better measure hedonic residential property price indexes Prepared by Mick Silver ${ }^{1}$ \\ Authorized for distribution by Claudia Dziobek
}

November 2016

\begin{abstract}
IMF Working Papers describe research in progress by the author(s) and are published to elicit comments and to encourage debate. The views expressed in IMF Working Papers are those of the author(s) and do not necessarily represent the views of the IMF, its Executive Board, or IMF management.
\end{abstract}

\begin{abstract}
Hedonic regressions are used for property price index measurement to control for changes in the quality-mix of properties transacted. The paper consolidates the hedonic time dummy approach, characteristics approach, and imputation approaches. A practical hedonic methodology is proposed that (i) is weighted at a basic level; (ii) has a new (quasi-) superlative form and thus mitigates substitution bias; (iii) is suitable for sparse data in thin markets; and (iv) only requires the periodic estimation of hedonic regressions for reference periods and is not subject to the vagrancies of misspecification and estimation issues.

JEL Classification Numbers: C43, E30, E31, R31.

Keywords: Hedonic Regressions; Residential Property Price Index; Commercial Property Price Index; House Price Index; Superlative Index Number; Thin Property Markets.

Author’s E-Mail Address: 01micksilver@gmail.org
\end{abstract}

\footnotetext{
${ }^{1}$ The author acknowledges comments by Gabriela Maciel (IMF, Research Department) and participants at the 2016 Conference of the Society of Economic Measurement, Thessaloniki, Greece, July 2016.
} 
Abstract

I. Introduction

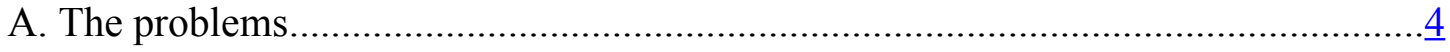

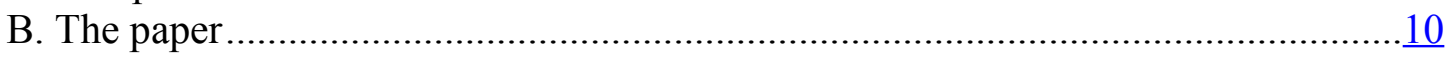

II. Measures of hedonic constant-quality property price change ....................................12

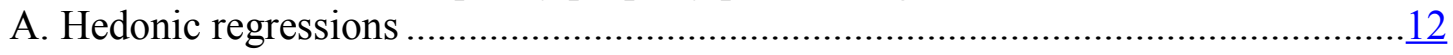

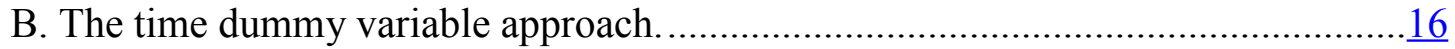

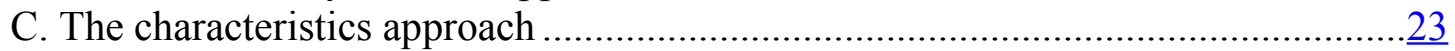

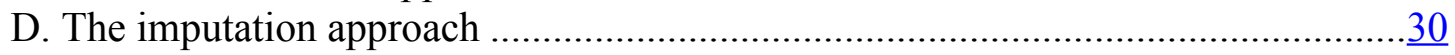

E. An indirect approach to hedonic price indexes ........................................... $\frac{32}{35}$

F. Arithmetic versus geometric aggregation: how much does it matter? ....................

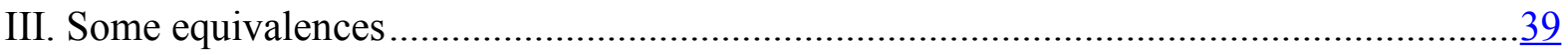

IV. Weights and superlative hedonic price indexes................................................ 43

A. Lower-level weights for a linear/arithmetic hedonic formulation ....................... $\frac{45}{49}$

B. Log-linear hedonic model ................................................................ 49

C. The nature of substitution bias for a hedonic price index ............................. $\frac{51}{52}$

D. Hedonic superlative indexes and sample selection bias.................................52

E. Hedonic superlative price index number formulas: Hill and Melser (2008) ...........54

F. Weights for the time dummy approach …..............................................

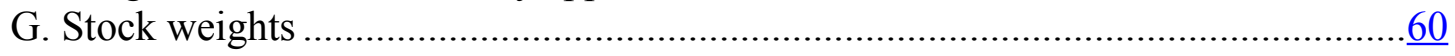

V. Hedonic property price indexes series: periodic rebasing, chaining and rolling windows $\underline{.61}$

VI. A practical choice of formula: equivalences, infrequent hedonic estimation, weighting, thin markets, and the indirect approach .....

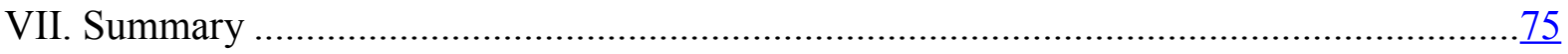

Tables

1. Illustrative linking of results from rolling window regression ....................................22

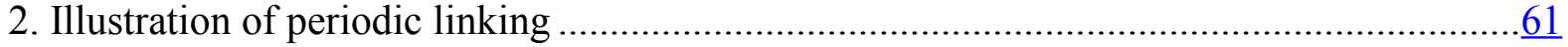

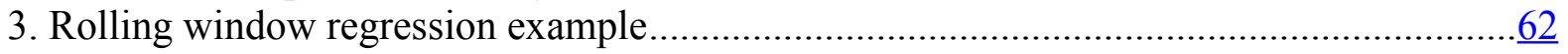

4. Illustration of quarterly adjacent period chaining ......................................................64

Annexes

A. Difference between hedonic arithmetic and geometric mean property price …................ $\underline{76}$

B. Outliers and leverage effects on coefficient estimates.............................................. 79

C. Equating an estimated coefficient on a time dummy from a log-linear hedonic model to the geometric mean of the price changes ..................................................................

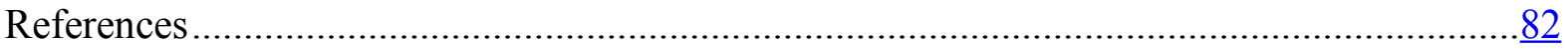




\section{INTRODUCTION}

\section{A. The problems}

Macroeconomists and central banks need measures of residential property price inflation. They need to identify bubbles, the factors that drive them, instruments that contain them, and analyze their relation to recessions. ${ }^{2}$ Such measures are also needed for the System of National Accounts and may be needed as part of the measurement of owner-occupied housing in a consumer price index - see Eurostat et al. (2013, chapter 3). Timely, comparable, proper measurement is a prerequisite for all of this, driven by concomitant data.

There have been major advances in this area foremost of which are: (i) recently developed international standards on methodology, the Eurostat et al. (2103) Handbook on Residential Property Price Indices (RPPIs), ${ }^{3}$ (ii) an impressive array of data hubs dedicated to the dissemination of house price indices and related series including the IMF's Global Housing Watch; the Bank for International Settlements' (BIS) Residential Property Price Statistics; the OECD Data Portal; the Federal Reserve Bank of Dallas' International House Price Database; Eurostat Experimental House Price Indices; and private sources; ${ }^{4}$ and (iii) encouragement in compiling and disseminating such measures: real estate price indexes are included as Recommendation 19 of the G-20 Data Gaps Initiative (DGI), and residential property price indexes are prescribed within the list of IMF Financial Soundness Indicators (FSIs), in turn included in the IMF's new tier of data standards, the Special Data Dissemination Standard (SDDS) Plus. ${ }^{5}$ In this paper we identify the challenges countries face in the hard problem of measuring hedonic residential property price indexes (RPPIs). While

\footnotetext{
${ }^{2}$ For salient papers see the recent Conference by Deutsche Bundesbank, the German Research Foundation (DFG) and the International Monetary Fund on "Housing Markets and the Macroeconomy: Challenges for Monetary Policy and Financial Stability" at:

http://www.bundesbank.de/Redaktion/EN/Termine/Research_centre/2014/2014_06_05_eltville.html

${ }^{3}$ http://epp.eurostat.ec.europa.eu/portal/page/portal/hicp/methodology/hps/rppi handbook.

4 The IMF's Global Housing Watch provides current data on house prices for 52 countries as well as metrics used to assess valuation in housing markets, such as house price-to-rent and house-price-to-income ratios: http://www.imf.org/external/research/housing/; the BIS has extensive country series on RPPIs along with details of, and links to, country metadata and source data: http://www.bis.org/statistics/pp.htm; OECD also disseminates country house price statistics and is developing a wide range of complementary housing statistics: http://www.oecd.org/statistics/; see also the Federal Reserve Bank of Dallas' International House Price Database, Mack and Martínez-García (2011), at: http://www.dallasfed.org/institute/houseprice/index.cfm and Eurostat Experimental House Price Indices at: http://appsso.eurostat.ec.europa.eu/nui/show.do?dataset=prc hpi q\&lang=en.
}

${ }^{5}$ The setting of such standards is a key element of Recommendation 19 of the report: The Financial Crisis and Information Gaps, endorsed at the meeting of the G-20 Finance Ministers and Central Bank Governors on November 7, 2009 and carries over for RPPIs and CPPIs to individual recommendations under the follow-up DGI-2; see Heath (2013) for details of SDDS Plus and the DGI and http://fsi.imf.org/ for FSIs under "concepts and definitions."

(continued...) 
the focus of the paper will be on RPPIs, the analysis and proposed methodology holds for the more difficult area of hedonic commercial property prices indexes (CPPIs). Indeed, the problem of infrequent transactions and property heterogeneity are more profound for CPPIs than RPPIs and the proposals in this paper for dealing with sparse data in thin markets more relevant.

We first, in this sub-section IA of the "Introduction" to the paper, provide a context to the paper by outlining the problem of RPPI measurement. ${ }^{6}$ In the next sub-section, IB, we outline the purpose and structure of the paper.

\section{The problem of quality-mix adjustment}

Critical to price index measurement is the need to compare, in successive periods, transaction prices of like-with-like representative goods and services. Price index measurement for consumer, producer, and export and import price indexes (CPI, PPI and XMPIs) largely rely on the matched-models method. The detailed specification of one or more representative brand is selected as a high-volume seller in an outlet, for example a single $330 \mathrm{ml}$. can of regular Coca Cola, and its price recorded. The outlet is then revisited in subsequent months and the price of the self-same item recorded and a geometric average of its price and those of similar such specifications in other outlets form the building blocks of a price index such as the CPI. There may be problems of temporarily missing prices, quality change, say size of can or sold as a bundled part of an offer if bought in bulk, but essentially the price of like is compared with like every month. ${ }^{7}$ RPPIs are much harder to measure.

First, there are no transaction prices every month/quarter on the same property. RPPIs have to be compiled from infrequent transactions on heterogeneous properties. A higher (lower) proportion of more expensive houses sold in one quarter should not manifest itself as a measured price increase (decrease). There is a need in measurement to control for changes in the quality of houses sold, a non-trivial task.

The main methods of quality adjustment are (i) hedonic regressions; (ii) use of repeat sales data only; (iii) mix-adjustment by weighting detailed relatively homogeneous strata; and (iv) the sales price appraisal ratio (SPAR). ${ }^{8}$ The method selected depends on the database used. There needs to be details of salient price-determining characteristics for hedonic regressions,

\footnotetext{
${ }^{6}$ We draw on Silver (2016a) for this sub-section IA.

${ }^{7}$ International manuals on all of these indexes can be found at under "Manuals and Guides/Real Sector" at: http://www.imf.org/external/data.htm\#guide. This site includes the CPI Manual: International Labour Office et al. (2004).

${ }^{8}$ Details of all these methods are given in Eurostat et al. (2013); see also Hill (2013) for a survey of hedonic methods for residential property price indexes; Silver and Heravi (2007) and Diewert, Heravi, and Silver (2008) on hedonic methods; Diewert and Shimizu (2013b) and Shimizu et al. (2010) for an application to Tokyo; and Shiller (1991, 1993, and 2014) on repeat-sales methodology.
} 
a relatively large sample of transactions for repeat sales, and good quality appraisal information for SPAR. In the US, for example, price comparisons of repeat sales are mainly used, akin to the like-with-like comparisons of the matched models method, Shiller (1991). There may be bias from not taking full account of depreciation and refurbishment between sales and selectivity bias in only using repeat sales and excluding new home purchases and homes purchased only once. However, the use of repeat sales does not require data on quality characteristics and controls for some immeasurable characteristics that are difficult to effectively include in hedonic regressions, such as a desirable or otherwise view from the property.

\section{The problem of source data}

Second, the data sources are generally secondary sources that are not tailor-made by the national statistical offices (NSIs), but collected by third parties, including the land registry/notaries, lenders, realtors (estate agents), and builders. The adequacy of these sources to a large extent depends on a country's institutional and financial arrangements for purchasing a house and varies between countries in terms of timeliness, coverage (type, vintage, and geographical), price (asking, completion, transaction), method of quality-mix adjustment (repeat sales, hedonic regression, SPAR, square meter) and reliability; pros and cons will vary within and between countries. In the short-medium run users may be dependent on series that have grown up to publicize institutions, such as lenders and realtors, as well as to inform users. Metadata from private organizations may be far from satisfactory.

We stress that our concern here is with measuring RPPIs for FSIs and macroeconomic analysis where the transaction price, that includes structures and land, is of interest. However, for the purpose of national accounts and analysis based thereon, such as productivity, there is a need to both separate the price changes of land from structures and undertake adjustments to price changes due to any quality change on the structures, including depreciation. This is far more complex since separate data on land and structures is not available when a transaction of a property takes place. Diewert, de Haan, and Hendriks (2011) and Diewert and Shimizu (2013a) tackle this difficult problem.

Figure 1 shows alternative data sources in its center and coverage, methods for adjusting for quality mix, nature of the price, and reliability in the four quadrants. Land registry data, for example, may have an excellent coverage of transaction prices, but have relatively few quality characteristics for an effective use of hedonic regressions, not be timely, and have a poor reputation. Lender data may have a biased coverage to certain regions, types of loans, exclude cash sales, have "completion" (of loan) price that may differ from transaction price, but have data on characteristics for hedonic quality adjustment. Realtor data may have good coverage, aside from new houses, data on characteristics for hedonic quality adjustment, but use asking prices rather than transaction prices. 
The importance of distinguishing between asking and transaction prices will vary between countries as the length of time between asking and transaction varies with the institutional arrangements for buying and selling a house and the economic cycle of a country.

\section{Whether measurement matters}

A natural question is whether the differences in source data and methodologies used matters to the overall outcome of the index. Silver (2015) undertook an extensive formal analysis based on the RPPIs and, as explanatory variables, the associated methodological and source data for 157 RPPIs from 2005:Q1 to 2010:Q1 from 24 countries. The resulting panel data had fixed-time and fixed-country effects; the estimated coefficients on the explanatory measurement variables were first held fixed and then relaxed to be time varying. Subsequently, the explanatory variables were interacted with the country dummies.

Figure 1. Methodological issues and data sources in RPPI measurement

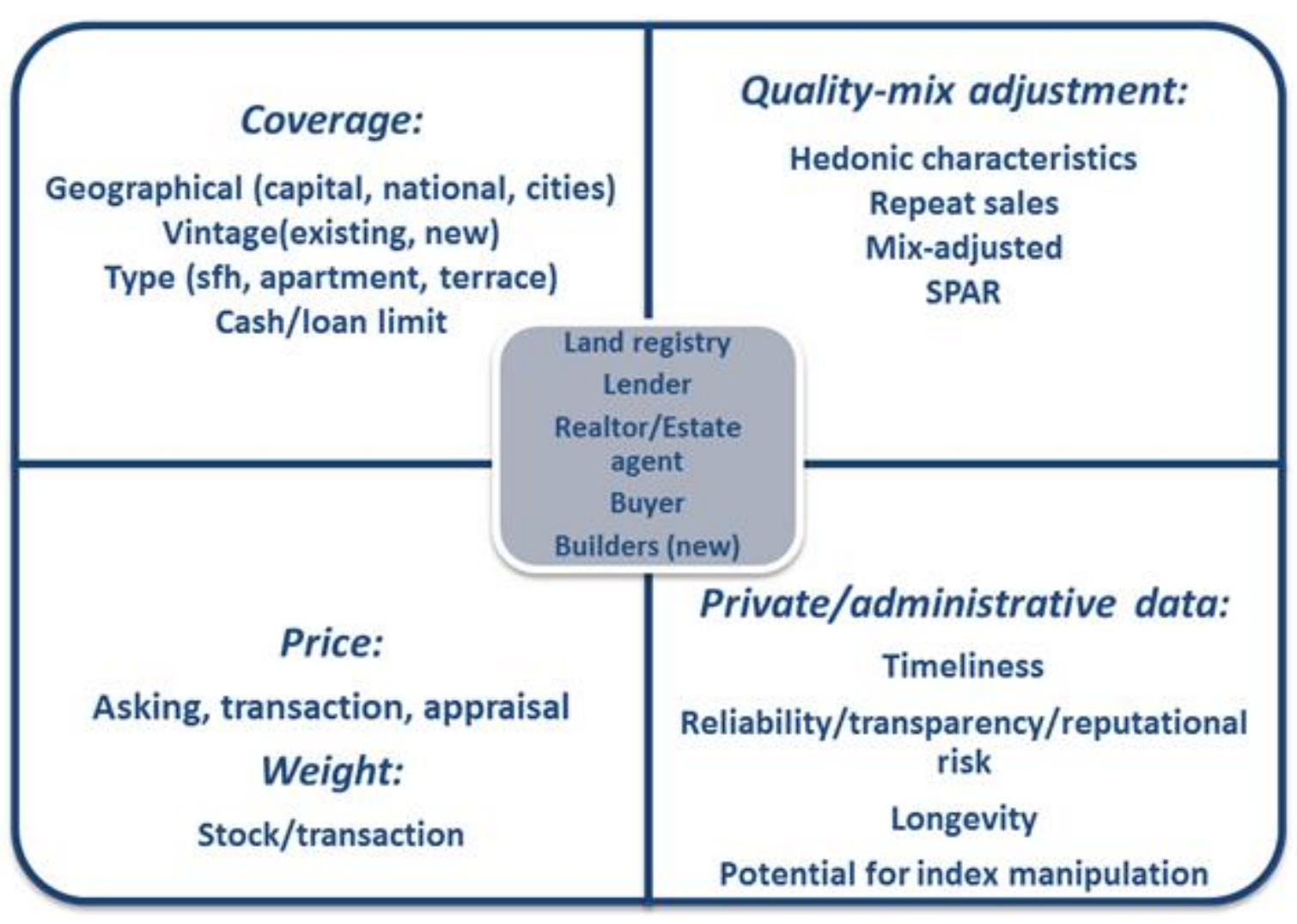

He found measurement-related variables as explanatory variables for house price inflation had substantial explanatory power, $\bar{R}^{2}$, especially over the period of recession, when it really matters, about 0.45 in mid-2009. He further investigated the impact of measurement on modelling, using an econometric model of house price inflation based on Igan and Loungani 
(2012). Using the residuals from the regression of house price index on measurement variables

as a "measurement-adjusted" house price index he found the measurement-adjusted model to perform better than the unadjusted one. Less formally, he provided some country illustrations. ${ }^{9}$

Figure 2 shows a feast of RPPIs available for the UK including the ONS (UK, hedonic mix-adjusted, completion price); Nationwide and Halifax (both UK, hedonic, own mortgage approvals, mortgage offer price; Halifax weights); the England and Wales (E\&W) Land Registry (E\&W, repeat sales, all transaction prices); and the ONS Median price index unadjusted for quality mixgiven for comparison. ${ }^{10}$ Other available RPPIs in the UK are LSL Acadata HPI (Land registry), ${ }^{11}$ Right move (realtor) and two RPPIs based on surveys of expert opinion. Measured inflation in 2008Q4 coming into the trough was 8.7 (ONS) -12.3 (Land registry) -16.2 (Halifax) -14.8 (Nationwide): and -4.9 (ONS Median unadjusted (for quality mix change); methodology and data source matter.

\section{Figure 2. A Feast of UK RPPIs, annual percent rate, quarterly}

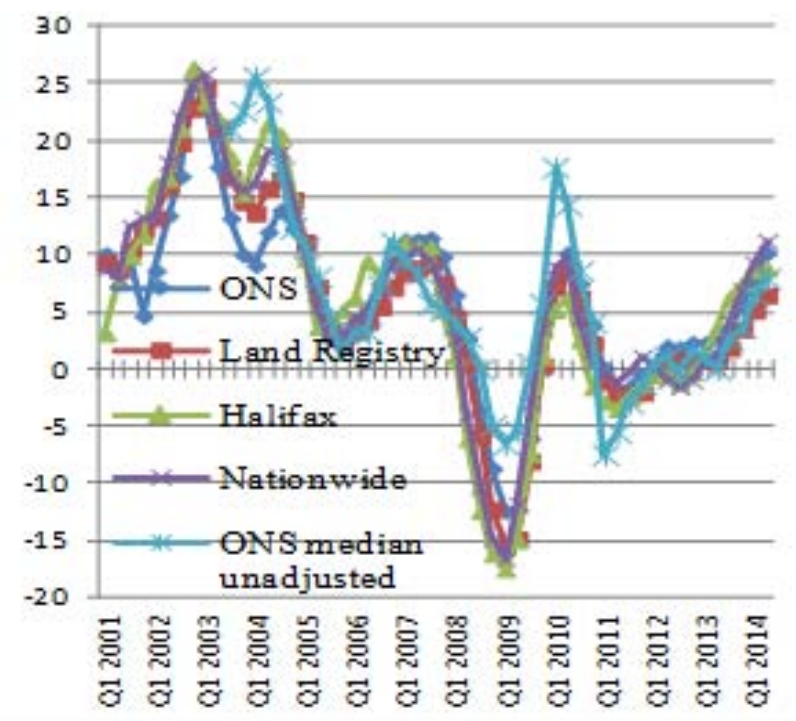

Source: http://www.bis.org/statistics/pp.htm, http://www.acadata.co.uk/acadHousePrices.php and http://www.ons.gov.uk/ons/rel/hpihouse-price-index/july2014/stb-july-2014.html.

\footnotetext{
${ }^{9}$ Data are generally sourced from: http://www.bis.org/statistics/pp.htm use also being made of: http://www.acadata.co.uk/acadHousePrices.php; http://www.ons.gov.uk/ons/rel/hpi/house-price-index/july2014/stb-july-2014.html; http://us.spindices.com/index-family/real-estate/sp-case-shiller; and http://www.fhfa.gov/KeyTopics/Pages/House-Price-Index.aspx

${ }^{10}$ A detailed account of the methodologies and source data underlying these RPPIs for the UK is given in Matheson (2010), Carless (2013), and ONS (2013); see also http://www.ons.gov.uk/ons/guide-method/userguidance/prices/hpi/index.html.

${ }^{11}$ Acadata use a purpose built "index of indices" forecasting methodology to help "resolve" the problem that only 38 percent of sales are promptly reported to Land Registry, considered by Acadata to be an insufficient sample to be definitive. The LSL Acad HPI "forecast" is updated monthly until every transaction is included. Effectively, an October LSL Acad E\&W HPI "final” result, published with the December LSL Acad HPI "forecast" is definitive.
} 
Figure 3 shows RPPIs available in the US including the: CoreLogic, Federal Housing Finance Agency (FHFA) purchases-only, Case-Shiller, and the FHFA extended-data House Price Index (HPI). CoreLogic, FHFA, and CaseShiller, the three primary RPPIs in the US, use repeat sales for quality-mix adjustment - the Census Bureau is a (hedonic) new houses only index based on a limited sample. The FHFA extended-data HPI includes, in addition to transaction prices from purchasemoney mortgages guaranteed by Fannie Mae and Freddie Mac, transactions records for houses with mortgages endorsed by the Federal Housing Administration (FHA) and county recorder data licensed from CoreLogic, appropriately re-weighted to ensure there is no undue urban over rural bias. This change in source data coverage accounted for the 4.6 percentage point difference in 2008 Q4 between the annual quarterly RPPI respective falls of 6.89 and 11.66 percent for the FHFA "All Purchases" and "Extended-Data" FHFA HPIs. Coverage limited to particular types of mortgages matters. ${ }^{12}$

Leventis (2008) decomposed into methodological and coverage differences the average difference between the FHFA (then Office of Federal Housing Enterprise Oversight (OFHEO)) and S\&P/Case-Shiller HPIs, covering 10 matched metropolitan areas, for the four-quarter price changes over 2006Q3-2007Q3. Among his findings was that of the overall 4.27 percent average difference, FHFA's use of a more muted down-weighting of larger differences in the lags between repeat sales, ${ }^{13}$ than use in Case-Shiller, accounts for an

\footnotetext{
12 http://www.fhfa.gov/PolicyProgramsResearch/Research/Pages/Recent-Trends-in-Home-Prices-Differencesacross-Mortgage-and-Borrower-Characteristics-.aspx.

13 The S\&P/Case-Shiller methodology materials suggest that its down-weighting is far more modest than FHFA. Over longer time periods, evidence suggests that there is greater dispersion in appreciation rates across homes. This variability causes heteroskedasticity, which increases estimation imprecision. The down-weighting mitigates the effect of the heteroskedasticity. Leventis (2008, page 3) notes that the S\&P/Case-Shiller methodological material suggest valuation pairs, which reflect the extent to which homes have appreciated or depreciated over a known time period, are given 20-45 percent less weight when the valuations occur ten years apart vis-à-vis when they are only six months apart. By contrast, OFHEO's down-weighting tends to give tenyear pairs about 75 percent less weight than valuation pairs with a two-quarter interval. Differences in filters and coverage of qualifying loans (FHFA) account for much of the rest.
} 
incremental 1.17 percent of the difference. It is not just that the use of different quality-mix adjustment methods matters, it does also the manner in which a method is applied.

\section{B. The paper}

This paper examines, consolidates, and provides improved practical methods for the timely estimation of hedonic RPPIs, though, as noted earlier, the proposed methods apply equally to CPPIs. Hedonic regressions are the main mechanism recommended for and used by countries for a crucial aspect of RPPI estimation - preventing changes in the quality-mix of properties transacted translating to price changes.

RPPIs and CPPIs are hard to measure. Houses, never mind commercial properties, are infrequently traded and heterogeneous. Average house prices may increase over time, but this may in part be due to a change in the quality-mix of the houses transacted; for example, more 4-bedroom houses in a better (more expensive) post-code transacted in the current period compared with the previous or some distant reference period would bias upwards a measure of change in average prices. A purpose and crucial challenge of RPPIs and CPPIs is to prevent changes in the quality-mix of properties transacted translating to measured price changes. The need is to measure constant-quality property price changes and while there are alternative approaches, ${ }^{14}$ the concern of this paper is with the hedonic approach as a recommended widely used methodology for this. ${ }^{15}$

The aim of this paper is to further develop a best practice methodology grounded in both the practical considerations and methodological rigor required for such an important statistic. The methodology is consistent with, but extends the provisions in, the 2013 Handbook on RPPIs (Eurostat et al., 2013) that form the international standards in this area.

The hedonic approach identifies properties as tied bundles of characteristics. The characteristics

\footnotetext{
${ }^{14}$ Alternatives include repeat sales, mix-adjustment by weighting more-homogeneous strata, and the sales price appraisal ratio (SPAR) are further alternatives. Each is used to form constant quality price indexes, SPAR by using the relationship between appraisal and transaction prices where such data coexist and predicting transaction prices. Repeat sales only uses that part of the dataset where there is more than one transaction over a given period. Details of all these methods are given in Eurostat et al. (2013); see also Hill (2013) for a survey of hedonic methods for residential property price indexes; Silver and Heravi (2007a) and Diewert, Heravi, and Silver (2009) on hedonic methods; Diewert and Shimizu (2013b) and Shimizu et al. (2010) for applications to Tokyo; and Shiller (1991, 1993, and 2014) on repeat-sales methodology., though see Case, Pollakowski, and Watcher (2003) for a hybrid repeat sales and hedonic model applied to house price indexes.

${ }^{15}$ Hill $(2013,906)$ concludes his survey paper: "Hedonic indexes seem to be gradually replacing repeat sales as the method of choice for constructing quality-adjusted house price indexes. This trend can be attributed to the inherent weaknesses of the repeat sales method (especially its deletion of single-sales data and potential lemons bias) and a combination of the increasing availability of detailed data sets of house prices and characteristics, including geospatial data, increases in computing power, and the development of more sophisticated hedonic models that in particular take account of spatial dependence in the data."
} 
are the price-determining ones, including size of property, number of bedrooms, location and so forth, and the sense in which they are "tied" is that the characteristics are not sold separately - there is no price in the market for each characteristic, only one for the house, structure and land, as a whole. Were there a price for a say additional bathroom, and houses transacted in the current period had more bathrooms, on average, we would have the means by which constant quality property price changes could be estimated. A hedonic regression of property prices on property characteristics allows us to "unbundle" the overall price and give estimated marginal values to the individual characteristics. This paper tackles the important question as to how, given estimated hedonic regressions, do we best compile hedonic, constant-quality, property price indexes?

The Handbook on Residential Property Price Indices (RPPIS) (Eurostat et al., 2013) provides international guidelines on RPPI measurement and chapter 5 contains three hedonic approaches - the hedonic time dummy approach, characteristics approach, and imputation approach. This follows previous literature in this area including Triplett (2006), Silver and Heravi (2007a) and Hill (2013). A problem is that there are many alternative forms for each approach depending on which period estimated hedonic coefficients, characteristic baskets, and weights are held constant, whether dual or single imputation is used for either prices or weights, a direct or indirect formulation is used, chained, rolling window or fixed baskets of characteristics, and more.

We first outline in section II the alternative approaches to hedonic property price indexes to ground the analysis. Throughout the paper this is undertaken for both linear and log-linear hedonic specification. In section III we demonstrate, for reasonable specifications of hedonic regressions, equivalences between the approaches and consolidate them to show that hedonic imputation and characteristics approaches yield the same result and the time dummy can be formulated as being a close approximation. The resulting formulas benefit from being justified by the different intuitions of the approaches.

In section IV we devise a weighting system for property price change at the elementary level, in this case for the price change of each individual property - an issue highlighted by Diewert (2005a). This is undertaken for the hedonic imputation approach but, due to the equivalences of the approaches, can also be mirrored in the characteristics approach to give the same result. While arithmetic (linear) formulation has a fortuitous implicit weighting system; however, the log-linear (geometric) price index equally weights property price changes. We develop for the log-linear (geometric) case a means by which explicit weights can be readily applied. Having done so, a natural next step is to define a superlative hedonic price index that makes symmetric use of reference period and current period weights. This is undertaken in two steps by defining hedonic "quasi-superlative" and re-defining "hedonic superlative" property price indexes, to advance on existing formulations in the literature of these target measures. The analysis so far is for bilateral price index number measurement, that is 
between a reference period and a current period. Section V extends the analysis to cover linking and chaining these bilateral indexes over time.

Practical problems are considered arising out of a concern with thin markets-sparse transaction price data. Controlling for the effect of heterogeneous properties requires a concomitant generous hedonic specification and care with estimation that is ill-served by frequent re-estimation using sparse data. It is particularly important to ground the hedonic price comparisons in a reference period that is relatively exhaustive of the property mix that arises in subsequent periods. The concern of the proposed methods is for parsimony of estimation, that is to not rely on estimates in successive periods and that better formulated to deal with sparse data.

In section VI a useful practical measure for countries is developed. The measure (i) benefits from a focus on the imputation approach, which is conducive to weighting, which provides equivalent result to the characteristics approach; (ii) requires that a hedonic regression only be run for the reference period; ${ }^{16}$ (iii) better accommodates sparse transaction data in thin markets; (iv) incorporates a quasi-superlative weighting system at the elementary level; (v) adopts an indirect approach to facilitate the use of dual imputations but also aids in interpretation; and (vi) can be readily extended as a conventional hedonic superlative index for retrospective studies.

\section{MEASURES OF HEDONIC CONSTANT-QUALITY PROPERTY PRICE CHANGE}

\section{A. Hedonic regressions}

The price index number problem for real estate is that measures of changes in the average price of properties reflect in part changes in the quality-mix of properties transacted. For example, there may be more 2-bedroom apartments sold in the current period than in some reference period. One way of tackling this problem is to determine the (marginal) value of an additional unit of each price-determining quality characteristic, such as the number of bedrooms, bathrooms, square footage of property, floor of apartment, possession or otherwise of parking, balcony, postcode, proximity to a metro, quality indicator of local school, and so forth. But such characteristics are not priced on the market, only the property as a whole.

Estimated hedonic regression equations explain variation in property prices, on the left hand side (LHS) of the equation, in terms of explanatory price-determining characteristics on the

\footnotetext{
${ }^{16}$ Though some re-estimation, say every year or two years, much like rebasing a consumer price index, would be advised, as would separate estimates for meaningful strata, say defined by location and type, for example, single family homes in the capital city.
}

(continued...) 
right hand side (RHS). The coefficients on each RHS characteristic are estimates of the marginal value of each respective characteristic. ${ }^{17}$ By considering properties as tied bundles of characteristics with associated estimated marginal values, we are equipped to solve the problem of adjusting changes in average property prices for changes in the quality-mix of properties transacted.

Our starting point is an estimated hedonic regression for a stratum of properties in a country, say apartments in the inner area of a capital city. The principles governing the specification and estimation of hedonic regressions are not the subject of this paper. ${ }^{18}$ Our concern is how hedonic regressions are used to derive property price indexes. Yet there is one issue that has a direct bearing on the derivation of hedonic price indexes and that is the functional form of the hedonic regression. Outlined here are two functional forms that are widely used, the latter more so: a linear and log-linear form. Choice between these forms should be based on $a$ priori and empirical grounds (testing), as outlined in Halvorsen and Pallakowski (1981), Cassel and Mendelsohn (1985), Can (1992), and Triplett (2006).

\section{Functional forms of the hedonic regression: a linear form}

Consider a linear hedonic functional form. An estimated hedonic regression would have the prices, $p_{i}^{t}$ of an individual property $i$ on the LHS and their associated $k$ characteristics, $z_{k, i}^{t}$ on the RHS as explanatory variables. Such hedonic regressions may be estimated for each defined stratum in a period 0 reference period (index $=100.00)$ and each successive period $t$ $(=1,2, . ., T)$. The linear functional form for period $t$ is given by:

(1).... $p_{i}^{t}=\gamma_{0}^{t}+\sum_{k=1}^{K} \gamma_{k}^{t} z_{k, i}^{t}+\varepsilon_{i}^{t}=h^{t}\left(z_{i}^{t}\right)+\varepsilon_{i}^{t}$ and estimated as:

(2).... $\hat{p}_{i}^{t}=\hat{\gamma}_{0}^{t}+\sum_{k=1}^{K} \hat{\gamma}_{k}^{t} z_{k, i}^{t}=h^{t}\left(z_{i}^{t}\right)$

where $\hat{p}_{i}^{t}$ (and $p_{i}^{t}$ ) are the predicted (actual) price of property $i$ in period $t ; z_{k, i}^{t}$ are the values of each $k=1, \ldots, K$ price-determining characteristic for property $i$ in period $t ; \gamma_{0}$ and $\gamma_{k}$ (and, below, $\beta_{0}$ and $\beta_{k}$ below) are the coefficients from a linear (and log-linear) hedonic equation;

\footnotetext{
${ }^{17}$ See Rosen (1975), Feenstra (1995), Diewert (2003b), Pakes (2003), and Silver (2004) for the theoretical basis of price indexes based on hedonic regressions.

${ }^{18}$ Readers are referred to Berndt (1991) and Triplett (2006) for a clear overview of hedonic regression methods, albeit not in the context of house prices, and for real estate: Sirmans et al (2006) on explanatory variables for the hedonic regression, de Haan and Diewert (2013), Coulson (2008), and Pace and LeSage (2004), Hill and Scholz (2013) and Silver and Graf (2012) for the increasing work on the spatial econometric modeling of house prices.
} 
$\varepsilon_{i}^{t}\left(\right.$ and $\left.v_{i}^{t}\right)$ i.i.d errors; and $h^{t}\left(z_{i}^{t}\right)$ a shorthand for a linear hedonic function estimated using period $t$ data and period $t$ characteristics.

Equation (1) has prices explained by a constant, $\gamma_{0}^{t}$, slope coefficients $\gamma_{k}^{t}$ for each $k$ pricedetermining characteristics, $z_{k, i}^{t}$, of which there are $K$, and an error term, $\varepsilon_{i}^{t}$. It is a linear relationship dictated, in equation (2), by the estimated constant and the slope coefficients, represented as hats "^" over the coefficients; for a single characteristic: $\hat{p}_{i}^{t}=\hat{\gamma}_{0}^{t}+\hat{\gamma}_{1}^{t} z_{1, i}^{t}$. The actual relationship may be non-linear and there will be omitted variable bias in using a linear form to (mis)represent the relationship. To counter this bias one possibility is to introduce some curvature via a squared term, $\hat{p}_{i}^{t}=\hat{\gamma}_{0}^{t}+\hat{\gamma}_{1}^{t} z_{1, i}^{t}+\hat{\gamma}_{2}^{t}\left(z_{1, i}^{t}\right)^{2}$, and test a null hypothesis as to whether $\gamma_{2}^{t}=0$, that is, whether the squared term has any explanatory power over and above that due to sampling error, say at a five percent level of significance. Interaction terms between more than one explanatory variable may also be introduced, Maddala and Lahiri (2009).

\section{Functional forms of the hedonic regression: a $\log ($ arithmic)-linear form}

An alternative functional form is a $\log$ (arithmic)-linear-also referred to as a semi-logarithmic - form of the hedonic regression. This form arises from a hedonic relationship between $p_{i}^{t}$ and $z_{k, i}^{t}$ given by:

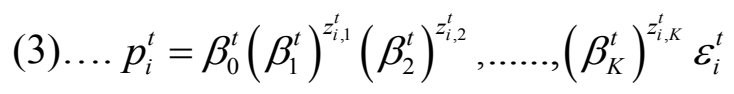

The log-linear form first allows for curvature in the relationships say between square footage and price, and second, for a multiplicative association between quality characteristics, i.e. that possession of a garage and additional bathroom may be worth more than the sum of the two. The estimation of ordinary least squares regression (OLS) equations requires a linear form; we transform the non-linear functional relationship in equation (3) into a linear form by taking logarithms of both sides of the equation and use OLS:

(4)... $\ln p_{i}^{t}=\ln \beta_{0}^{t}+\sum_{k=1}^{K} z_{k, i}^{t} \ln \beta_{k}^{t}+\ln \varepsilon_{i}^{t}=\tilde{h}^{t}\left(z_{i}^{t}\right)+\varepsilon_{i}^{t}$

where the tilde across $\tilde{h}^{t}\left(z_{i}^{t}\right)$ designates a log-linear functional form. An OLS regression estimated for the logarithm of prices, $\ln \hat{p}_{i}^{t}$, on characteristics, $z_{k, i}^{t}$, is given as: 
(5).... $\ln \hat{p}_{i}^{t}=\ln \hat{\beta}_{0}^{t}+\sum_{k=1}^{K} z_{k, i}^{t} \ln \hat{\beta}_{k}^{t}=\sum_{k=0}^{K} z_{k, i}^{t} \ln \hat{\beta}_{k}^{t}=\tilde{h}^{t}\left(z_{i}^{t}\right)$

It is important to note that the log-linear regression output from estimating equation (4), that is $\ln p_{i}^{t}$ on $z_{k, i}^{t}$, provides us with the logarithms of the coefficients from the original loglinear formulation in equation (3). Exponents of the estimated coefficients from the output of the software have to be taken if the parameters of the original function, that is equation (3), are to be recovered, that is: $\exp \left(\ln \hat{\beta}_{k}^{t}\right)=\hat{\beta}_{k}^{t}$. $^{19}$

Since many explanatory variables are dummy variables taking a value of zero or one - possession or otherwise of a characteristic — and since logarithms cannot be taken of zero values, the log-linear form is more convenient than a double-logarithmic transformation that would require logarithms be taken of the $z_{k, i}^{t}$ on the RHS. It should be noted that the interpretation of coefficients from a log-linear form differs from that of coefficients from a linear form. For a log-linear form our estimated coefficients are the logarithms of $\hat{\beta}_{1}, \hat{\beta}_{2}$, and $\hat{\beta}_{3}$ : a unit change in the say square footage, $z_{1, i}$, leads to a $\hat{\beta}_{1}$ percent change in price, while for a dummy explanatory variable, say "possession of a balcony, $z_{2, i}=1$ as opposed to $z_{2, i}=0$ otherwise," leads to an estimated $\left(\exp \left(\beta_{2}\right)-1\right) \times 100$ percent change in price, as will be explained in more detail in the next section.

We consider in this paper that hedonic regressions take a generally applicable linear and lo-linear forms given by equations (2) and (5) and that these have been estimated. Outlines of the three main hedonic approaches to deriving constant quality price indexes from these estimated equations, along their relative merits, are given below in sections B, C and E. These approaches are the (i) hedonic time dummy variable, (ii) hedonic characteristics and (iii) hedonic imputation approaches. The approaches are outlined and discussed in the context of bilateral period 0 (reference period $=100.00$ ) and current period $t$ price level comparisons where $t=1,2, \ldots, T$. While our main concern will be with quarter-on-quarter inflation rates, the principles can be readily extended to quarter-on-same quarter in previous year, though see Rambaldi and Rao (2103). The concern of section F is with the periodic updating or chaining of the reference period estimates.

\footnotetext{
${ }^{19}$ Again squared terms and cross-product interaction terms can be added to increase the flexibility of the functional form to better represent underlying relationships.
} 


\section{B. The time dummy variable approach.}

\section{The method}

A single hedonic regression equation may be estimated from data across properties over several time periods including the reference period 0 and successive subsequent periods $t$. Prices of individual properties are regressed on their characteristics, but also on dummy variables for time, taking the values of $\delta^{1}$ if the house is sold in period 1, and zero otherwise, $\delta^{2}$ if the house is sold in period 2 and zero otherwise, $\ldots, \delta^{T}$ if the house is sold in period $T$ and zero otherwise. We exclude in this case a period 0 dummy time variable and interpret the $\delta^{t}$ as the difference between the current period and reference period 0 average prices, having controlled for quality-mix change via the variables in the hedonic regression on their characteristics. The method has been widely applied including Fisher, Geltner, and Webb (1994), Hansen, (2009), and Shimizu et al. (2010).

Consider a linear form of the hedonic regression given by equation (1) but estimated over say two adjacent periods, 0 and 1 :

(6) $\ldots p_{i}^{0,1}=\beta_{0}+\delta^{1} D_{i}^{1}+\sum_{k=1}^{K} \beta_{k} z_{k, i}^{0,1}+\varepsilon_{i}^{0,1}$

The data for prices and characteristics extend over the two periods 0 and 1 , yet only a single parameter, $\beta_{k}$, is estimated for each characteristic's slope coefficient. The restriction is that the slopes of the regression lines for period 0 and period $t$ are the same: $\beta_{k}=\beta_{k}^{0}=\beta_{k}^{t}$ for each of $k=1, \ldots, K$ characteristics.

For simplicity, consider a single explanatory variable, the square footage of an individual apartment, $z_{i}^{0}$ or $z_{i}^{1}$ in periods 0 and 1 respectively. Separate regression equations can be estimated for each of period 0 and period 1 , but the slope coefficient, the estimated marginal value of an additional square foot, is restricted to be the same in each period, namely $\beta_{1}$ :

(7a) $\ldots p_{i}^{0}=\beta_{0}^{0}+\beta_{1} z_{i}^{0}+\varepsilon_{i}^{0} \quad$ for period 0 , and

(7b) $\ldots p_{i}^{1}=\beta_{0}^{1}+\beta_{1} z_{i}^{1}+\varepsilon_{i}^{1}$ for period 1 .

The estimated coefficients on the intercepts in each period are respectively $\hat{\beta}_{0}^{0}$ and $\hat{\beta}_{0}^{1}$. These are estimates of the average price in periods 0 and 1 having controlled for variation in the square footage of the apartments - the "average" is an arithmetic mean for this linear formulation (and a geometric mean for a log-linear formulation). 
We can represent equations ( $7 \mathrm{a}$ and $\mathrm{b}$ ) in a single hedonic regression:

(8) $\ldots p_{i}^{0,1}=\beta_{0}^{0}+\delta^{1} D_{i}^{1}+\beta_{1} z_{i}^{0,1}+\varepsilon_{i}^{0,1}=\beta_{0}^{0}+\left(\beta_{0}^{1}-\beta_{0}^{0}\right) D_{i}^{1}+\beta_{1} z_{i}^{0,1}+\varepsilon_{i}^{0,1}$

The dummy variable $D_{i}^{1}$ in equation (8) is equal to 1 if the data are in period 1 , and zero otherwise and its estimated coefficient $\hat{\delta}^{1}=\left(\hat{\beta}_{0}^{1}-\hat{\beta}_{0}^{0}\right)$. This representation of equations $7 \mathrm{a}$ and $7 \mathrm{~b}$ can be seen by inserting $D_{i}^{1}=0$ (period 0 data) into the RHS term of equation (8) to give equation (7a) and inserting $D_{i}^{1}=1$ (period 0 data) to give equation (7b), assuming $E\left(\varepsilon_{i}^{0,1}\right)=E\left(\varepsilon_{i}^{0}\right)=E\left(\varepsilon_{i}^{1}\right)$

The estimated coefficient on the dummy variable, $\delta^{1}$, is the basis for an estimate of a constant quality property price index between periods 0 and 1 . The estimate is of the difference between the period 0 and period 1 intercepts, ${ }^{20}$ that is the difference in the average prices of period 1 and period 0 transactions from their regression lines for period 0 and period 1 having controlled for variation in the quality characteristics $\sum_{k=1}^{K} \beta_{k} z_{k, i}^{0, t}$, as in equation (6), whereby each $k$ characteristic is valued at its associated $\hat{\beta}_{k}$.

A log-linear specification is given by:

(9)... $\ln p_{i}^{0, t}=\beta_{0}+\sum_{k=1}^{K} z_{k, i}^{0, t} \ln \beta_{k}+\sum_{t=1}^{T} \delta^{t} D_{i}^{t}+\varepsilon_{i}^{t}$

The $\hat{\delta}^{t}$ are estimates of the proportionate change in price arising from a change between the reference period $t=0$ - the period not specified as a dummy time variable - and successive periods $t=1, \ldots, T$ having controlled for changes in the quality characteristics via the term $\sum_{k=1}^{K} \beta_{k} z_{k, i}^{0, t}$

The constant-quality price index is given for each period $t=1, . ., T$, with respect to period $t=0$, which equals 100.00 , by $100 \times \exp \left(\hat{\delta}^{t}\right)$. In principle $100 \times \exp \left(\hat{\delta}^{t}\right)$ requires an adjustment-

\footnotetext{
${ }^{20}$ It may be thought that this interpretation is for the intercepts only when the explanatory variables are zero, but this is not the case. By restricting the slope coefficients to be the same, the regression lines for equations 7(a) and 7 (b) run in parallel and the difference in the intercepts is the same for any value of the $z_{k, i}^{0,1}$ characteristics.
}

(continued...) 
for it to be a consistent (and almost unbiased) approximation of the proportionate impact of the time dummy. The adjustment is given by: $\left.\left[\exp \left(\hat{\delta}_{t}\right) / \exp \left(V\left(\hat{\delta}_{t}\right) / 2\right)\right)\right]-1$, where $V\left(\hat{\delta}_{t}\right)$ is the variance (standard error squared) of $\hat{\delta}_{\mathbf{t}}$ and is generally very small; the estimate of constantquality price change is given by: ${ }^{21}$

(10)... $P_{T D}^{0 t}=100 \times \frac{\exp \left(\hat{\beta}_{0}+\operatorname{var}\left(\hat{\beta}_{0}\right) / 2+\hat{\delta}^{t}+\operatorname{var}\left(\hat{\delta}^{t}\right) / 2\right)}{\exp \left(\hat{\beta}_{0}+\operatorname{var}\left(\hat{\beta}_{0}\right) / 2\right)} \approx 100 \times \exp \left(\hat{\delta}^{t}\right)=100 \times \exp \left(\hat{\beta}_{0}^{t}-\hat{\beta}_{0}^{0}\right)$

The time dummy method has many positive features. Given data have been collected over time on price and quality characteristics, it is relatively easy to apply simply requiring the inclusion of time dummy variables into the panel (cross-section (property) time series) data set - a data set that requires no matching of properties since $\sum_{k=1}^{K} \beta_{k} z_{k, i}^{0, t}$ controls for changes in the quality mix over time. The estimates are readily derived from the estimated coefficients of the time-dummy variables, $\hat{\delta}^{t}$.

\section{Features of the method}

The method implicitly restricts the coefficients on the quality characteristics to be constant over time: for example, for adjacent period 0 and 1 regressions, $\beta_{k}=\beta_{k}^{0}=\beta_{k}^{1}$, as apparent from equations (6) and (9). This regression line for period 0 is parallel to that of period 1.

\footnotetext{
${ }^{21}$ We follow Kennedy (1981) and use for this log-linear form as the estimate of the proportionate impact of the period $t$ time dummy, the consistent (and almost unbiased) approximation: $\square\left[\exp \left(\hat{\delta}_{t}\right) / \exp \left(V\left(\hat{\delta}_{\mathrm{t}} / 2\right)\right)\right]-1$ where $\hat{\delta}_{\mathrm{t}}$ is the OLS estimator of $\delta_{\mathrm{t}}$ in equation (9) above and $V\left(\hat{\delta}_{\mathrm{tt}}\right)$ its estimated variance. The approximation is shown by Giles (2011) to be extremely accurate, even for quite small samples. The $\hat{\delta}_{\mathrm{t}}$ estimated impact of the period $t$ time dummy is proportionate to the estimated constant, $\hat{\beta}_{0}$ - the base (omitted) period $t=0$ intercept, acting as a benchmark. The constant-quality index is given by equation (10). The numerator is the constant (period $t=0$ intercept) plus the intercept shift of the time dummy, and the denominator the estimated period $t=0$ intercept. The simplified right-hand-side of equation (10) is derived by assuming the correction is minimal, as is usually the case but should be empirically checked in any application and, for the index measurement, cancelling out the $\hat{\beta}_{0}$. This leaves a readily interpretable approximation of $\exp \left(\hat{\delta}^{t}\right)$ - see also Van Garderen and Shah (2002) and the Note at the end of Hill (2013).
}

(continued...) 
The extent of this restriction depends on the length of the time period over which the regression is run. ${ }^{22}$ If, for example, the regressions are run over quarterly data for a rolling 10-year window, a property price comparison between say 2006Q1 and 2016Q1 with valuations of characteristics held constant may stretch credibility, though this can be alleviated by shorter windows and or adjacent period regressions as outlined below.

The time dummy method is criticized throughout the literature for holding the estimated coefficients constant. However, as will be outlined below in section C and D, a constant quality price index has to hold something constant over time to separate out the price change from the quality-mix change. In what we will term the "direct method," the quantities of price determining (quality) characteristics are held constant over time, for example for apartment prices, that the average number of bedrooms is held constant at 3.2 , the square footage at 1,150, and so forth and re-priced each period.

An advantage of the time dummy approach is that it the estimates are generated for a regression formulation. This facilitates the exploration of how the addition and deletion of explanatory variables, changes in the functional form and estimator have on the resulting price index number estimates. It also allows for confidence intervals ${ }^{23}$ to be drawn up around these estimates and, as Hill (2013, section 5) outlines, geo-spatial data ad spatial dependence can be readily integrated into the estimating framework (see also Pace and LeSage, 2004).

The time dummy approach uses the "indirect method" and adjusts (divides) the change in mean prices by changes in the volume of characteristics over time. However, this adjustment requires the estimated coefficients (characteristic prices) to be constant so that only changes in the volume of characteristics are measured. It is difficult to argue that constraining characteristic prices, the marginal value given to an additional bedroom and so forth, is less tenable than constraining average characteristics, the say average number of bedrooms in houses transacted in period 0 compared with 1 . There are no grounds for dismissing the time dummy approach on the grounds of constrained coefficients. Indeed, we show in section IV, and in Diewert, Heravi and Silver (2009), an equivalence between the direct and indirect methods.

\footnotetext{
22 The restriction is also for a particular stratum. If separate time dummy regressions are run by strata for types of house by major cities, the coefficients on quality characteristics for such properties have the flexibility to differ from those for other strata. Indeed, null hypotheses of no difference between one or more coefficient being the same across strata can be readily tested. These tests may be "nested" F-tests or likelihood ratio tests on the hedonic regressions that restrict such estimated coefficients to be the same and then allow them, say through dummy slope variables, to be different (Maddala and Lahiri, 2009). This can help inform practical considerations as to the detail at which strata can be defined.

${ }^{23}$ Our interest is with confidence intervals, not significance tests. The latter take the form of having a null hypothesis of say the time dummy being zero. It may be that actual house price inflation is zero, or close to it. A significance test as to whether the difference between the (exponent of the) estimated coefficient and zero is over and above that due t sampling errors at a given level of significance is of little meaning.
} 
If used for regular index number production, past values of the index will be revised each period as new data enter the regression. A "problem" with the revision of past values of the index should not be overstated. The three main RPPIs long-established and well-publicized in the United States, the Case-Shiller, FHFA, and CoreLogic indexes, are all repeat-sales indexes whose past values are revised each period without public concern. Second, the estimated coefficients for the quality characteristics are determined using data on price and quantity characteristics over the whole period of the regression. Thus some element of the estimate of property price inflation for the current period compared with the previous period is determined by past, if not quite distant, data. This lends some stability to the property price index, but may also smooth the results and risk some credibility when there is apparent volatility in the prices not mirrored in the index.

The rolling window approaches differ from the time dummy method in the important respect that estimated coefficients are not restricted to be constant over time: they are time varying. A say period $t$ to $t+1$ rolling adjacent period index is based on data in these two periods of concern, rather than the whole period. Rambaldi and Fletcher (2014) provide an extensive outline, and an empirical study, of the use of a Kalman Filter Smoother (KS) ${ }^{24}$ as against the rolling adjacent-period window approach. They argue that the Kalman Filter Smoother is preferred on the grounds that it optimally weights past values of the series when estimating the regression rather than just weighting the observations in the current window. The parameter estimates vary over time but are modeled as stochastic processes and can be applied to the time-dummy hedonic indexes (Schwann, 1998 and Francke, 2008) and the hedonic imputation approach (Rambaldi and Rao, 2011 and 2013). There is a trade-off between the extent to which an index is smoothed and volatility dampened, by drawing on more distant data either through a longer rolling window or Kalman Filter Smoother, and its ability to reflect current price changes in the market, albethey subject to more volatility. Smoothing methods are particularly suitable when data are sparse, that is in "thin" markets, as discussed below in section IV.

\section{Chaining, rolling windows and smoothing}

We can militate against the criticisms of undue restriction of coefficients, revisability, and stale data by using a chained rolling window - for illustration here, 4 quarters. Consider a fixed base index of the type described by equations (1) and (2) in which each period's index, say 2015Q4, is derived from the coefficient of the dummy variable on time for the period in question, compared with the (omitted) period $t=0$, say 2005Q1. The example is thus of the equation (6), or in log-linear form, equation (9), estimated on a quarterly basis over say 10 years. The fixed base estimated index from equations (9) for 2015Q4, where 2005Q1=100.0 is:

\footnotetext{
${ }^{24}$ An alternative smoothing estimator, as outlined in Rambaldi and Fletcher (2014), is a Kalman Smoother though this requires both past and future observations, not available for the real-time compilation of an index.
} 
(11) $\ldots . R P_{T D}^{2005 Q 1 \rightarrow 2015 Q 4}=\exp \left(\hat{\delta}^{2015 Q 4}\right) \times 100$

The adjacent period index is derived from successive multiplication-chaining —of regression estimates based on successive adjacent periods, i.e. a regression is first run on $2005 \mathrm{Q} 1$ and 2005Q2 data with a time dummy that is equal to 1 if the transaction is in 2005Q2 and zero otherwise. The estimated coefficient on this time dummy is an estimate of the change in price between the two periods, controlling for changes in quality.

(12)...R $P_{A J}^{2005 Q 1 \rightarrow 2005 Q 2}=\exp \left(\hat{\delta}^{2005 Q 2}\right) \times 100$.

The chained adjacent period index for 2005Q1 to 2015Q4 is:

(13) $\ldots . . R P_{C A J}^{2005 Q 1 \rightarrow 2015 Q 4}=R P_{A J}^{2005 Q 1 \rightarrow 2005 Q 2} \times R P_{A J}^{2005 Q 2 \rightarrow 2005 Q 3} \times \ldots \ldots \ldots . . R P_{A J}^{2015 Q 3 \rightarrow 2015 Q 4} \times 100$

The least restrictive formulation, in terms of assumption $\mathrm{f}$ constant coefficients, is to use a rolling window of adjacent periods only (Diewert (2005b). However, the method requires an adequate sample size of transactions over the two periods. Given the same number of transactions in each quarter, in this example say 100, the fixed base equations (6) and (9) formulation use $100 \times 10 \times 4=4,000$ observations over say 10 years while the adjacent period formulation uses $100 \times 2=200$ each quarter. There may well be degrees of freedom problems in estimating the hedonic regression, especial if there are many locational variables such as dummy variables for each postcode. Further, in using rolling window adjacent period regressions, compilers have to bear in mind two things: (i) it is desirable to compile RPPIs as weighted sums of constant-quality price indexes across strata of different types of houses, locations, and other meaningful and useful factors. Larger samples enable a more detailed stratification; and (ii) sample sizes of transactions for some strata may appear adequate say if the index is developed outside of a recession, but may become inadequate as an economy moves into and during a recession, when measurement really matters. ${ }^{25}$

A more general formulation is to use a rolling window time dummy regression. For example, for 2005Q1 to 2015Q4, where 2005Q1=100.0, a 4-quarters rolling window has the first regression estimated over the first four quarters, 2005Q1 to 2005Q4, the second regression drops the first observation in this window, 2005Q1, and adds the next quarter, 2006Q1, and so forth. For example, where $R P_{R W 2005 \Omega(\rightarrow Q 4}^{2000 Q 2}$ is the index for 2005Q2, with 2005Q1 $=100.00$, from a rolling window regression based on 2005Q1 to 2005Q4 data, $R W 2005 Q 1 \rightarrow 2005 Q 4$ :

\footnotetext{
${ }^{25}$ A less-detailed stratification or estimation over more than two time periods could of course be used in such an event.
} 
$(14) \ldots$

$$
\begin{aligned}
& R P_{T D M W}^{2005 Q 1 \rightarrow 2015 Q 4}=100 \times R P_{M W 2005 Q 1 \rightarrow Q 4}^{2005 Q 2} \times R P_{M W 2005 Q 1 \rightarrow Q 4}^{2005 Q 3} \times R P_{M W 2005 Q 1 \rightarrow Q 4}^{2005 Q 4} \times\left(O_{\text {verlap }}^{2005 Q 4} \times R P_{M W 2005 Q 2 \rightarrow 2006 Q 1}^{2006 Q 1}\right) \times \\
& \left(O_{\text {verlap }}^{2006 Q 1} \times R P_{M W 2005 Q 3 \rightarrow 2006 Q 2}^{2006 Q 2}\right), \ldots \ldots \ldots,\left(O_{\text {verlap }}^{2015 Q 3} \times R P_{M W 2015 Q 1 \rightarrow 2015 Q 4}^{2015 Q 4}\right) .
\end{aligned}
$$

Table 1. Illustrative linking of results from rolling window regression

\begin{tabular}{|c|c|c|c|}
\hline Period & $\begin{array}{c}\text { Rolling window } \\
\text { 2005Q1 to 2005Q4 } \\
\text { time dummy } \\
\text { 2005Q1=100.0 }\end{array}$ & $\begin{array}{c}\text { Rolling window } \\
\text { 2005Q2 to 2006Q1 } \\
\text { time dummy } \\
\text { 2005Q2=100.0 }\end{array}$ & $\begin{array}{c}\text { 4-quarter rolling } \\
\text { window index } \\
\text { 2005Q1=100.0 }\end{array}$ \\
\hline 2005Q1 & 100.0 & 100.0 & 100.0 \\
2005Q2 & 101.2 & 102.3 & 101.2 \\
2005Q3 & 101.1 & 101.5 & 101.1 \\
2005Q4 & 100.9 & 101.0 & 100.9 \\
2006Q1 & & & 101.9 \\
\end{tabular}

The overlap terms require explanation. Table 1 shows illustrative results for the first four periods of the index simply based on the results for $\exp \left(\hat{\delta}_{t}\right) \times 100$.0 from a rolling window regression for 2005Q1 to 2005Q4. The next window regression is estimated from 2005Q2 to 2006Q1 data. This window extends the results into the next quarter, 2006Q1 (2005Q2 $=100.0)$. There is a need to similarly extend the 2005Q1=100.0 index. An overlap of the two indexes for 2005Q4 allows us to rescale the 2006Q1 index from the 2005Q2 $=100$ window to $2005 \mathrm{Q} 1=100$, that is: $\frac{101.9}{101.5} \times 101.0=101.4$.

There is a trade-off here. The 4-quarters rolling window smoothes and lags the RPPI results to their detriment given the need for a timely indicator. However, with limited sample sizes available, it can provide more reliable results through more detailed stratification and smaller standard errors and thus confidence intervals.

Compilers of the index would gain from experimental RPPIs being estimated at different frequencies of rolling windows, including where possible, adjacent-period regressions and, where appropriate, provide users with studies of/regular data on smoothed as well as adjacent-period results, akin to the spirit of measures of core inflation and consumer price indexes. 


\section{The characteristics approach}

The characteristics approach in a Laspeyres-type form takes as its starting point the average characteristics of properties in a reference period, say period 0 , and revalues these characteristics in successive periods $t .{ }^{26} \mathrm{~A}$ hedonic regression is run to determine the pricedetermining characteristics of properties in say period 0 ; the average property in period 0 can then be defined as a tied bundle of the averages of each price-determining characteristic, for example, 2.8 bathrooms, 3.3 bedrooms, 0.8 garages and so forth-our starting point. ${ }^{27}$

The characteristics approach takes the predicted price of these period 0 average characteristics from a period $\boldsymbol{t}$ regression - in the numerator - and then compares it with the predicted price of these period 0 average characteristics from a period 0 regression in the denominator. The result is a constant (period 0 ) quality property price index. It is a price index of a constant quality since the characteristics are held constant in period 0 and valued (for the denominator) and revalued (for the numerator) using period 0 and period $t$ hedonic regressions respectively. The numerator provides an answer to a counterfactual question: what would be the estimated transaction price of a property with period 0 average characteristics if it was on the market in period 1 ?

For illustration: if only the size (square footage) of an apartment determined its price and the estimated regression equation for apartments in an inner city area were, for period 0 , $\hat{p}_{i}^{0}=89.255 .632+301.894 S q f t_{i}^{0}$ and for period $1, \hat{p}_{i}^{1}=101.336+324.735 S q f t_{i}^{1}$. Say the average size in period $0, \bar{z}^{0}=1,023.4$ square feet; the constant (period 0 ) quality index is: (15).... $\frac{\hat{p}_{\bar{z}^{0}}^{t}}{\hat{p}_{\bar{z}^{0}}^{0}}=\left(\frac{101.336+324.735 \times 1,023.4}{89.255+301.894 \times 1,023.4}\right) \times 100=107.568$, a 7.568 percent price increase.

As a notational matter, the predicted price is no longer for property $i$, previously used as a subscript, but for the average of $\bar{z}^{0}$, now designated as a subscript in equation (15). Before continuing we need to say something about the concept of the "average" characteristics values.

\section{What "averages" of characteristic values to use? Means, median, and representative characteristic values}

\footnotetext{
${ }^{26}$ A characteristics approach in a Paasche-type form, for an index comparing period 0 with period $t$, would take the average characteristics of properties in current period $t$ and revalues these characteristics in a preceding reference period 0 .

${ }^{27}$ Indeed, the results from a hedonic regression can also be used to help define strata. Say locational dummy variables of major conurbations are included along with slope interaction terms for characteristics in these locations. For example, the number of bedrooms in apartments had a dummy variable as to whether the apartment was located in the inner or outer area of a capital city. The $t$-test on the dummy variable is of a null hypothesis of no difference in their respective marginal values. If the test is rejected at an acceptable level of significance, there would be a case for having separate strata, sample size permitting.
} 
The average values may be a mean, median, or pre-defined representative property. The means are generally not of actual values for an individual property. For example, the mean square foot and mean number of bedrooms for apartments may increase from 1,209.6 to 1,227.1 and from 1.7 to 1.9 respectively over periods 0 and 1 . The median is a better representation of a "typical" apartment say increasing from 1,050.0 to 1,075.0 square feet and possessing 2-bedrooms in each period. The median will not be affected by outliers even if they extend to an abnormal "tail" in up to half of the data. Representative apartments have their characteristics held constant by definition; say two bedroom 1,000 to 1,300 square foot apartments. The assumption is that price changes of all apartments follow the measured price changes of the representative one. ${ }^{28}$

Where the distribution of characteristics is highly skewed there is a case for preferring geometric means or medians to arithmetic means to downplay extreme values on the tails of the distributions of characteristics, or for that matter prices. ${ }^{29}$ However, an alternative, and more informed approach, is to identify and validate, or otherwise, outliers prior to running the regressions, with further validation by examining the residuals of the regression. The aim is not just to clean the data, but to identify clusters of characteristics responsible for extreme prices and incorporate them into the modeling. Indeed, extreme values may also signal an inadequate sampling of a cluster of perfectly valid observations and a need for a strategy to increase the sample size in this regard.

\section{Hedonic characteristics indexes: a linear functional form}

Consider first two linear hedonic regression, as given by equation (2), and repeated below as equations (16) and (17) — but adopting the simplification that the constants $\hat{\gamma}_{k}^{0}$ and $\hat{\gamma}_{k}^{t}$ are included in the summations as $k=0$ where $z_{0, i}^{0}=1$ and $z_{0, i}^{t}=1-$ in their respective reference period 0 and successive periods $t=1, \ldots, T$ :

\footnotetext{
${ }^{28}$ These model or representative properties might be justified on pragmatic grounds if, for a stratum of properties, there is a sizable cohort of well-defined similar properties of a specific type sold over time, with transactions for the remaining properties in the stratum of mixed characteristics with inadequate data on the characteristic change.

${ }^{29}$ While the choice between the geometric mean and mean is argued to be dependent on the functional form of the hedonic regression, the difference between the averages may not be as great as first considered. It can be demonstrated that the ratio of an index based on arithmetic means to geometric means is given by the difference between the changes in half the variance of prices - as the variance of prices of properties, their heterogeneity, increases, so too will the arithmetic mean index exceed a geometric mean one. However, Silver and Heravi (2007b) show that for a constant-quality price index, the variances will be reduced along with the differences between the arithmetic and geometric indexes-demonstrated in Annex 1. Use of a hedonic regression that better explains property price variability and better removes price variability, leads to smaller differences between arithmetic and geometric constant-quality property price indexes, and thus more confidence in their use.
} 
(16)... $\hat{p}_{i}^{0}=\hat{\gamma}_{0}^{0}+\sum_{k=1}^{K} \hat{\gamma}_{k}^{0} z_{k, i}^{0}=\sum_{k=0}^{K} \hat{\gamma}_{k}^{0} z_{k, i}^{0}=h^{0}\left(z_{i}^{0}\right)$
(17)... $\hat{p}_{i}^{t}=\hat{\gamma}_{0}^{t}+\sum_{k=1}^{K} \hat{\gamma}_{k}^{t} z_{k, i}^{t}=\sum_{k=0}^{K} \hat{\gamma}_{k}^{t} z_{k, i}^{t}=h^{t}\left(z_{i}^{t}\right)$

and for simplicity of exposition, hereafter $k=0$ designates the constant for which $z_{0, i}^{t}=1$.

(18).... $\bar{z}_{k}^{0}=1 / N^{0} \sum_{i \in N^{0}} z_{i, k}^{0}$ and $\bar{z}_{k}^{t}=1 / N^{t} \sum_{i \in N^{t}} z_{i, k}^{t}$

Constant quality hedonic property price indexes can be defined in two immediately apparent ways. Both require a comparison of the price change of a constant basket of characteristics priced from a hedonic regression in period 0 and again in period $t$, yet in the first definition it is a constant period 0 basket and in the second a constant period $t$ basket.

Consider a constant period 0 basket of characteristics; we take the averages of each $k$ quality characteristic $\bar{z}_{k}^{0}$ in period 0 , and ask what would be the price of a property with these $k$ average characteristics if sold in period $t$. This predicted price is then compared with a valuation of the self-same average characteristics using the estimated period 0 hedonic regression. We compare estimated prices of constant period 0 average characteristics. A constant period $t$ basket of characteristics $\bar{z}_{k}^{t}$ is similarly defined.

The Dutot (ratio of arithmetic means) hedonic base (reference) period 0 index (DHB $)^{30}$ has in the numerator period 0 mean characteristics valued at period $t$ characteristic-prices and in the denominator period 0 mean characteristics valued at period 0 characteristic-prices:

\footnotetext{
${ }^{30} \mathrm{We}$ depart from the naming standards in the RPPI Handbook (Eurostat (2013) and de Haan and Diewert (2013) in particular). We identify two levels of weighting and commensurate formulas in this paper. The first is based on sample selection, that is, for a bilateral price comparison between period 0 and period $t$, whether we use the transactions in period 0 (also imputed to period $t$ ), or the transactions in period $t$ (also imputed to period 0). Eurostat (2013) refer to these as hedonic "Laspeyres" and "Paasche" indexes respectively, even though they are unweighted. The second level of weighting is based on the weight (expenditure share) at the elementary level given to a price change for an individual property. More weight is given to the price change of more expensive properties for a plutocratic index. Reasonable weighted formulations include weights for the reference period, current period, and some average of the two. We use the terms hedonic base and current period Dutot (HBD, HCD) and hedonic base and current period Jevons (HBJ, HCJ) as arithmetic and geometric forms of these aggregators for unweighted indexes-De Haan and Diewert (2013) refer to this nomenclature in paragraph 5.14 ff.6. In section IV we refer to hedonic Laspeyres, hedonic Paasche, and hedonic geometric Laspeyres and hedonic geometric Paasche and so forth for weighted indexes including superlative indexes. A third form of weighting is that given to characteristics; these are weighted by their estimated coefficients, explicitly in the characteristics approach and implicitly in the derivation of predicted imputed values. The use of Jevons or Dutot is argued here to arise from the choice between a linear (Dutot) of log-linear (Jevons) hedonic functional form and impacts on the weights given to the characteristics.
} 
(19).... $P_{H D B: z_{k}^{0}}^{0 t}=\frac{\sum_{k=0}^{K} \hat{\gamma}_{k}^{t} \bar{z}_{k}^{0}}{\sum_{k=0}^{K} \hat{\gamma}_{k}^{0} \bar{z}_{k}^{0}}=\frac{h^{t}\left(\bar{z}_{k}^{0}\right)}{h^{0}\left(\bar{z}_{k}^{0}\right)}$

and a Dutot hedonic current period $t$ quality index is defined as:

(20).... $P_{H D C: z_{k}^{t}}^{0 t}=\frac{\sum_{k=0}^{K} \hat{\gamma}_{k}^{t} \bar{z}_{k}^{t}}{\sum_{k=0}^{K} \hat{\gamma}_{k}^{0} \bar{z}_{k}^{t}}=\frac{h^{t}\left(\bar{z}_{k}^{t}\right)}{h^{0}\left(\bar{z}_{k}^{t}\right)}$

If, in a perfect market, preferences change and the implicit prices of one characteristic, say an additional bedroom, increase at an above average rate; other things being equal, utilitymaximizing buyers would substitute expenditure towards other characteristics, say more overall space. The use of a constant period 0 characteristic basket, $\bar{z}_{k}^{0}$ would understate price increases - the $\frac{\hat{\gamma}_{k}^{0} \bar{z}_{k}^{0}}{\sum_{k=0}^{K} \hat{\gamma}_{k}^{0} \bar{z}_{k}^{0}}$ expenditure weights in equation (21) do not reflect the substitution away from characteristics with above average price increases - and of a constant period $t$ characteristic basket, $\bar{z}_{k}^{t}$, overstate it. This is because, as we show in section VC, the constant quality price change of each characteristic from equations (19) and (20) are implicitly weighted by the estimated relative values of the characteristic. For example, using the notation in equation (15) and equations (16) and (19):

(21)... $\frac{\hat{p}_{\bar{z}^{0}}^{t}}{\hat{p}_{\bar{z}^{0}}^{0}}=\frac{\sum_{k=0}^{K} \hat{\gamma}_{k}^{t} \bar{z}_{k}^{0}}{\sum_{k=0}^{K} \hat{\gamma}_{k}^{0} \bar{z}_{k}^{0}}=\frac{\sum_{k=0}^{K} \frac{\hat{\gamma}_{k}^{t}}{\hat{\gamma}_{k}^{0}} \hat{\gamma}_{k}^{0} \bar{z}_{k}^{0}}{\sum_{k=0}^{K} \hat{\gamma}_{k}^{0} \bar{z}_{k}^{0}}$

For the aforementioned substitution bias relating to characteristics, a geometric mean of equations (19) and (20) - a hedonic Fisher-type price index number — is justifiable on grounds of economic theory, axiomatic properties, and intuition. ${ }^{31}$

${ }^{31}$ The Consumer Price Index (CPI) Manual (ILO et al., 2004) recommends superlative price indexes-the Fisher, Törnqvist, and Walsh indexes — as the target formulas for the higher-level indexes. These formulas generally produce similar results, using symmetric weights based on quantity or expenditure information from both the reference and current periods. They derive their support as superlative indexes from economic theory. A utility function underlies the definition of (constant utility) cost of living index (COLIs) in economic theory. Different index number formulas can be shown to correspond with different functional forms of the utility function. Laspeyres, for example, corresponds to a highly restrictive Leontief form. The underlying functional 
(22)...P $P_{\sqrt[\bar{z}^{0} \bar{z}^{t}]{D H F}}^{=\sqrt{P_{\bar{z}^{0}}^{D H B} \times P_{\bar{z}^{t}}^{D H C}}}$

The theory of hedonic regressions can be found in Rosen (1974), Triplett (1987), Feenstra (1995) — and for an application, Silver (1999) —Diewert (2003b), and Silver (2004); the theory of Laspeyres and Paasche bounds is in Konūs (1924) and of substitution effects warranting a (superlative) geometric mean of a Laspeyres and Paasche formula, in Diewert $(1976,1978$ and 2004).

Note that the denominator in equation (19) is the imputed or predicted price, rather than actual price, in period $0, h_{k}^{0}\left(\bar{z}_{k}^{0}\right)$, and similarly in the numerator of equation (20) we use the imputed or predicted price rather than actual price in period $t, h_{k}^{t}\left(\bar{z}_{k}^{t}\right)$. In calculating equation (19) we take the ratio of two imputations: the imputed price of $\bar{z}_{k}^{0}$ valued at period $t$ characteristic prices in the numerator and at period 0 characteristic prices in the denominator - a dual imputation. For a linear form the average predicted price in period 0 from an Ordinary least squares regression is equal to the average actual price, $h_{k}^{0}\left(\bar{z}_{k}^{0}\right)=\bar{p}_{k}^{0}$ and, though equation (19) is hardly complex, it can be calculated with a "single imputation" as the much simpler:

(23).... $\frac{h^{t}\left(\bar{z}_{k}^{0}\right)}{\bar{p}_{k}^{0}}$.

We return to issues of dual versus single imputation later in this section and in section IV.

\section{Types of hedonic characteristics indexes: log-linear functional form}

A constant-quality characteristics price index for a log-linear hedonic regression equation follows similar principles: for properties $i$, in a given stratum, for the reference period 0 and successive periods $t=1, \ldots, T$ the estimated hedonic regressions are:

(24)... $\ln \hat{p}_{i}^{0}=\sum_{k=0}^{K} z_{k, i}^{0} \ln \hat{\beta}_{k}^{0}=\tilde{h}^{0}\left(z_{i}^{0}\right)$

forms for superlative indexes, including Fisher and Törnqvist, are flexible: they are second-order approximations to other (twice-differentiable) homothetic forms around the same point. It is the generality of functional forms that superlative indexes represent that allows them to accommodate substitution behavior and be desirable indexes. The Fisher price index is also recommended on axiomatic grounds and from a fixed quantity basket perspective (ILO et al., 2004). 
(25) $\ldots \ln \hat{p}_{i}^{t}=\sum_{k=0}^{K} z_{k, i}^{t} \ln \hat{\beta}_{k}^{t}=\tilde{h}^{t}\left(z_{i}^{t}\right)$

The tilde above $\tilde{h}$ denotes a log-linear functional form, the constant is included as $\hat{\beta}_{0}^{* 0}$ for which $z_{0, i}^{0}=1$, and similarly for period $t$, over all observations, and periods 0 and $t$ average values of each $k$ characteristic are arithmetic means: ${ }^{32}$

(26).... $\bar{z}_{k}^{0}=1 / N^{0} \sum_{i \in N^{0}} z_{i, k}^{0}$ and $\bar{z}_{k}^{t}=1 / N^{t} \sum_{i \in N^{t}}^{N^{t}} z_{i, k}^{t}$

Constant quality property price indexes can be defined in two immediately apparent ways. A hedonic geometric Laspeyres-type constant period 0 characteristics index takes the means of a set of characteristic $\bar{z}_{k}^{0}$ for the reference period $t=0$, and values them in the numerator in equation (11) by their respective marginal valuations $\hat{\beta}_{k}^{t}$ from a log-linear hedonic regression, estimated just from data on transacted properties in period $t$, and compares this overall valuation with the same set of characteristics valued using period $t=0$ estimated coefficients, that is, $\hat{\beta}_{k}^{0}$, in the denominator. The index is a ratio of geometric means with characteristics held constant in the base (reference) period: (27).... $P_{H G M B: \bar{z}^{0}}^{0, t}=\frac{\prod_{k=0}^{K}\left(\bar{z}_{k}^{0}\right)^{\hat{\beta}_{k}^{t}}}{\prod_{k=0}^{K}\left(\bar{z}_{k}^{0}\right)^{\hat{\beta}_{k}^{0}}}=\frac{\exp \left(\sum_{k=0}^{K} \bar{z}_{k}^{0} \ln \hat{\beta}_{k}^{t}\right)}{\exp \left(\sum_{k=0}^{K} \bar{z}_{k}^{0} \ln \hat{\beta}_{k}^{0}\right)}=\frac{\tilde{h}^{t}\left(\bar{z}_{k}^{0}\right)}{\tilde{h}^{0}\left(\bar{z}_{k}^{0}\right)}=\frac{\tilde{h}^{t}\left(\bar{z}_{k}^{0}\right)}{\bar{p}^{0}}$

Equation (27) holds the (quality) characteristic set constant in period 0, though a similar index could be equally justified by valuing in each period a constant period $t$ average quality set. A hedonic geometric Laspeyres-type constant-period (arithmetic mean) $t$ characteristics index is given by:

\footnotetext{
${ }^{32}$ It is apparent from the $\log$-linear transformation $\ln p_{i}=\ln \beta_{0}+z_{1, i} \ln \beta_{1}+z_{2, i} \ln \beta_{2}+z_{3, i} \ln \beta_{3}+\ln \varepsilon_{i}$, that the $z_{k, i}$, are not in logarithms and arithmetic averages of $z_{k, i}$ are appropriate. The average of the characteristics for both a linear and log-linear formulations are an arithmetic means. There is in any event an immediate problem with taking a geometric mean of dummy variables since logarithms cannot be taken of zero values. However, there is a work-around. Where $N$ is the sample size, and there are $n^{1}$ values of 1 and $n^{0}$ of zero, the geometric mean is $\left(n^{1} \times \operatorname{Geomean}\left(n^{1}\right)+n^{0} \times \operatorname{Geomean}\left(n^{0}\right)\right) / N$ equals $\left(n^{1} \times \operatorname{Geomean}\left(n^{1}\right)\right) / N$. Since the Geomean $\left(n^{1}\right)=\operatorname{Arithmean}\left(n^{1}\right)$ for the $n^{1}$ values of unity, it is quite straightforward. For example, with $\mathrm{N}=60$, of which 16 are unity, the mean is the simple proportion, 16/60=0.267.
} 
$(28) \ldots P_{H G M C: z^{t}}^{0, t}==\frac{\prod_{k=0}^{K}\left(\bar{z}_{k}^{t}\right)^{\hat{\beta}_{k}^{t}}}{\prod_{k=0}^{K}\left(\bar{z}_{k}^{t}\right)^{\hat{\beta}_{k}^{0}}}=\frac{\exp \left(\sum_{k=0}^{K} \bar{z}_{k}^{t} \ln \hat{\beta}_{k}^{t}\right)}{\exp \left(\sum_{k=0}^{K} \bar{z}_{k}^{t} \ln \hat{\beta}_{k}^{0}\right)}=\frac{\tilde{h}^{t}\left(\bar{z}_{k}^{t}\right)}{\tilde{h}^{0}\left(\bar{z}_{k}^{t}\right)}=\frac{\bar{p}^{t}}{\tilde{h}^{0}\left(\bar{z}_{k}^{t}\right)}$

\section{Dual imputations}

A natural question arises as to the phrasing of the second to last terms in equations (27) and (28) as dual imputations, that is they use predicted (imputed) prices in both the denominator and numerator-Silver (2001) and de Haan (2004a). As we will see in section IV, the use of equation (28) only requires that a hedonic regression be estimated for the reference period, that actual period prices may be used, and we lose this feature if we adopt dual imputations. Here we explain that while there is a well-established logic for the use of dual imputations, it need not hold in this instance, though is important in our work on weighting as explained in section IV.

Dual imputation requires a predicted (imputed) price in both the denominator and numerator of equations (27) and (28) as opposed to a single imputation, the last term in both equations (27) and (28), for which $\tilde{h}_{k}^{0}\left(\bar{z}_{k}^{0}\right)=\bar{p}_{k}^{0}$ and $\tilde{h}_{k}^{t}\left(\bar{z}_{k}^{t}\right)=\bar{p}_{k}^{t}$. For example, in equation (27) the single imputation hedonic approach uses the actual price in the denominator, and predicted price in the numerator. The logic for the need for dual imputations is that the above equalities only hold for perfectly specified hedonic regressions estimated without bias. However, this would lead to a biased price comparison if there were substantive omitted variables in the hedonic specification. For example, cheaper terraced houses may have no front yard (garden) opening directly onto the street. This poorer feature would be reflected in the actual price (denominator) of a constant period 0 index, but may be excluded or not properly represented in the hedonic specification and thus predicted price (numerator). The numerator would be biased upwards and index downwards. The dual imputation hedonic index would to some extent offset an upwards bias by using predicted prices in both the numerator and denominator. Dual imputations are generally advised for hedonic price indexes, see Silver (2001 and 2004), de Haan (2004a), Hill and Melser (2008), Diewert, Heravi and Silver (2009), associated comments (de Haan 2009) and response, Hill (2013) and section IV, where we consider an alternative workaround.

Yet a feature of the OLS estimator is that the mean of actual prices is equal to the mean of

predicted prices; $\frac{1}{N^{0}} \sum_{i \in N^{0}} \hat{p}_{i \mid z_{i}^{0}}^{0}=\frac{1}{N^{0}} \sum_{i \in N^{0}} p_{i}^{0}$ and $\frac{1}{N^{t}} \sum_{i \in N^{t}} \hat{p}_{i \mid z_{i}^{t}}^{t}=\frac{1}{N^{t}} \sum_{i \in N^{t}} p_{i}^{t}$. Thus the last terms in equations (27) and (28)—see also (de Haan and Diewert, 2013, paragraph 5.38). A problem arises, however, with the use of weights at this lower level, as explained in section IV, for which we need dual imputations. 
Neither a period 0 constant-characteristics index nor a period $t$ constant-characteristic quantity basket can be considered to be superior, both acting as bounds for their theoretical counterparts. Some average or compromise solution is required. Diewert $(1976,1978)$ defined in economic theory a class of index number to be superlative. We consider definitions of superlative indexes in section III. This includes the Törnqvist index formula given in this log-linear context by:

(29)...P $P_{\sqrt{\bar{z}^{0} \bar{z}^{t}}}^{T H B}=\frac{\exp \left(\sum_{k=0}^{K} \bar{z}_{k}^{\tau} \ln \hat{\beta}_{k}^{t}\right)}{\exp \left(\sum_{k=0}^{K} \bar{z}_{k}^{\tau} \ln \hat{\beta}_{k}^{0}\right)}=\frac{\prod_{k=0}^{K}\left(\bar{z}_{k}^{\tau}\right)^{\hat{\beta}_{k}^{t}}}{\prod_{k=0}^{K}\left(\bar{z}_{k}^{\tau}\right)^{\hat{\beta}_{k}^{0}}}=\frac{\tilde{h}^{t}\left(\bar{z}_{k}^{\tau}\right)}{\tilde{h}^{0}\left(\bar{z}_{k}^{\tau}\right)}$

where $\bar{z}_{k}^{\tau}=\left(\bar{z}_{k}^{0}+\bar{z}_{k}^{t}\right) / 2$

\section{The imputation approach}

The imputation approach differs from the characteristics approach. For the characteristics approach the average (arithmetic mean) values of characteristics were derived in, for example, period 0 as 3.1 bedrooms, 0.71 possession of a garage, 1,215 square feet, and then revalued using estimated hedonic characteristic coefficients estimated from data in period $t$. The characteristics approach answered a counterfactual question: what would be the price change of a set of average period 0 characteristics valued first, at period 0 hedonic valuations, and second, at period $t$ hedonic valuations?

In contrast the imputation approach works at the level of individual properties, rather than the average values of their characteristics. It tackles a similar counterfactual question: what would a property $i$ with its given characteristics in period 0 be worth if the same such characteristics were revalued using period $t$ hedonic valuations? An average of these is then taken over the individual properties, and compared with an average of matched period 0 valuations of period 0 properties. The summation is over the predicted prices of $i=1, \ldots, N^{0}$ period 0 properties.

The rational for the imputation approach lies in the matched model method. Consider a set of properties transacted in period 0 . We want to compare their period 0 prices with the prices of the same matched properties in period $t$. In this way there is no contamination of the measure of price change by changes in the quality-mix of properties transacted. However, the period 0 properties were not sold in period $t$ - there is no corresponding period $t$ price. The solution is to impute the period $t$ price of each period 0 property. We use a period $t$ regression to predict prices of properties sold in period 0 to answer the counterfactual question: what would a property with period 0 characteristics have sold at in period $t$ ? Equation (25) provides the answer. It is a hedonic regression using period $t$ data, to estimate period $t$ characteristic prices and then apply them to period 0 characteristics values. 
The requirements of the imputation method for a linear functional form using constant period 0 characteristics are to: (i) estimate a hedonic regression for the reference period 0 and each successive period $t$; (ii) identify the values of the characteristics of each property sold in period 0 , say property 1 had 4 bedrooms, 2 bathrooms and so forth; (iii) using the hedonic regressions impute/predict the price of each individual period 0 property would have sold at in periods 0 and period $t$; and (iv) using imputed property prices, determine the average price of period 0 properties in period 0 and period $t$ and as a ratio, the change in the average period 0 constant-quality prices - the different formulations of hedonic imputation indexes are outlined in Silver and Heravi (2007a).

Hedonic imputation indexes based on prices of individual properties $i$ are derived from a linear functional form and given by a Dutot (ratio of arithmetic means) index of constant period 0 quality by:

(30).... $P_{H I B: z_{i}^{0}}^{0, t}=\frac{\frac{1}{N^{0}} \sum_{i \in N^{0}} \hat{p}_{i \mid z_{i}^{0}}^{t}}{\frac{1}{N^{0}} \sum_{i \in N^{0}} p_{i}^{0}}=\frac{\frac{1}{N^{0}} \sum_{i \in N^{0}} \hat{p}_{i \mid z_{i}^{0}}^{t}}{\frac{1}{N^{0}} \sum_{i \in N^{0}} \hat{p}_{i}^{0}}=\frac{\sum_{i \in N^{0}} \frac{\hat{p}_{i \mid z_{i}^{0}}^{t}}{\hat{p}_{i \mid z_{i}^{0}}^{0}} \hat{p}_{i \mid z_{i}^{0}}^{0}}{\sum_{i \in N^{0}} \hat{p}_{i}^{0}}=\frac{h^{t}\left(z_{i}^{0}\right)}{h^{0}\left(z_{i}^{0}\right)}$

where $\hat{p}_{i \mid z_{i}^{0}}^{t}$ and $\hat{p}_{i \mid z_{i}^{0}}^{0}$ are the predicted prices in periods 0 and $t$ respectively conditioned on (controlling for) property $i$ 's period 0 characteristics, $z_{i}^{0} \cdot{ }^{33}$ Note that the characteristics are valued in the numerator and denominator at period $t$ and 0 respectively, but the characteristic values are held constant at period 0 . Further, there is an implicit weighting given to each property's price change; its relative (predicted) price/value in the reference period 0 , as shown in equation (30) and considered in more detail in section VC on weighting.

Equation (31) is a Paasche-type constant period $t$ quality index:

(31)...P $P_{H D C: z_{i}^{t}}^{0, t}=\frac{\sum_{i \in N^{t}} \hat{p}_{i \mid z_{i}^{t}}^{t}}{\sum_{i \in N^{t}} \hat{p}_{i \mid z_{i}^{t}}^{0}}=\frac{h^{t}\left(z_{i}^{t}\right)}{h^{0}\left(z_{i}^{t}\right)}$.

Hedonic imputation indexes for individual properties derived from a log-linear functional form are given by Jevons (ratio of geometric means) index for a Laspeyres-type, $z_{i}^{0}$, characteristics index for an individual property $i$ :

\footnotetext{
${ }^{33}$ Hill $(2013,890-891)$ reminds us that a similar bias correction to that used for the time dummy estimates (section IIB) is required for predicted values for the imputation (and characteristics) approaches when using a log-linear hedonic formulation, that is the addition of half the variance of the error term from the hedonic regression (Kennedy, 1981) and Giles (2011).
} 
(32) $\ldots P_{H J B: z_{i}^{0}}^{0, t}=\frac{\prod_{i \in N^{0}}\left(\hat{p}_{i \mid z_{i}^{0}}^{t}\right)^{\frac{1}{N^{0}}}}{\prod_{i \in N^{0}}\left(\hat{p}_{i \mid z_{i}^{0}}^{0}\right)^{\frac{1}{N^{0}}}}=\frac{\exp \left(1 / N^{0} \sum_{i \in N^{0}} \ln \hat{p}_{i \mid z_{i}^{0}}^{t}\right)}{\exp \left(1 / N^{0} \sum_{i \in N^{0}} \ln \hat{p}_{i \mid z_{i}^{0}}^{0}\right)}$.

The value in the numerator of equation (32) is the geometric mean of the period $t$ price of period 0 quantities price-determining characteristic $z_{i, k}^{0}$. These are compared, in the denominator, with the geometric mean of the period 0 price of the selfsame period 0 characteristics, $z_{i, k}^{0}$. For each property, the quantities of characteristics are held constant at $z_{i, k}^{0}$ ; only the characteristic prices change.

And a Jevons (ratio of geometric means), Paasche-type, constant period $t$ characteristics, $z_{i}^{t}$, is given by:

(33)... $P_{H I P}^{J}=\frac{\prod_{i \in N^{t}}\left(\hat{p}_{i, z_{i}^{t}}^{t}\right)^{\frac{1}{N^{t}}}}{\prod_{i \in N^{t}}\left(\hat{p}_{i, z_{i}^{t}}^{0}\right)^{\frac{1}{N^{t}}}}=\frac{\exp \left(1 / N^{t} \sum_{i \in N^{t}} \ln \hat{p}_{i, z_{i}^{t}}^{t}\right)}{\exp \left(1 / N^{t} \sum_{i \in N^{t}} \ln \hat{p}_{i, z_{i}^{t}}^{0}\right)}$

\section{E. An indirect approach to hedonic price indexes}

The indirect approach is not new. The literature on its properties and application include Feenstra (1995), Silver and Heravi (2001), Diewert (2003a), Pakes (2003), Triplett (2006), Heravi and Silver (2009), and de Haan and Diewert (2013). Consider the change in arithmetic mean prices phrased as actual or, for an OLS regression, predicted prices: ${ }^{34}$

(34)... $\Delta P=\frac{\frac{1}{N^{t}} \sum_{i \in N^{t}} p_{i \mid z_{i}^{t}}^{t}}{\frac{1}{N^{0}} \sum_{i \in N^{0}} p_{i}^{0}}=\frac{\frac{1}{N^{t}} \sum_{i \in N^{t}} \hat{p}_{i \mid z_{i}^{t}}^{t}}{\frac{1}{N^{0}} \sum_{i \in N^{0}} \hat{p}_{i \mid z_{i}^{0}}^{0}}$

and as a ratio of geometric mean prices:

\footnotetext{
${ }^{34}$ Note that we use the ratio of average predicted prices which, from an OLS regression, equals the ratio of average actual prices. Our use of predicted prices is to enable terms in equations (34) and (35) to more obviously cancel, as we proceed.
} 


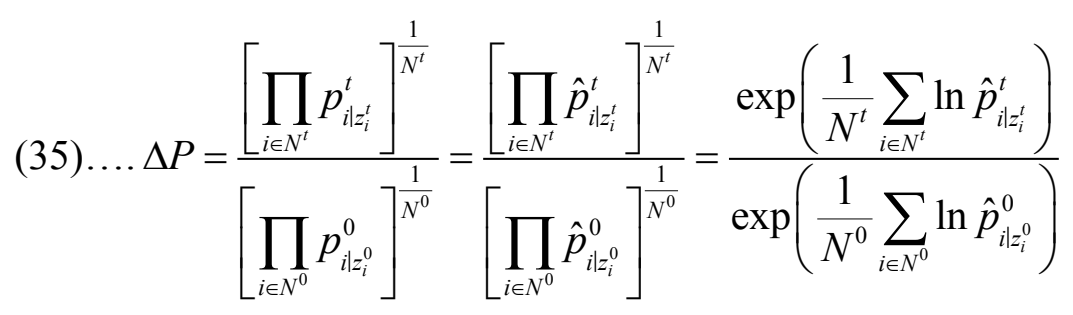

Equations (34) and (35) are measures of the change in average price, not constant-quality price change. The $N^{t}$ properties transacted in period $t$ may well have quite different characteristics than the $N^{0}$ properties transacted in period 0 . The measure of the change in prices of properties transacted is contaminated by changes in the quality-mix of properties sold ${ }^{35}$ In this indirect approach the change in the average price of properties transacted given in equations (34) and (35) - the raw average price change, $\Delta P$-is divided by (adjusted for) the volume change, $\Delta V^{\text {qual }}$, in the quality of transacted houses between the two periods to obtain a constant-quality price index, that is: ${ }^{36}$

(36).... $P^{\text {const-qual }}=\Delta P \div \Delta V^{\text {quality }}$.

Consider a linear hedonic regression and characteristics (quality) volume index where, in equation (37), the arithmetic means of the volume of characteristics change from $\bar{z}_{k}^{0}$ in period 0 in the denominator to $\bar{z}_{k}^{t}$ in period $t$ in the numerator. However, the estimated

characteristics' valuations are held constant, in this case in period $0, \hat{\gamma}_{k}^{0}$, as can be seen from both the characteristics and imputation approaches:

(37).... $\Delta V^{\text {qual }}=\frac{\sum_{k=0} \bar{z}_{k}^{t} \hat{\gamma}_{k}^{0}}{\sum_{k=0} \bar{z}_{k}^{0} \hat{\gamma}_{k}^{0}}=\frac{\frac{1}{N^{t}} \sum_{i \in N^{t}} \hat{p}_{i z z_{i}^{t}}^{0}}{\frac{1}{N^{0}} \sum_{i \in N^{0}} \hat{p}_{i z z_{i}^{0}}^{0}}=\frac{h_{k}^{0}\left(\bar{z}_{k}^{t}\right)}{h_{k}^{0}\left(\bar{z}_{k}^{0}\right)}$

Using equation (37) and the feature of an OLS regression, that the mean of predicted 'left hand side' values equals the mean of their actual values:

\footnotetext{
${ }^{35}$ It may be that a few properties are sold in both periods, for which a sub-index based on matched actual prices can be calculated, and weighted into an overall index. Even then, these properties may have improved/deteriorated between the two periods, sometimes with major renovations such as the addition of bedrooms, bathrooms, finishing of basements.

${ }^{36}$ In national accounting changes in nominal values are decomposed into price changes and volume changes (2008 SNA, chapter 15). The latter includes changes in the quality of what is produced/consumed. If, for example, the nominal values of houses transacted increased, on average, by 10 percent, the number of houses sold increased by 5 percent, the quality of houses sold increased by 1 percent, then the price change is equal to the nominal value change of 1.10 divided by the volume change (1.05 times 1.01 ) which equals 1.03725 , a 3.725 percent increase. Changes in average property prices already reflect an adjustment for the change in the number of houses sold.
} 
(38).... $\frac{1}{N^{0}} \sum_{i \in N^{0}} \hat{p}_{i \mid z_{i}^{0}}^{0}=\frac{1}{N^{0}} \sum_{i \in N^{0}} p_{i}^{0}$ and $\frac{1}{N^{t}} \sum_{i \in N^{t}} \hat{p}_{i||_{i}^{t}}^{t}=\frac{1}{N^{t}} \sum_{i \in N^{t}} p_{i}^{t}$

and adopting the hedonic imputation approach, an indirect constant period $t$ characteristics price index is:

(39).... $P^{\text {const-qual }}=\left(\frac{\frac{1}{N^{t}} \sum_{i \in N^{t}} p_{i}^{t}}{\frac{1}{N^{0}} \sum_{i \in N^{0}} p_{i}^{0}}\right) /\left(\frac{\frac{1}{N^{t}} \sum_{i \in N^{t}} \hat{p}_{i \mid z_{i}^{t}}^{0}}{\frac{1}{N^{0}} \sum_{i \in N^{0}} \hat{p}_{i \mid z_{i}^{0}}^{0}}\right)=\frac{\frac{1}{N^{t}} \sum_{i \in N^{t}} \hat{p}_{i \mid z_{i}^{t}}^{t}}{\frac{1}{N^{t}} \sum_{i \in N^{t}} \hat{p}_{i \mid z_{i}^{t}}^{0}}$

or equivalently, phrased as a hedonic characteristics index, again using equation (38), the indirect constant period $t$ characteristics price index is:

$$
\begin{gathered}
(40) \ldots \Delta P^{\text {const-qual }}=\left(\frac{\frac{1}{N^{t}} \sum_{i \in N^{t}} p_{i}^{t}}{\frac{1}{N^{0}} \sum_{i \in N^{0}} p_{i}^{0}}\right) /\left(\frac{\sum_{k=0} \bar{z}_{k}^{t} \hat{\gamma}_{k}^{0}}{\sum_{k=0} \bar{z}_{k}^{0} \hat{\gamma}_{k}^{0}}\right)=\left(\frac{\frac{1}{N^{t}} \sum_{i \in N^{t}} \hat{p}_{i \mid z_{i}^{t}}^{t}}{\frac{1}{N^{0}} \sum_{i \in N^{0}} \hat{p}_{i \mid z_{i}^{0}}^{0}}\right) /\left(\frac{\sum_{k=0} \bar{z}_{k}^{t} \hat{\gamma}_{k}^{0}}{\sum_{k=0} \bar{z}_{k}^{0} \hat{\gamma}_{k}^{0}}\right) \\
=\left(\frac{\sum_{k=0} \bar{z}_{k}^{t} \hat{\gamma}_{k}^{t}}{\sum_{k=0} \bar{z}_{k}^{0} \hat{\gamma}_{k}^{0}}\right) /\left(\frac{\sum_{k=0} \bar{z}_{k}^{t} \hat{\gamma}_{k}^{0}}{\sum_{k=0} \bar{z}_{k}^{0} \hat{\gamma}_{k}^{0}}\right)=\frac{\sum_{k=0} \bar{z}_{k}^{t} \hat{\gamma}_{k}^{t}}{\sum_{k=0} \bar{z}_{k}^{t} \hat{\gamma}_{k}^{0}}=\frac{h_{k}^{t}\left(\bar{z}_{k}^{t}\right)}{h_{k}^{0}\left(\bar{z}_{k}^{t}\right)}
\end{gathered}
$$

For example, if larger properties, with more bedrooms, having garages and so forth were selling in period $t$ as opposed to period 0 , then the $\Delta V^{\text {qual }}$ index in equation (37) would increase as the mean quantities of characteristics in equation (38) increased from $\bar{z}_{k}^{0}$ to $\bar{z}_{k}^{t}$, each valued by its estimated marginal values in period 0 . Since the numerator, $\Delta P$, is the change in average prices calculated from the sample of properties sold in period $t, i \in N^{t}$, compared with period $0, i \in N^{0}$, the final terms in equations (39) and (40), $\Delta P^{\text {const-qual }}$, are measures of price change adjusted for changes in the quality-mix of properties transacted.

Note that the resulting indirect indexes in equations (39) and (40) are hedonic current period $t$ valued (weighted) index, though constant period 0 characteristics price indexes can be similarly defined. ${ }^{37}$

\footnotetext{
${ }^{37}$ A well-established feature of Laspeyres and Paasche is that they jointly pass the factor reversal test, that is: the product of a Laspeyres price (quantity) and Paasche quantity (price) index is equal to an index of the change in value, Diewert (2004, chapter 16). In equations (39) and (40) the change in average monetary value was divided by a Laspeyres-type quality volume index to result in a hedonic current period price index.
} 


\section{and in log-linear form:}

$$
\begin{aligned}
(41) \ldots \Delta P^{\text {const-qual }} & =\frac{\exp \left(\frac{1}{N^{t}} \sum_{i \in N^{t}} \ln \hat{p}_{i \mid z_{i}^{t}}^{t}\right)}{\exp \left(\frac{1}{N^{0}} \sum_{i \in N^{0}} \ln \hat{p}_{i \mid z_{i}^{0}}^{0}\right)} / \frac{\exp \left(\sum_{k=0} \bar{z}_{k}^{t} \ln \hat{\beta}_{k}^{0}\right)}{\exp \left(\sum_{k=0} \bar{z}_{k}^{0} \ln \hat{\beta}_{k}^{0}\right)} \\
& =\frac{\exp \left(\sum_{k=0} \bar{z}_{k}^{t} \ln \hat{\beta}_{k}^{t}\right)}{\exp \left(\sum_{k=0} \bar{z}_{k}^{t} \ln \hat{\beta}_{k}^{0}\right)}=\frac{\tilde{h}_{k}^{t}\left(\bar{z}_{k}^{t}\right)}{\tilde{h}_{k}^{0}\left(\bar{z}_{k}^{t}\right)} .
\end{aligned}
$$

In calculating equation (41) we take the change in average prices in the numerator and divide it by the volume change in average characteristics, from $\bar{z}_{k}^{0}$ to $\bar{z}_{k}^{t}$, holding the marginal valuations of these average characteristics constant in period $0, \hat{\beta}_{k}^{0}$. This yields a constantquality characteristics price index with quality characteristics held constant at current period values, $\bar{z}_{k}^{t}$.

\section{F. Arithmetic versus geometric aggregation: how much does it matter?}

\section{On the importance of a geometric versus an arithmetic hedonic formulation}

Throughout this exposition the distinction between an arithmetic mean and geometric mean of constant-quality price changes has been emphasized. Its impact is going to be an empirical matter which will vary from country to country, and region and type of property within a country. In this section we consider the differences in the aggregation formulas: arithmetic versus geometric means.

Much of this paper has been concerned with outlining the paths of aggregation for a linear hedonic regression using an arithmetic aggregation and log-linear hedonic regression using a geometric aggregation. There are questions as to how much the functional form of the aggregator, linear (Dutot) versus geometric (Jevons) matters, what are the factors determining the magnitude of the difference between a hedonic Jevons and hedonic Dutot indexes, and mechanisms for further minimizing the difference? The difference between hedonic unweighted indexes was developed by Silver and Heravi (2007b) and integrated into the sampling and axiomatic approaches to index number theory. 


\section{Dutot's failure of the units of measurement (commensurability) test}

In consumer price index number theory, the Jevons index is superior to the Dutot index, on axiomatic grounds (Diewert, 2004, chapter 16). The Dutot index fails the units of measurement (commensurability) test, ${ }^{38}$ which Jevons passes $;{ }^{39}$ has an arbitrary element that depends on the units of measurement. The recommendation is that Dutot should only be applied to heterogeneous goods and services, something that properties are not:

"Under these circumstances [heterogeneous items], it is important that the elementary index satisfies the commensurability test, since the units of measurement of the heterogeneous items are arbitrary, and hence the price statistician can change the index simply by changing the units of measurement for some of the items." (Diewert (2004, chapter 20 paragraph 20.65, Consumer Price Index Manual).

However, as was shown in section II, a special feature of an imputation property price index is that price changes are aggregated across individual properties. The Dutot index number formula implicitly weights individual property price changes, $i$, by their relative prices in the reference period, $w_{i, z_{i}^{0}}^{0}$, and these relative prices of individual properties are synonymous with the relative values of each property:

$(42) \ldots \frac{\sum_{i \in N^{0}} \hat{p}_{i, z_{i}^{0}}^{t}}{\sum_{i \in N^{0}} \hat{p}_{i, z_{i}^{0}}^{0}}=\frac{\sum_{i \in N^{0}} \frac{\hat{p}_{i, z_{i}^{0}}^{t}}{\hat{p}_{i, z_{i}^{0}}^{0}} \hat{p}_{i, z_{i}^{0}}^{0}}{\sum_{i \in N^{0}} \hat{p}_{i, z_{i}^{0}}^{0}}=\sum_{i \in N^{0}} \frac{\hat{p}_{i, z_{i}^{0}}^{t}}{\hat{p}_{i, z_{i}^{0}}^{0}} w_{i, z_{i}^{0}}^{0}$.

The Dutot index in this context is a value-weighted index of individual property price changes. Frisch (1930, page 400) shows that a general condition that the commensurability test is satisfied is that, as in equation (42), it can be phrased as a value weighted average of price changes. Thus in the context of using the formula for property price indexes for individual properties, its failure of the commensurability test is not an issue.

We note that the failure of the commensurability test is not mitigated by the quality adjustment. The units of measurement of properties while originally diverse, say some

\footnotetext{
38 The commensurability test requires that the index number shall be unaffected by a change in units of measurement; that is, if for any commodity the price, $p$, is replaced by $\lambda p$ and at the same time the quantity $q$ is replaced by $q$ / $\lambda$ both at the time 0 and at the time 1 , then the price index between periods 0 and $t$ shall remain unchanged, regardless of the value of $\lambda$.

${ }^{39}$ Diewert (2004, chapter 20 paragraph 20.68) notes in the Consumer Price Index Manual that "If there are heterogeneous items in the elementary aggregate, this is a rather serious failure and hence price statisticians should be careful in using this [Dutot] index under these conditions."
} 
properties of differing sizes, number of bedrooms and so forth, have as an intention of the hedonic adjustment that each of the price changes are of properties of similar characteristics - a constant quality index. This might be achieved without essentially any change to each property's period 0 characteristics. The price change of an individual property $i$, is measured by $\hat{p}_{i \mid z_{i}^{0}}^{t} / \hat{p}_{i \mid z_{i}^{0}}^{0}$; that is, the counterfactual predicted prices in period $t$ of period 0 characteristics, $\hat{p}_{i \mid z_{i}^{0}}^{t}$ are compared with the predicted prices in period 0 of the self-same period 0 characteristics, $\hat{p}_{i \mid z_{i}^{0}}^{0}$. The hedonic standardization of units is for each property over time, rather than across properties in a single period, as would be meaningful for the commensurability test.

Similarly, for a constant period $t$ quality, the hedonic adjustment is applied to ensure the price change is of constant quality, that is:

(43) $\ldots . \frac{\sum_{i \in N^{t}} \hat{p}_{i z z_{i}^{t}}^{t}}{\sum_{i \in N^{t}} \hat{p}_{i z_{i}^{t}}^{0}}=\left[\frac{\sum_{i \in N^{t}} \hat{p}_{i \mid z_{i}^{t}}^{t}}{\sum_{i \in N^{t}} \hat{p}_{i \mid z_{i}^{t}}^{0}\left(\frac{\hat{p}_{i z t_{i}^{t}}^{t}}{\hat{p}_{i \mid z_{i}^{t}}^{0}}\right)^{-1}}\right]^{-1}$

There is little a priori reason to expect there to be less variance, and thus more similar units of measurement, in the period 0 predicted prices of the sample of $i=N^{t}$ characteristics, than the period 0 predicted prices of the sample of $i=N^{0}$ characteristics.

So commensurability is not an issue. This is an important matter since we can argue that the choice between using a linear/arithmetic formulation as opposed to a log-linear/geometric formulation can be determined by the appropriateness of the functional form of the hedonic regression, as opposed to the axiomatic failings, or otherwise, of the aggregation formulas.

\section{So what determines the difference between hedonic Dutot and Jevons and when will it be minimal?}

First, a second-order approximation to the relationship between the Dutot and Jevons indexes - without constant quality hedonic adjustments - has been defined by Diewert (1995a; 2002c; and 2004, chapter 20), Dalen (1992), Balk (2005 and 2008), and Silver and Heravi (2007b) - also Annex B of this paper. The Dutot index, $I^{D}$, is equal to the Jevons index multiplied by the change in the variances of prices, terms of the difference in the variances of $\log$-prices between periods 0 and $t$, terms of the difference in the variances of $\log$-prices between periods 0 and $t,\left(\varepsilon_{t}^{2}-\varepsilon_{0}^{2}\right)$ : 
(44).... $I^{D}=\frac{\mu^{t}}{\mu^{0}}=I^{J} \times \frac{\exp \left(\varepsilon_{t}^{2} / 2\right)}{\exp \left(\varepsilon_{0}^{2} / 2\right)}=I^{J} \times \exp \left[\left(\varepsilon_{t}^{2}-\varepsilon_{0}^{2}\right) / 2\right]$

Note that the variances might be considerable, but it is their change that matters. It is apparent that as property heterogeneity and price dispersion decrease, so too will the difference between the two indexes. Since the variance of prices, as a measure, is specific to the mean, as property price inflation falls, so too is the likelihood that the variances will fall, and vice versa - a positive relationship between inflation and its dispersion (Friedman, 1977, Balk, 1983, Reinsdorf, 1991, and Silver, 2001) — and, thus, the difference between the two formulas. The differences can readily be numerically ascertained by compilers of property price indexes by simply using both formulas. For property price indexes, a calculation routine for summing the price observations for a Dutot index simply has to be modified to sum the logarithms of prices, and take the exponent of the total, for the Jevons index.

However, our concern is with hedonic-adjusted versions of these formulas. Silver and Heravi (2007b) extend the above analysis to indexes that control for observable product heterogeneity through hedonic regressions. The comparison of quality adjusted prices removes some of the quality heterogeneity of the properties making the use of a heterogeneity-controlled Dutot more acceptable. The relationship between a heterogeneitycontrolled Dutot and Jevons is given by:

(45).... $\hat{P}_{D}^{*}=\exp \left(\hat{\beta}_{1}\right) \times \exp \left[\left(\xi_{t}^{2}-\xi_{0}^{2}\right) / 2\right]=P_{J}^{*} \times \exp \left[\left(\xi_{t}^{2}-\xi_{0}^{2}\right) / 2\right]$.

where the ${ }^{*}$ denotes heterogeneity-controlled and where $\xi_{\tau}^{2}$, for $\tau=0, t$, are the variances of the residuals of observations from a hedonic regression in periods 0 and $t$ respectively. Thus the difference between the Jevons and the Dutot hedonic price index is related to the change in the variance of the residuals over time. Assuming $\left(\xi_{t}^{2}-\xi_{0}^{2}\right)<\left(\varepsilon_{t}^{2}-\varepsilon_{0}^{2}\right)$ (from (39) and (40) respectively) then the discrepancy between the Jevons and Dutot indices in (39) will be greater than the discrepancy between the heterogeneity-controlled Jevons and Dutot indexes in (40). Note that the difference between $P_{J}^{*}$ and $P_{D}^{*}$ is reduced as, first, for $\tau=0, t, \xi_{\tau}^{2} \rightarrow 0$, and second, for $\left(\xi_{t}^{2}-\xi_{0}^{2}\right)<\left(\varepsilon_{t}^{2}-\varepsilon_{0}^{2}\right)$, if the hedonic regression controls for the same proportion of price variation in each period, that is $\xi_{\tau}^{2}=\delta_{\tau} \varepsilon_{\tau}^{2}$ for $\tau=0, t$ where Annex B provides details.

Of note is that hedonic imputation and characteristics indexes are considered in section IV for cases where there are sparse data in thin markets. In these cases, the robust periodic re-estimation of hedonic regression equations in each period may be considered infeasible. The use of a single reference period hedonic regression, advocated in this section, is less 
likely to suffer from changes in $\xi_{t}^{2}-\xi_{0}^{2}$ due to changes in the specification and fit of the regression. ${ }^{40}$

In the next section we continue the focus on hedonic base and current period index number formulas, but consolidate and narrow down the options. The myriad options considered here arise from having formulas from (i) three direct approaches and an indirect one; (ii) for each approach, two different functional forms for the hedonic regression; (iii) commensurate arithmetic and geometric formula; (iv) different periods at which quantities (and for the indirect method prices), are held constant; and (v) the use or otherwise of dual imputation. First, to help consolidate these approaches, we look at equivalences, then at weighting systems, and then formulate target indexes. This is followed by a practical consideration of working in thin markets with sparse data and a concern with periodic hedonic regression estimation.

\section{SOME EQUIVALENCES}

The three approaches have quite different, yet quite valid, intuitions. We show here that (i) the characteristics and imputations approaches yield the same answer under the quite credible conditions of using either a linear or log-linear functional form as long as arithmetic means are taken of characteristics/imputed prices; (ii) reiterate that for these formulations, the indirect approach to each, as shown above, is equal to the direct approach; and (iii) show the time dummy to have the same intuition as the indirect approach and outline the conditions for the equivalence of the time dummy and imputation/characteristics approaches. It is argued that there is an axiomatic sense in which the equality of results from quite different intuitions argues well for these formulations.

\section{When imputation index equals characteristics index}

For a linear functional form the characteristics and imputation approaches give the same answer if, (i) for the characteristics approach, $\bar{z}_{k}^{0}$ and $\bar{z}_{k}^{t}$ are arithmetic means of characteristic values and (ii) for the imputation approach, the ratio of average predicted prices is a ratio of arithmetic means. An index with characteristics held constant in the reference period 0 is given by: ${ }^{41}$

\footnotetext{
${ }^{40}$ Further, de Gregorio (2012) has shown that that the effectiveness of stratified sample designs can reduce the source of discrepancies between the Dutot and Jevons index number formulas.

${ }^{41}$ Since $\sum_{i=1}^{J} \sum_{j=1}^{K} a_{i j}=\sum_{j=1}^{K} \sum_{i=1}^{J} a_{j i}$.
} 
(46).... $P_{\bar{z}^{0}}^{D H I B}=\frac{\overline{\hat{p}}_{\bar{z}_{k}^{0}}^{t}}{\overline{\hat{p}}_{\bar{z}_{k}^{0}}^{0}}=\frac{\sum_{k=0}^{K} \hat{\gamma}_{k}^{t} \bar{z}_{k}^{0}}{\sum_{k=0}^{K} \hat{\gamma}_{k}^{0} \bar{z}_{k}^{0}}=\frac{\frac{1}{N^{0}} \sum_{k=0}^{K} \sum_{i \in N^{0}} \hat{\gamma}_{k}^{t} z_{i, k}^{0}}{\frac{1}{N^{0}} \sum_{k=0}^{K} \sum_{i \in N^{0}} \hat{\gamma}_{k}^{t} z_{i, k}^{0}}=\frac{\sum_{i \in N^{0}} \sum_{k=0}^{K} \hat{\gamma}_{k}^{t} z_{k, i}^{0}}{\sum_{i \in N^{0}} \sum_{k=0}^{K} \hat{\gamma}_{k}^{t} z_{k, i}^{0}}=\frac{\frac{1}{N^{0}} \sum_{i \in N^{0}} \hat{p}_{i \mid z_{i}^{0}}^{t}}{\frac{1}{N^{0}} \sum_{i \in N^{0}} \hat{p}_{i \mid z_{i}^{0}}^{0}}$

and characteristics held constant in the current period $t$ by:

(47).... $P_{\bar{z}^{0}}^{D H I B}=\frac{\overline{\hat{p}}_{\bar{z}_{k}^{t}}^{t}}{\overline{\hat{p}}_{\bar{z}_{k}^{t}}^{0}}=\frac{\sum_{k=0}^{K} \hat{\gamma}_{k}^{t} \bar{z}_{k}^{t}}{\sum_{k=0}^{K} \hat{\gamma}_{k}^{0} \bar{z}_{k}^{t}}=\frac{\frac{1}{N^{t}} \sum_{k=0}^{K} \sum_{i \in N^{t}} \hat{\gamma}_{k}^{t} z_{i, k}^{t}}{\frac{1}{N^{t}} \sum_{k=0}^{K} \sum_{i \in N^{t}} \hat{\gamma}_{k}^{t} z_{i, k}^{t}}=\frac{\sum_{i \in N^{t}} \sum_{k=0}^{K} \hat{\gamma}_{k}^{t} z_{i, k}^{t}}{\sum_{i \in N^{t}} \sum_{k=0}^{K} \hat{\gamma}_{k}^{t} z_{i, k}^{t}}=\frac{\frac{1}{N^{t}} \sum_{i \in N^{t}} \hat{p}_{i \mid z_{i}^{t}}^{t}}{\frac{1}{N^{t}} \sum_{i \in N^{t}} \hat{p}_{i \mid z_{i}^{t}}^{0}}$

The equivalences also holds when equations (46) and (47) are phrased as weighted price changes whereby the weight given to the price change of a characteristic $\frac{\hat{\gamma}_{k}^{t}}{\hat{\gamma}_{k}^{0}}$ is the relative value of that characteristics in the reference period, $\frac{\hat{\gamma}_{k}^{0} \bar{z}_{k}^{0}}{\sum_{k=0}^{K} \hat{\gamma}_{k}^{0} \bar{z}_{k}^{0}}$ and the index is a weighted arithmetic mean of price changes, $\frac{\sum_{k=0}^{K}\left(\frac{\hat{\gamma}_{k}^{t}}{\hat{\gamma}_{k}^{0}}\right) \hat{\gamma}_{k}^{0} \bar{z}_{k}^{0}}{\sum_{k=0}^{K} \hat{\gamma}_{k}^{0} \bar{z}_{k}^{0}}$. For example, for the period 0 characteristic index in equation (46):

(48).... $P_{\bar{z}^{0}}^{D H B}=\frac{\overline{\hat{p}}_{\bar{z}_{k}^{0}}^{t}}{\hat{\hat{p}}_{\bar{z}_{k}^{0}}^{0}}=\frac{\sum_{k=0}^{K} \hat{\gamma}_{k}^{t} \bar{z}_{k}^{0}}{\sum_{k=0}^{K} \hat{\gamma}_{k}^{0} \bar{z}_{k}^{0}}=\frac{\sum_{k=0}^{K}\left(\frac{\hat{\gamma}_{k}^{t}}{\hat{\gamma}_{k}^{0}}\right) \hat{\gamma}_{k}^{0} \bar{z}_{k}^{0}}{\sum_{k=0}^{K} \hat{\gamma}_{k}^{0} \bar{z}_{k}^{0}}=\frac{\sum_{i \in N^{0}} \hat{p}_{i \mid z_{i}^{0}}^{t}}{\sum_{i \in N^{0}} \hat{p}_{i \mid z_{i}^{0}}^{0}}=\frac{\sum_{i \in N^{0}} \frac{\hat{p}_{i \mid z_{i}^{0}}^{t}}{\hat{p}_{i \mid z_{i}^{0}}^{0}} \hat{p}_{i \mid z_{i}^{0}}^{0}}{\sum_{i \in N^{0}} \hat{p}_{i \mid z_{i}^{0}}^{0}}$

For a log-linear functional form the characteristics and imputation approaches give the same answer if, (i) for the characteristics approach, $\bar{z}_{k}^{0}$ and $\bar{z}_{k}^{t}$ are arithmetic means of characteristic values and (ii) for the imputation approach, the ratio of average predicted prices is a ratio of geometric means. A similar result is given in Hill and Melser (2008) and Hill (2013) though they confine the equivalence to the log-linear (semilog) hedonic model:

"T3 [a geometric mean of a Geometric Laspeyres and geometric Paasche hedonic indexes] ... has attractive properties when the hedonic takes the semilog form. The fact that it can be defined in either goods or characteristics space adds flexibility to t6he way the results can be interpreted. For example, T3 can be interpreted either as measuring the average of the ratios over the two region-periods of the imputed price 
of each house or as the ratio of the imputed price of the average house. Which perspective is most useful may depend on the context." Hill and Melser (2008, page 602).

An index with characteristics held constant in the reference period 0 is given by:

$$
\begin{gathered}
\text { (49)... } P_{\bar{z}^{0}}^{D H I B}=\frac{\hat{p}_{\bar{z}_{k}^{0}}^{t}}{\hat{p}_{\bar{z}_{k}^{0}}^{0}}=\frac{\prod_{k=0}^{K}\left(\hat{\beta}_{k}^{t}\right)^{\bar{z}_{k}^{0}}}{\prod_{k=0}^{K}\left(\hat{\beta}_{k}^{0}\right)^{\bar{z}_{k}^{0}}}=\frac{\exp \left(\sum_{k=0}^{K} \bar{z}_{k}^{0} \ln \hat{\beta}_{k}^{t}\right)}{\exp \left(\sum_{k=0}^{K} \bar{z}_{k}^{0} \ln \hat{\beta}_{k}^{0}\right)}=\frac{\exp \left(\frac{1}{N^{0}} \sum_{k=0}^{K} \sum_{i \in N^{0}} z_{i, k}^{0} \ln \hat{\beta}_{k}^{t}\right)}{\exp \left(\frac{1}{N^{0}} \sum_{k=0}^{K} \sum_{i \in N^{0}} z_{i, k}^{0} \ln \hat{\beta}_{k}^{0}\right)} \\
=\frac{\exp \left(\frac{1}{N^{0}} \sum_{i \in N^{0}} \sum_{k=0}^{K} z_{k, i}^{0} \ln \hat{\beta}_{k}^{t}\right)}{\exp \left(\frac{1}{N^{0}} \sum_{i \in N^{0}} \sum_{k=0}^{K} z_{k, i}^{0} \ln \hat{\beta}_{k}^{0}\right)}=\frac{\prod_{i \in N^{0}}\left(\hat{p}_{i \mid z_{i}^{0}}^{t}\right)^{\frac{1}{N^{0}}}}{\prod_{i \in N^{0}}\left(\hat{p}_{i \mid z_{i}^{0}}^{0}\right)^{\frac{1}{N^{0}}}}
\end{gathered}
$$

and characteristics held constant in the current period $t$ by:

$$
\begin{aligned}
(50) \ldots P_{\bar{z}^{0}}^{D H I B} & =\frac{\hat{p}_{\bar{z}_{k}^{t}}^{t}}{\hat{p}_{\bar{z}_{k}^{t}}^{0}}=\frac{\prod_{k=0}^{K}\left(\hat{\beta}_{k}^{t}\right)^{\bar{z}_{k}^{t}}}{\prod_{k=0}^{K}\left(\hat{\beta}_{k}^{0}\right)^{\bar{z}_{k}^{t}}}=\frac{\exp \left(\sum_{k=0}^{K} \bar{z}_{k}^{t} \ln \hat{\beta}_{k}^{t}\right)}{\exp \left(\sum_{k=0}^{K} \bar{z}_{k}^{t} \ln \hat{\beta}_{k}^{0}\right)}=\frac{\exp \left(\frac{1}{N^{t}} \sum_{k=0}^{K} \sum_{i \in N^{t}} z_{i, k}^{t} \ln \hat{\beta}_{k}^{t}\right)}{\exp \left(\frac{1}{N^{t}} \sum_{k=0}^{K} \sum_{i \in N^{t}} z_{i, k}^{t} \ln \hat{\beta}_{k}^{0}\right)} \\
= & \frac{\exp \left(\frac{1}{N^{t}} \sum_{i \in N^{t}} \sum_{k=0}^{K} z_{k, i}^{t} \ln \hat{\beta}_{k}^{t}\right)}{\exp \left(\frac{1}{N^{t}} \sum_{i \in N^{t}} \sum_{k=0}^{K} z_{k, i}^{t} \ln \hat{\beta}_{k}^{0}\right)}=\frac{\prod_{i \in N^{t}}\left(\hat{p}_{i \mid z_{i}^{t}}^{t}\right)^{\frac{1}{N^{t}}}}{\prod_{i \in N^{t}}\left(\hat{p}_{i \mid z_{i}^{t}}^{0}\right)^{\frac{1}{N^{t}}}}
\end{aligned}
$$

While we stress the importance of using arithmetic means for the linear and log-linear hedonic functional forms, we note that it is straightforward to demonstrate that geometric means of characteristic values have equivalences for imputation and characteristics approaches for a $\log -\log$ (double-logarithmic) hedonic functional form (though see section IIA on limitations of use of this form for hedonic regressions).

The imputations and characteristics approaches both have an intuition: the former as a ratio of average constant price changes of matched properties, and the latter as a ratio of prices of a constant-quality basket of characteristics. That the two approaches yield the same answer is an important factor in the selection of a credible formula. 
Further, this section on equivalences consolidates the choice of methods and allows further work on weighting to be written in the quiet confidence that when using the imputation approach as a more natural vehicle for developing weights, corresponding results apply for the characteristics approach.

\section{Additivity}

Moreover, the formulas are additive in the sense that as the arithmetic mean of characteristics of properties can extended to include more properties, say a merger of two stratum $s^{1}$ and $s^{2}$ of sizes $n^{1}$ and $n^{2}$ respectively, where $n^{1}+n^{2}=N$. The imputation approach using a weighted arithmetic means of characteristics of both strata, will give the same result as the characteristics approach using the arithmetic mean of the two strata combined.

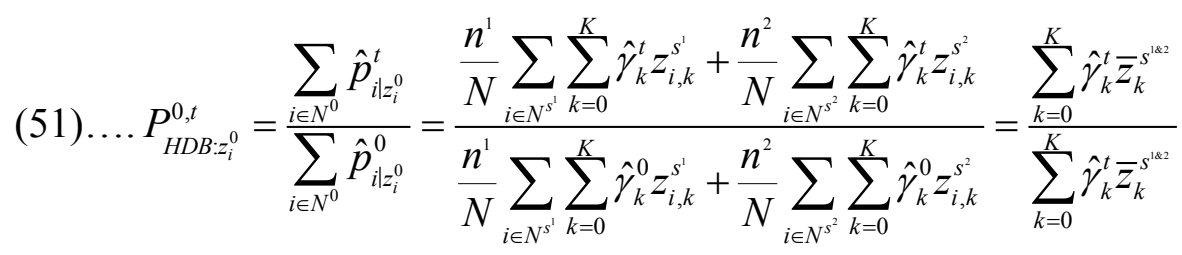

That the indirect imputation/characteristics approach is equivalent to the direct imputation/characteristics approach

Equations (39) to (41) show the direct and indirect approaches yield the same result. For example, equation (40) for a linear functional form of an indirect hedonic property price index that holds characteristics constant in period $t$ is given by:

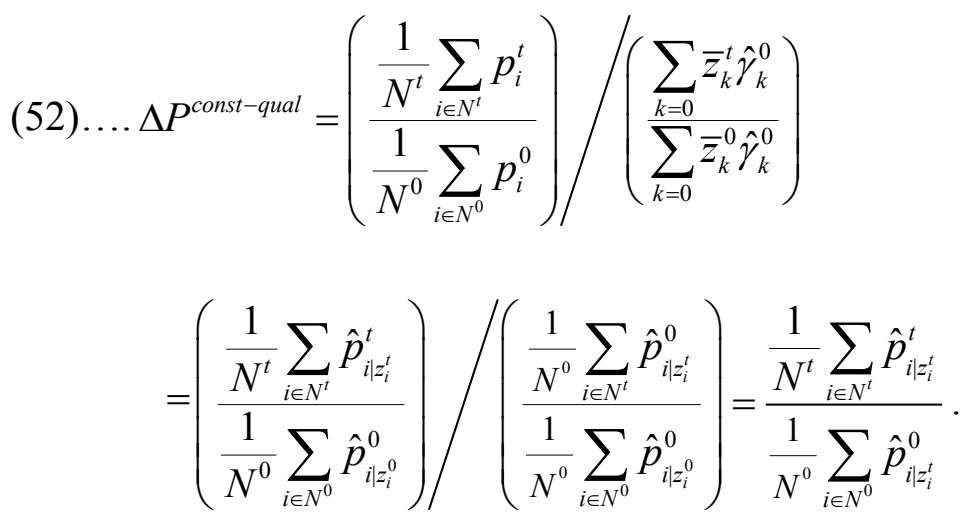

Similarly, for a log-linear hedonic regression and a geometric-current period $t$ hedonic characteristics index, using equations (41): 


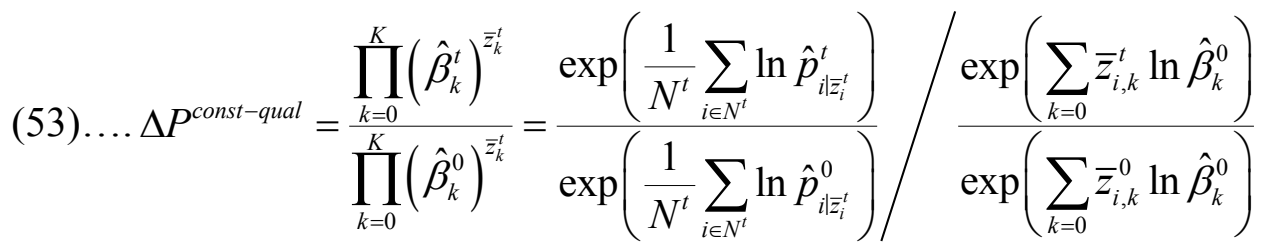

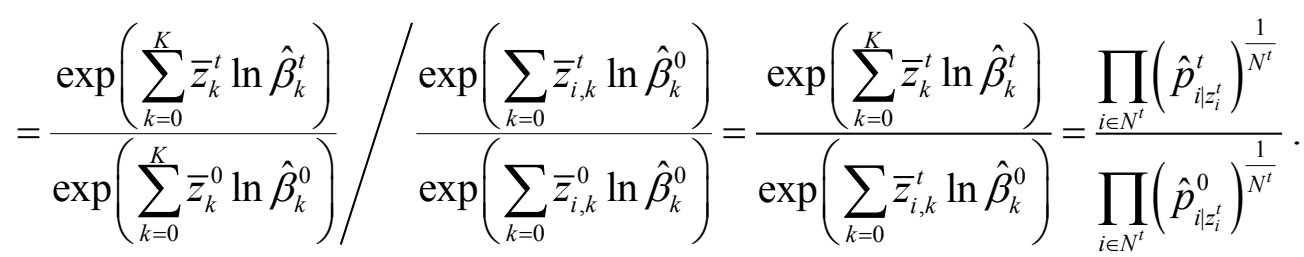

Equation (53) can be written in a more intuitively appealing way as the change in average price divided by the change in the volume of average characteristics, each characteristic being valued by its estimated hedonic characteristic marginal value.

$$
\text { (54)... } \Delta P^{\text {const-qual }}=\frac{\frac{1}{N^{t}}\left(\prod_{i \in N^{t}} p_{i}^{t}\right)^{1 / N^{t}}}{\frac{1}{N^{0}}\left(\prod_{i \in N^{0}} p_{i}^{t}\right)^{1 / N^{0}}} / \exp \left(\sum_{k=0} \ln \hat{\beta}_{k}^{t}\left(\bar{z}_{k}^{t}-\bar{z}_{k}^{0}\right)\right)
$$

The above formulas weight each price equally. The needs of a plutocratic index are that price changes be weighted by the relative value of the transactions (see Rambaldi and Rao (2013) for details of a democratic index).

\section{WEIGHTS AND SUPERLATIVE HEDONIC PRICE INDEXES}

So far we have made no mention of an essential element of index number construction: the weighting of price changes. If one index number formula has a superior weighting, other things being equal, it is preferred. As noted by Griliches (1971, page 326): "There is no good argument except simplicity for the one-vote-per-model approach to regression analysis." ${ }^{42}$

We distinguish between two levels of aggregation: the lower and higher levels. Property price indexes are often stratified by type and location to form more homogeneous strata of

\footnotetext{
${ }^{42}$ Griliches (1961, 1964), Adelman and Griliches (1961) revived the hedonic approach to the construction of price indexes. Griliches (1971) raised methodological issues that foreshadowed many of the issues of concern in this paper including the need for weighting in regression estimates and the empirical form of the relationship, commenting on the preferred use of semi-logarithmic form.
}

(continued...) 
properties, say apartments in the downtown area of a capital city. ${ }^{43}$ At the lower or elementary level constant-quality price indexes are estimated for each stratum. The national or some higher-level index is compiled as a weighted average of the constant-quality price changes of the individual strata indexes.

The higher-level weights can be the relative values of transactions or stocks of properties for each stratum. ${ }^{44}$ This choice between the use of "transactions" or "stocks" as weights depends on the purpose of the property price index and availability of adequate data on the stock of properties. Fenwick (2013) outlines issues relevant to such a choice, the concern here being with the incorporation of weights, implicitly or explicitly, into the lower level within stratum measured constant-quality property price index.

There is a literature on elementary price index number formulas based on the needs of consumer, producer and trade price indexes. While some of these results have a bearing on the analysis here, the context differs in two important respects. First, the matched prices are predicted constant-quality prices for individual properties. The transaction quantity to be assigned to each price is unity. Second, the elementary property price indexes are constantquality indexes that make use of hedonic (or repeat sales) regressions. The weights given to the property price observations, for a time dummy method, are implicit in the way observations of prices enter into the regression or aggregation formula. We provide an improved mechanism for weighting at this lower elementary level. ${ }^{45}$

In this section we consider three issues which allow us to develop a hedonic superlative price index number: a proposed method for weighting hedonic property price indexes to form quasi-superlative indexes for both the linear/arithmetic (section A) and log-linear/geometric (section B) formulations; since sections $\mathrm{A}$ and $\mathrm{B}$ are concerned with quasi-superlative hedonic indexes we say something in section $\mathrm{C}$ about our understanding of substitution bias in this context. In section $\mathrm{D}$ we define hedonic superlative price indexes and show how they differ from the "quasi" formulations in terms of an absence of sample selectivity bias. This formulation differs from accepted wisdom and in section $\mathrm{E}$ we use, the in many ways seminal paper by, Hill and Melser (2008) to show how this formulation improves on the one they advocate, one used by others in much subsequent work. The discussion in sections $\mathrm{A}$ to $\mathrm{E}$ is

\footnotetext{
${ }^{43}$ It is well established in sampling theory (Cochran 1977) and its application to price indexes that stratification can lead to large reductions in sampling error, see Dalèn and Ohlsson (1995) and Dorfman et al. (2006). There are trade-offs. A finer classification results in more similar houses - that is, each stratum has more homogeneous properties - and better estimates of quality-mix change. However, the resulting sample size of transactions in each stratum will be relatively small and estimates of the constant-quality price change inefficient - have relatively wide confidence intervals. A relatively coarse stratum classification will lead to efficient estimates of constant-quality price indexes, but ones based on a restrictive assumption that the coefficients for quality attributes across the many strata now included, are the same.

${ }^{44}$ Rambaldi and Rao (2013, 14-17) provide details on hedonic price indexes using democratic (equal) weights as opposed to plutocratic (stock or expenditure-share) weights.

${ }^{45}$ The author is currently working on weighting systems at the higher level.
} 
concerned with the hedonic imputation approach as a natural framework to use to incorporate explicit weighting but, as demonstrated by Hill and Melser (2008), has an equivalence to the characteristics approach. In section $\mathrm{F}$ we turn to the time dummy approach and methods for introducing weights. In spite of (again seminal) work by Diewert (2005a) we find the hedonic imputation approach a more natural method and outline our concerns about introducing weights into the time dummy approach. Finally, in section $\mathrm{G}$ we consider the adoption of stock, as opposed to transaction value, weights.

\section{A. Lower-level weights for a linear/arithmetic hedonic formulation}

Say there is transaction price for a property in the reference period, but not in the current period. We want to estimate the constant-quality price change of the property. The property's matched current period price is estimated as the predicted price in the current period $t$ of the property using its period 0 characteristics. Given a hedonic regression is run in each over all properties transacted in period $t$, then the counterfactual period $t$ predicted price of an individual property $i$ with $k$ characteristics whose values are $z_{i, k}^{0}$ in period 0 can be estimated as $\hat{p}_{i \mid z_{i}^{0}}^{t}$. (For ease of exposition we drop the $k$ subscript in subsequent algebra: $z_{i}^{0}$ refers to the values of all individual characteristics in the hedonic regression). If, for example, a detached property with 4 bedrooms in a particular postcode, 3 bathrooms, a floor area of 3,000 square feet, and so forth, is sold in period 0 for 750,000, we can use a hedonic regression estimated in period $t$ to answer a question as to the estimated price of a property with the same period 0 characteristics sold in period $t$. By comparing the average price in period 0 with the average predicted price in period $t$ of properties with the same period 0 characteristics, we have a measure of constant quality price change. This is the hedonic imputation approach, which we focus on since it is a more natural form to consider issues of weights given to each matched property price transaction. Its equivalence to the characteristics approach, for these formulations, was established in section III though we return to this issue later.

Consider the hedonic imputation Dutot index in equation (42): a simple ratio of (constant period 0 quality) arithmetic mean prices of properties sold in period 0 . The denominator is the average actual prices of properties transacted in period 0 and the numerator is the average (by definition, counterfactual) predicted price in period $t$ of period 0 properties:

(55)...P $P_{H D B: z_{i}^{0}}^{0, t}=\frac{\frac{1}{N^{0}} \sum_{i \in N^{0}} \hat{p}_{i \mid z_{i}^{0}}^{t}}{\frac{1}{N^{0}} \sum_{i \in N^{0}} \hat{p}_{i}^{0}}=\frac{\sum_{i \in N^{0}}\left(\frac{\hat{p}_{i \mid z_{i}^{0}}^{t}}{\hat{p}_{i \mid z_{i}^{0}}^{0}}\right) \hat{p}_{i \mid z_{i}^{0}}^{0}}{\sum_{i \in N^{0}} \hat{p}_{i \mid z_{i}^{0}}^{0}}=\frac{\sum_{i \in N^{0}}\left(\frac{\hat{p}_{i \mid z_{i}^{0}}^{t}}{\hat{p}_{i \mid z_{i}^{0}}^{0}}\right) \hat{p}_{i \mid z_{i}^{0}}^{0}}{\sum_{i \in N^{0}} \hat{p}_{i \mid z_{i}^{0}}^{0}}$

since for OLS: $\frac{1}{N^{0}} \sum_{i \in N^{0}} p_{i \mid z_{i}^{0}}^{0}=\frac{1}{N^{0}} \sum_{i \in N^{0}} \hat{p}_{i \mid z_{i}^{0}}^{0}$ 
A corresponding index for a sample of period $t$ properties with constant period $t$ characteristics is given by:

$$
\text { (56)...P P.t }=\frac{\frac{1}{N^{t}} \sum_{i \in N^{t}} p_{i}^{t}}{\frac{1}{N^{t}} \sum_{i \in N^{t}} \hat{p}_{i \mid z_{i}^{t}}^{0}}=\frac{\frac{1}{N^{t}} \sum_{i \in N^{0}} \hat{p}_{i \mid z_{i}^{t}}^{t}}{\frac{1}{N^{t}} \sum_{i \in N^{0}} \hat{p}_{i \mid z_{i}^{t}}^{0}}=\left[\frac{\sum_{i \in N^{t}} \hat{p}_{i \mid z_{i}^{t}}^{t}}{\sum_{i \in N^{t}}\left(\frac{\hat{p}_{i \mid z_{i}^{t}}^{0}}{\hat{p}_{i \mid z_{i}^{t}}^{t}}\right) \hat{p}_{i \mid z_{i}^{t}}^{t}}\right]^{-1}
$$

Equations (55 and 56) respectively use constant period 0 and $t$ bundles of characteristics. Note that the denominator of the first term in equation (56) is a counterfactual predicted price in period 0 of period $t$ characteristics, the numerator, due to the use of an OLS estimator, is equivalent to an average of predicted prices as required by the needs of a dual imputation argued above, and given as such in the second term. The last term in equation (56) is a weighted (predicted price/value) of the price changes of properties in period $t$ phrased as a harmonic (Paasche-type) period $t$ index as opposed to the arithmetic (Laspeyres-type) form in equation (55).

These formulas are interesting on three counts. First, since our interest is in price change; the implicit weight given by equation (55) to each property's price change is seen from the last term to be the relative price in the reference period 0. Properties that are more expensive in period 0 get commensurately more weight attributed to their price change when using a hedonic Dutot index. ${ }^{46}$ The relative price of each singular property is equal to the relative expenditure, an appropriate measure of the relative weight to attach to that property's price change in the regression. ${ }^{47}$ The Dutot aggregation, equation (55), gets it right for a period 0 expenditure weighting.

Second, we use dual imputation for our price change. By their counterfactual nature, $\hat{p}_{i \mid z_{i}^{0}}^{t}$ (and $\hat{p}_{i \mid z_{i}^{t}}^{0}$ ) are predicted: there is no nominal actual price equivalent to the predicted price in period $t($ period 0$)$ for a property with period $0($ period $t)$ characteristics. Because of likely

\footnotetext{
${ }^{46}$ There is a sampling approach to elementary index number formulas, given by Balk (2005 and 2008) and Diewert (2004, chapter 20) in the context of a consumer price index for which we could, somewhat heroically, treat the Dutot index as a sample estimator of a population (housing stock) Dutot index. The sample period 0 transaction expenditures shares in equation (55) would be probabilities of selection of that type of property from the stock of all properties.

${ }^{47}$ In the context of a say consumer price index the sample of prices/price changes from outlets of cans of regular Coca Cola, for example, are representative of all such cans sold, or even soft drinks. Quantity/value weights can be applied to these prices/price changes because the items are more or less identicalhomogeneous. It is the heterogeneity of properties that leads top prices being weighted at the observation level of the individual property.
} 
omitted variable bias present in predicted prices, but not actual prices, the price index should have predicted prices in both numerators and denominator (or actual prices in both) - see Hill and Melser (2008, pages 598-600 for a formal analysis). The solution is to estimate separate regression equations for period 0 and current period $t$ and use predicted values instead of the actual values in equation (55). Dual imputation can require estimated hedonic regressions for each of the reference and current periods. We provide in section III a workaround for converting the single imputation to the dual imputation in the absence of continuing hedonic regression estimates.

Third, the weights, by the nature of the derivation, are relative predicted prices (expenditures). This derivation of equation (55) requires explanation; the numerator in the last algebraic term is by its nature a predicted price; of period 0 characteristics evaluated using a period $t$ hedonic regression. A constant period 0 quality price change is required for each property; for a dual imputation, the predicted price in the numerator needs to be compared with a predicted price in period 0 of (again) period 0 characteristics in the denominator. Thus the numerator in the last term of equation (55) must be a measure of (constant quality) price change and to maintain its equality to $\frac{1}{N^{0}} \sum_{i \in N^{0}} \hat{p}_{i \mid z_{i}^{0}}^{t}$, we need to phrase it as the price change multiplied by its predicted price in period $0, \sum_{i \in N^{0}}\left(\frac{\hat{p}_{i \mid z_{i}^{0}}^{t}}{\hat{p}_{i \mid z_{i}^{0}}^{0}}\right) \hat{p}_{i \mid z_{i}^{0}}^{0}$. The denominator for an OLS estimator is the average price of actual values that happens to equal the average price of predicted values $\frac{1}{N^{0}} \sum_{i \in N^{0}} p_{i \mid z_{i}^{0}}^{0}=\frac{1}{N^{0}} \sum_{i \in N^{0}} \hat{p}_{i \mid z_{i}^{0}}^{0}$. Thus the use of single (or double) imputation in equations (55) and (56) attributes to the constant (period 0 and period $t$ respectively) quality price changes an implicit weighting of relative predicted values. A fortuitous characteristics of the simple equation (50) is that it equates to a dual imputation measure of constant quality price change weighted by relative (predicted) expenditure weights.

\section{Use of actual prices as weights}

Relative actual prices can be used for weights rather than the predicted ones. Equation (57) shows this for equation (50); it is easily achieved computationally by multiplying the predicted price of each property $i$ in the numerator of the first term of equation (55) by the ratio of period 0 actual to predicted price:

$$
(57) \ldots P_{H I D}^{0 t}=\frac{\frac{1}{N^{0}} \sum_{i \in N^{0}} \hat{p}_{i \mid z_{i}^{0}}^{t}\left(\frac{p_{i}^{0}}{\hat{p}_{i \mid z_{i}^{0}}^{0}}\right)}{\frac{1}{N^{0}} \sum_{i \in N^{0}} p_{i \mid z_{i}^{0}}^{0}}=\frac{\sum_{i \in N^{0}} \hat{p}_{i \mid z_{i}^{0}}^{0}\left(\frac{\hat{p}_{i \mid z_{i}^{0}}^{t}}{\hat{p}_{i \mid z_{i}^{0}}^{0}}\right)\left(\frac{p_{i}^{0}}{\hat{p}_{i \mid z_{i}^{0}}^{0}}\right)}{\sum_{i \in N^{0}} p_{i \mid z_{i}^{0}}^{0}}=\frac{\sum_{i \in N^{0}} p_{i \mid z_{i}^{0}}^{0}\left(\frac{\hat{p}_{i \mid z_{i}^{0}}^{t}}{\hat{p}_{i|| z_{i}^{0}}^{0}}\right)}{\sum_{i \in N^{0}} p_{i \mid z_{i}^{0}}^{0}} \neq \frac{\sum_{i \in N^{0}} \hat{p}_{i \mid z_{i}^{0}}^{t}}{\sum_{i \in N^{0}} \hat{p}_{i \mid z_{i}^{0}}^{0}}
$$


There is a natural question as to which of equations (55) and (57) is appropriate; should relative actual prices or relative predicted prices be used as weights? ${ }^{48}$ However, equation (57) is contrived in the sense that it does not arise from a natural Dutot ratio of average prices. We advocate equation (55).

\section{Quasi-superlative indexes: Fisher indexes}

Another question is whether we can improve on equations (55) and (56) by including current period weights while still using the sample of reference period 0 transactions. We distinguish between a problem of substitution bias that will be ameliorated by — for a given sample of transactions, say reference period 0 - a symmetric use of reference period and current period $t$ weights and sample selection bias, that will be ameliorated by using both transactions in period 0 and period $t{ }^{49} \mathrm{We}$ consider each in turn, the first for a "quasi" version of a superlative hedonic price index and the second as a full version.

As outlined above, the implicit weight given to each property's price change is the relative (predicted) price in the reference period 0. Properties that are more expensive in period 0 get commensurately more weight attributed to their price change. The relative price of each singular property is equal to the relative expenditure, an appropriate measure of the relative weight to attach to that property's price change in the regression. ${ }^{50}$ A Dutot aggregation, equation (55), gets it right for a period 0 weighting and sample selection and equation (56) gets it right for a period $t$ weighting and sample selection. Note that there is no need to introduce explicit weights. However, our interest is with a superlative hedonic index commensurate with this arithmetic aggregation and underlying linear hedonic functional form. A hedonic quasi-Fisher superlative index that is a geometric mean of the hedonic Laspeyres and hedonic Paasche indexes, namely of equations (55) and (56) is given by:

\footnotetext{
${ }^{48}$ Hill $(2013,891)$ also raised the distinction between the two alternatives forms of weights - his equations L1 and L2 - though provides no guidance on their relative merits. De Haan and Gong $(2014,12)$ do not discuss the issue but use predicted prices as weights. Rambaldi and Rao $(2013,14-15)$ note that the use of predicted values for weights is synonymous with defining a hedonic price index as a simple ratio of average (quality-adjusted) prices, though work with actual values as weights.

49 The sample selectivity problem with these hedonic indexes is not new. Griliches (1971) argued that "By using constant base-period characteristics, "new" models that exist in the current period but not in the base period are excluded. Similarly, by using constant current-period characteristics, "old" models that exist in the base period but not in the current period are excluded." For housing transactions, the problem may be less profound since it does not follow that properties transacted in period $t$ need be newer that those in period 0 .

${ }^{50}$ In the context of a say consumer price index the sample of prices/price changes from outlets of cans of regular Coca Cola, for example, are representative of all such cans sold, or even soft drinks. Quantity/value weights can be applied to these prices/price changes because the items are more or less identicalhomogeneous. It is the heterogeneity of properties that leads top prices being weighted at the observation level of the individual property.
} 
$\sqrt{\frac{\sum_{i \in N^{0}}\left(\frac{\hat{p}_{i z z_{i}^{0}}^{t}}{\hat{p}_{i z z_{i}^{0}}^{0}}\right) \hat{p}_{i z z_{i}^{0}}^{0}}{\sum_{i \in N^{0}} \hat{p}_{i z z_{i}^{0}}^{0}} \times\left[\frac{\sum_{i \in N^{0}} \hat{p}_{i \mid z_{i}^{t}}^{t}}{\sum_{i \in N^{0}}\left(\frac{\hat{p}_{i \mid z_{i}^{t}}^{0}}{\hat{p}_{i \mid z_{i}^{t}}^{t}}\right) \hat{p}_{i \mid z_{i}^{t}}^{t}}\right]^{-1}}$

A counterpart index that uses the sample of period $t$ transactions is:

$$
\sqrt{\frac{\sum_{i \in N^{t}}\left(\frac{\hat{p}_{i z z_{i}^{0}}^{t}}{\hat{p}_{i z z_{i}^{0}}^{0}}\right) \hat{p}_{i z z_{i}^{0}}^{0}}{\sum_{i \in N^{t}} \hat{p}_{i z z_{i}^{0}}^{0}} \times\left[\frac{\sum_{i \in N^{t}} \hat{p}_{i \mid z_{i}^{t}}^{t}}{\sum_{i \in N^{t}}\left(\frac{\hat{p}_{i \mid z_{i}^{t}}^{0}}{\hat{p}_{i \mid z_{i}^{t}}^{t}}\right) \hat{p}_{i \mid z_{i}^{t}}^{t}}\right]^{-1}}
$$

Both are constructed to alleviate substitution bias though each is based on a different sample of transactions. The OLS linear hedonic model equation (58) works in that (i) dual imputations are employed for the measure of constant-quality price changes; and (ii) the price changes, from periods 0 to $t$, of period 0 property transactions are weighted first by their relative (predicted) prices (expenditures) in period 0 in a Laspeyres-type form and second by their relative prices (expenditures) in period $t$ in a Paasche-type form; a (symmetric) geometric mean taken of the two indexes. They are individually "quasi" because sample selection is restricted to period 0 and period $t$ transactions in equations (58) and (59) respectively. ${ }^{51}$

\section{B. Log-linear hedonic model}

Consider below the log-linear hedonic imputation model and use of geometric means for period 0 transactions; the index is a measure of price change for constant-period 0 characteristics property price indexes:

$$
(60) \ldots P_{H L L}^{J}=\frac{\prod_{i \in N^{0}}\left(\hat{p}_{i \mid z_{i}^{0}}^{t}\right)^{\frac{1}{N^{0}}}}{\prod_{i \in N^{0}}\left(p_{i \mid z_{i}^{0}}^{0}\right)^{\frac{1}{N^{0}}}}=\prod_{i \in N^{0}}\left[\frac{\hat{p}_{i \mid z_{i}^{0}}^{t}}{\hat{p}_{i \mid z_{i}^{0}}^{0}}\right]^{\frac{1}{N^{0}}}
$$

\footnotetext{
${ }^{51}$ The hedonic Törnqvist price index given by equation (57) weights each sample $S(0 \neg t)$ and $S(t \neg 0)$ according to the relative expenditure in that period. The hedonic Fisher equally weights these components.
} 
Unlike the linear arithmetic case above, equal weights are implicitly attached to each price change - such indexes are generally referred to as "unweighted" indexes. The price change measured here is based on predicted values for reasons similar to those given above for the arithmetic aggregation. There are three problems with this measure: (i) property price changes are equally weighted; (ii) the index is based on only the sample of properties transacted in period 0 ; and (iii) the introduction of explicit weights precludes our previous use of equating average predicted prices to average actual prices, as a means by which dual imputations are introduced. We consider each in turn.

Application of explicit reference and current period weights: a hedonic quasi-Törnqvist price index

The first task is to apply weights to these price changes. A useful opportunity exists using the imputation approach to explicitly introduce weights at this very lowest level. The approach, to the author's knowledge, was first proposed in Feenstra (1995) and used by Ioannidis and Silver (1999) in an application, using scanner data, of hedonic methods to the quality adjustment price indexes for television sets, but has not since received attention.

As outlined in section IIB, the imputation approach works at the level of individual properties, rather than the average values of their characteristics. This allows us to explicitly attach to each property's price change a weight. Period 0 weights would be $\frac{\hat{p}_{i \mid z_{i}^{0}}^{0}}{\sum_{i \in N^{0}} \hat{p}_{i \mid z_{i}^{0}}^{0}}$ given to each price change, $\left(\frac{\hat{p}_{i \mid z_{i}^{t}}^{t}}{\hat{p}_{i \mid z_{i}^{0}}^{0}}\right)$ in equation (55). We explicitly weight price changes by their relative (predicted) price/transaction value in period 0 . The price changes of more expensive properties are given a higher (period 0) proportionate weight:

(61).... $P_{H G L: z_{i}^{0}}^{0, t}=\prod_{i \in N^{0}}\left[\frac{\hat{p}_{i \mid z_{i}^{0}}^{t}}{\hat{p}_{i \mid z_{i}^{0}}^{0}}\right]^{\left(\sum_{i \in N^{0}}^{\hat{p}_{i \mid i i_{i}^{0}}^{0}}\right)}=\exp \left(\sum_{i \in N^{0}}\left(\frac{\hat{p}_{i \mid z_{i}^{0}}^{0}}{\sum_{i \in N^{0}} \hat{p}_{i \mid z_{i}^{0}}^{0}}\right) \ln \left[\frac{\hat{p}_{i \mid z_{i}^{0}}^{t}}{\hat{p}_{i \mid z_{i}^{0}}^{0}}\right]\right)$

There is then the question of why only period 0 weights are used for this measure of constant quality price change. We can use a symmetric average of period 0 and period $t$ weights: a hedonic quasi-Törnqvist price index but based on a period 0 sample selections given by: 
$(62) \ldots$

$$
P_{H G P: z_{i}^{t}}^{0, t}=\prod_{i \in N^{0}}\left(\frac{p_{i \mid z_{i}^{t}}^{t}}{\hat{p}_{i \mid z_{i}^{t}}^{0}}\right)^{\hat{w}_{i}^{\tau}}=\frac{\prod_{i \in N^{0}}\left(p_{i \mid z_{i}^{t}}^{t}\right)^{\hat{w}_{i}^{\tau}}}{\prod_{i \in N^{0}}\left(\hat{p}_{i \mid z_{i}^{t}}^{0}\right)^{\hat{w}_{i}^{\tau}}}=\exp \left(\sum_{i \in N^{0}} \hat{w}_{i}^{\tau} \ln \left(\frac{p_{i \mid z_{i}^{t}}^{t}}{\hat{p}_{i \mid z_{i}^{t}}^{0}}\right)\right)=\exp \left(\sum_{i \in N^{0}} \hat{w}_{i}^{\tau} \ln \left(p_{i \mid z_{i}^{t}}^{t}-\hat{p}_{i|| z_{i}^{t}}^{0}\right)\right)
$$

where $\hat{w}_{i}^{\tau}=\frac{1}{2}\left(\frac{\hat{p}_{i \mid z_{i}^{t}}^{t}}{\sum_{i \in N^{0}} \hat{p}_{i \mid z_{i}^{t}}^{t}}+\frac{\hat{p}_{i \mid z_{i}^{t}}^{0}}{\sum_{i \in N^{0}} \hat{p}_{i \mid z_{i}^{t}}^{0}}\right)$ which is a quasi-hedonic formulation of a Törnqvist index

(Feenstra, 1995, Ioannidis and Silver, 1999, and Balk, 2008), an index that has excellent properties in economic theory as a superlative index (Diewert, 2004). It is "quasi" in the sense that it does not make use of period $t$ transactions.

Equation (62) uses a period 0 sample of transactions. A similar quasi-hedonic Törnqvist index based on period $t$ transactions is given by:

(63).... $P_{H I G P}^{J}=\prod_{i \in N^{t}}\left(\frac{p_{i \mid z_{i}^{t}}^{t}}{\hat{p}_{i \mid z_{i}^{t}}^{0}}\right)^{\hat{w}_{i}^{\tau}}=\exp \left(\sum_{i \in N^{t}} \hat{w}_{i}^{\tau} \ln \left(\frac{p_{i \mid z_{i}^{t}}^{t}}{\hat{p}_{i \mid z_{i}^{t}}^{0}}\right)\right)=\exp \left(\sum_{i \in N^{t}} \hat{w}_{i}^{\tau} \ln \left(p_{i \mid z_{i}^{t}}^{t}-\hat{p}_{i \mid z_{i}^{t}}^{0}\right)\right)$

These innovative quasi hedonic superlative formulas depart from conventional hedonic formulations - Diewert (2003), de Haan (2004a), Silver and Heravi (2005), de Haan and Krsinich (2014, Appendix A) - in which the weights attached to each price change for transactions in period 0 are the relative expenditures in period 0 (for $i \in N^{0}$ ) and for period $t$ are the relative expenditures in $t$, (for $i \in N^{t}$ ), as opposed to an average of period 0 and $t$, as in equations (52) and (53). Given, say, using equation (50) for period 0 transactions, we have a comparison between actual prices in period 0 and counterfactual predicted prices in period $t$, and given that these predicted prices act as corresponding weights in period $t$ for the price change, it would be wasteful to abandon the thought experiment for the weights but not for the price change. Indeed abandoning $\hat{w}_{i}^{\tau}$ in favor of $\hat{w}_{i}^{0}$ would remove the analytical power of taking some account of substitution bias.

\section{The nature of substitution bias for a hedonic price index}

A concern with both (geometric) Laspeyres-and Paasche-indexes is that they are both subject to substitution bias. They form bounds on a superlative index, an index that has good approximation properties to a theoretical index that does not have any substitution bias. A periodically updated or chained Laspeyres or Paasche may alleviate substitution bias and be closer to a theoretical index than its fixed base counterpart (Balk, 2008: 122-126). 
Consider each property to have, for the large part, a unique seller and is open for purchase to many buyers. Buyers can respond to above average characteristic price increases, say of extra square footage and below average price increases of an additional bedroom by favoring larger properties with fewer bedrooms, though with a delay to the purchase in thin markets. A Paasche-type hedonic price index holds quantities of characteristics constant in the current period and has a substitution bias in that their current period weight over-emphasizes the substitution of purchases to properties whose characteristics have above average price increases. Laspeyres-type characteristic price indexes understate a true Laspeyres-type index and Paasche-type characteristic price indexes overstate a true Paasche-type characteristics' price index.

The bounds can also be considered from a producer's perspective. Assume a builder of an apartment block has the flexibility to reconfigure some of the tied characteristics of the apartments when near completion; again say an additional bedroom can be substituted for a smaller area space of the living room, master bedroom and bathroom. If the characteristic price of an additional bedroom increased faster than that of the concomitant increased "living" square footage, a revenue-maximizing producer would substitute bedrooms for living space. The supply side has a substitution towards property characteristics with above average price increases and Paasche-type index would understate a true Paasche-type hedonic index. Retrospective Paasche-type and quasi-Fisher hedonic price indexes can be calculated and the empirical placing of the bounds, whether upper or lower, can be determined and considered alongside a priori reasoning. As a result, a Paasche-type property price index derived from equation (35) can be properly interpreted in terms of substitution bias.

\section{Hedonic superlative indexes and sample selection bias}

The quasi-hedonic Fisher indexes in equations (58) and (59) were each based on samples of period 0 and $t$ transactions respectively as were the quasi-Törnqvist indexes in equations (63) and (64). In both cases the problem is not one of substitution bias; it is a sample selection bias. Substitution bias arises from using, in this context, period 0 or period $t$ weights, rather than a symmetric mean of the two period's expenditure weights, as in a Törnqvist (or of quantities, as in a Walsh) price index number formulas, or a symmetric mean of formulas that respectively utilize period 0 and period $t$ weights, as in a Fisher price index. The quasisuperlative formulas outlined above make symmetric use of both periods' weights, but limits the sample to transactions either period 0 or period $t$. Our hedonic Fisher and our hedonic Törnqvist price index should be based on samples of period 0 and period $t$ transactions.

Some additional notation may help clarify the formulas. Let $S(0 \cap t)$ be the set of properties that are present in both periods 0 and $t, S(0 \neg t)$ is the set of properties that are present in period 0 but not period $t, S(t \neg 0)$ is the set of properties that are present in period 
$t$ but not period 0 , and $S(t \cap 0)$ the set properties transacted in both periods. The weights for each term are the relative transaction values of these sets of data. The weights for each term are the relative transaction values of these sets of data, that is, where $V$ is the total value of transaction prices (or stocks) for $S(0 \cap t), S(0 \neg t)$ and $S(t \neg 0)$, $V=\sum_{i \in S(t \neg 0) \cap S(0 \neg t) \cap S(0 \cap t)} v_{i} ; v_{0 \neg t}=\sum_{i \in 0 \neg t} v_{i}, v_{t \neg 0}=\sum_{i \in t \neg 0} v_{i}$; and $v_{0 \cap t}=\sum_{i \in 0 \cap t} v_{i}$ and $w_{i}^{\tau}$ is an arithmetic mean of the weight (relative stock value or transaction (price) value) given to each property in periods 0 and $t$, that is $\hat{w}_{i}^{\tau}=\frac{1}{2}\left(\hat{w}_{i}^{0}+\hat{w}_{i}^{t}\right)$. Bear in mind that we are weighting the price change of each individual property and the weight is the relative expenditure which equates to the price of the property. In this unusual situation we can use predicted prices for weights, as argued above:

$\hat{w}_{i}^{\tau}=\frac{1}{2}\left(\frac{\hat{p}_{i z i t}^{t}}{\sum_{i \in S(0-t)} \hat{p}_{i z z_{i}^{t}}^{t}}+\frac{\hat{p}_{i z z_{i}^{t}}^{0}}{\sum_{i \in S(0-t)} \hat{p}_{i z_{i}^{t}}^{0}}\right)=\frac{1}{2}\left(\hat{w}_{i}^{0}+\hat{w}_{i}^{t}\right)$. The hedonic Törnqvist price index is:

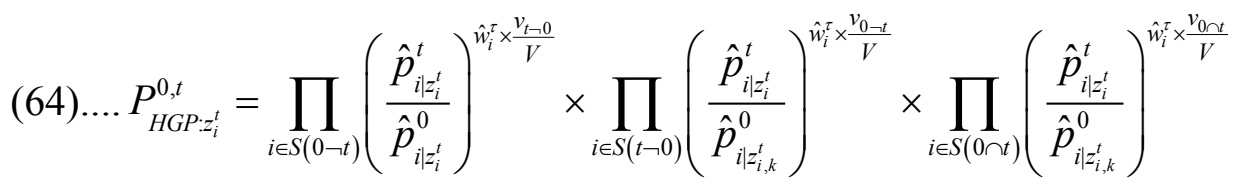

The superlative Törnqvist hedonic price index follows Triplett and McDonald (1977), Diewert (2002), Triplett (2006), de Haan (2004a), and Silver and Heravi (2005).52 We note that for repeat sales, $S(0 \cap t)$, we have used a double imputation, that is predicted prices, when actual prices are available. At first sight this goes against the principles of matched models measurement whereby actual prices are compared, say for the price change of a single standard can of Coca Cola for a consumer price index: the price of like is compared over time with the price of like. However, as Hill and Melser (2008) explain:

"As far as we are aware, the possibility of always imputing for a repeat observation ..... has not previously been considered in the literature. For the case of computers, this would be hard to justify since a particular model is the same irrespective of when it is sold. Housing, however, is another matter. There is no guarantee even for a repeat sale that we are comparing like with like. This is because the characteristics of a house may change over time due to renovations or the building of a new shopping center nearby, etc. The only way to be sure that like is compared with like is to double impute all houses (even with repeat sales)." Hill and Melser (2008, page 600).

\footnotetext{
52 This paper acknowledges the contribution from Erwin Diewert (University of British Columbia) who helpfully provided rigorous derivations of the results in a previous working version of this paper.
} 
Equation (66) has the following attributes:

- Its general form is a Törnqvist index, a superlative price index — an index number formulas with good approximation to a price index without substitution bias. ${ }^{53}$

- It has no sample selectivity bias in that it includes estimates of constant quality price change using three sets of price observations: (i) transacted in period 0 (but not in period $t$ ); (ii) price observations transacted in period $t$ (not in period 0 ); and (iii) repeat price transactions available in both periods 0 and $t$.

- For the aggregate of each set of transactions is weighted by the expenditure share of that set, for example, if there are few repeat transactions in periods 0 and $t$, these price changes have a commensurately less weight, $v_{0 \cap t} / V$. This is appropriate for a sample selection issue.

- For each of these sets of price observations, weights are estimated for both the reference and current periods and a symmetric average of these two weights used, $\hat{w}_{i}^{\tau}=\left(\hat{w}_{i}^{0}+\hat{w}_{i}^{t}\right) / 2$, akin to a superlative Törnqvist formulation.

- A dual imputation is used for the constant quality price change and, for the weights, relative predicted values for reasons outlined below.

\section{E. Hedonic superlative price index number formulas: Hill and Melser (2008)}

Our formulation of a hedonic superlative index, equation (59), differs from Hill and Melser (2008) - hereafter HM — reiterated in Hill (2013) and used by Rambaldi and Rao (2013). ${ }^{54}$ Hill and Melser (2008, pages 601-602) derive hedonic Fisher and Törnqvist hedonic price indexes from the imputation and characteristics approach for a semi-logarithmic functional form of a hedonic regression. In an important contribution they first, show how the derivations from the two approaches provide the same results. Second, they solve the absence of matched models (infrequent transactions) by separately considering a geometric Laspeyres for (constant period 0 characteristics) and a geometric Paasche indexes (for constant period $t$ characteristic), and then taking a geometric mean of the two to derive a superlative hedonic price index. We show both of these below but take issue with their formulation of a hedonic superlative price index compared with our equation (64).

Hill and Melser (2008, page 601) show how a geometric Laspeyres hedonic price index from an imputation approach equates to one from a characteristics approach:

${ }^{53}$ For matched models of actual transaction prices, the Törnqvist index is given by $I_{T}^{0 \rightarrow t}=\prod_{i=1}^{N}\left(\frac{p_{i, t}}{p_{i, 0}}\right)^{\left(s_{i, 0}+s_{i, t}\right) / 2}$.

${ }^{54}$ De Haan and Diewert (2013) in the RPPI Handbook (Eurostat et. al., 2013) have a similar formulation to Hill and Melser (2008) except that it is unweighted. 


$$
\begin{gathered}
\left.(65) \ldots \prod_{i \in N^{0}}\left[\frac{\hat{p}_{i \mid z_{i}^{0}}^{t}}{\hat{p}_{i \mid z_{i}^{0}}^{0}}\right] \sum_{i \in N^{0}}^{p_{i \mid z_{i}^{0}}^{0} p_{i \mid i_{i}^{0}}^{0}}\right)=\prod_{i \in N^{0}}\left[\frac{\hat{p}_{i \mid z_{i}^{0}}^{t}}{\hat{p}_{i \mid z_{i}^{0}}^{0}}\right]^{w_{i}^{0}}=\prod_{i \in N^{0}}\left[\exp \left(\sum_{k=0}^{K} w_{i}^{0}\left(\hat{\beta}_{k}^{t}-\hat{\beta}_{k}^{0}\right) z_{i, c}^{0}\right)\right] \\
=\exp \left(\sum_{k=0}^{K}\left(\hat{\beta}_{k}^{t}-\hat{\beta}_{k}^{0}\right) \sum_{i \in N^{0}} w_{i}^{0} z_{i, c}^{0}\right)=\exp \left(\sum_{k=0}^{K}\left(\hat{\beta}_{k}^{t}-\hat{\beta}_{k}^{0}\right) \bar{z}_{i, c}^{0}\right)
\end{gathered}
$$

where $w_{i}^{0}=p_{i \mid z_{i}^{0}}^{0} / \sum_{i \in N^{0}} p_{i \mid z_{i}^{0}}^{0}$ and $\bar{z}_{k}^{0}=\sum_{i \in k \cap N^{0}} w_{i}^{0} z_{i, k}^{0}$ is an arithmetic mean and the $\hat{p}_{i \mid z_{i}^{0}}^{t}$ and $\hat{p}_{i \mid z_{i}^{0}}^{0}$ are generated from semi-logarithmic hedonic regressions.

The derivation is helpful since it clearly shows how weights are introduced into a characteristics approach via the measure of the average value of each $k$ characteristic, $\bar{z}_{k}^{0}=\sum_{i \in k \cap N^{0}} w_{i}^{0} z_{i, k}^{0}$. Compilers simply have to take their explicit weights, the relative price $w_{i}^{0}=p_{i \mid z_{i}^{0}}^{0} / \sum_{i \in N^{0}} p_{i \mid z_{i}^{0}}^{0}$, for each transaction, and multiply them by the corresponding characteristics values. This is equivalent to the hedonic imputation approach which we focus on here as a more natural formulation in this context for dealing with aggregating over predicted values of each property transacted with associated weights. ${ }^{55}$

The geometric Paasche version of equation (65) is:

(66).... $\prod_{i \in N^{t}}\left[\frac{\hat{p}_{i \mid z_{i}^{t}}^{t}}{\hat{p}_{i \mid z_{i}^{t}}^{0}}\right]^{w_{i}^{t}}=\exp \left(\sum_{k=0}^{K}\left(\hat{\beta}_{k}^{t}-\hat{\beta}_{k}^{0}\right) \bar{z}_{i, c}^{t}\right)$

and a superlative formulation covering $i \in N^{0} \cap N^{t}$ is a geometric mean of the period 0 and period $t$ hedonic indexes:

$$
\text { 67).... } \sqrt{\prod_{i \in S(0 \neg t)}\left[\frac{\hat{p}_{i \mid z_{i}^{0}}^{t}}{\hat{p}_{i \mid z_{i}^{0}}^{0}}\right]^{w_{i}^{0}} \times \prod_{S(t \neg 0)}\left[\frac{\hat{p}_{i \mid z_{i}^{t}}^{t}}{\hat{p}_{i \mid z_{i}^{t}}^{0}}\right]^{w_{i}^{t}}}=\exp \left(\frac{1}{2} \sum_{k=0}^{K}\left(\hat{\beta}_{k}^{t}-\hat{\beta}_{k}^{0}\right)\left(\bar{z}_{i}^{0}+\bar{z}_{i}^{t}\right)\right) .
$$

${ }^{55}$ Using an arithmetic formulation for the Dutot period 0 hedonic imputation-to-characteristics approach:

$$
\frac{\sum_{i \in N^{0}} p_{i \mid z_{i}^{0}}^{t}}{\sum_{i \in N^{0}} p_{i \mid z_{i}^{0}}^{0}}=\frac{\sum_{i \in N^{0}} \sum_{k=0}^{K} \frac{\hat{\gamma}_{k}^{t}}{\hat{\gamma}_{k}^{0}} \hat{\gamma}_{k}^{0} z_{k, i}^{0}}{\sum_{i \in N^{0}} \sum_{k=0}^{K} \hat{\gamma}_{k}^{0} z_{k, i}^{0}}=\frac{\sum_{k=0}^{K} \frac{1}{N^{0}} \sum_{i \in N^{0}} \frac{\hat{\gamma}_{k}^{t}}{\hat{\gamma}_{k}^{0}} \hat{\gamma}_{k}^{0} z_{k, i}^{0}}{\sum_{k=0}^{K} \frac{1}{N^{0}} \sum_{i \in N^{0}} \hat{\gamma}_{k}^{0} z_{k, i}^{0}}=\frac{\sum_{k=0}^{K} \frac{\hat{\gamma}_{k}^{t}}{\hat{\gamma}_{k}^{0}} \hat{\gamma}_{k}^{0} \bar{z}_{k}^{0}}{\sum_{k=0}^{K} \hat{\gamma}_{k}^{0} \bar{z}_{k}^{0}} \text { where } \bar{z}_{k}^{0} \text { is a weighted mean. }
$$


Note that this formulation differs from the one we proposed in equation (64) in some important respects:

- While the HM formulation captures the samples of transactions in periods 0 and $t$, it does not include the symmetric weights of each transaction, as does the quasiTörnqvist hedonic indexes of equations (67) and (68) and superlative hedonic formulation of equation (72). The HM formulation cannot take account of substitution effects since the price change of a property is not weighted by a (symmetric or otherwise) average of reference and current period weights. Price changes of period 0 transactions are weighted by $w_{i}^{0}$ and price changes of period $t$ transactions by $w_{i}^{t}$, as opposed to $\hat{w}_{i}^{\tau}$.

- We advocate the use of the predicted values of prices as expenditure weights rather than HM's use of actual values. ${ }^{56}$ In the HM formulation period 0 observations are weighted only by (actual) period 0 prices. Period $t$ weights are not used to weight these observations since HM only uses actual prices and there are no actual prices for the counterfactual price of period 0 characteristics at period $t$ prices. In our formulation each period 0 observation's price change and each period $t$ observation's price change has an average of their corresponding period 0 and period $t$ (predicted) weights. Thus we include an approximation of substitution effects for constant quality price change of period 0 transactions, and similarly for price change observations in period $t$.

- The sets of the price changes in the HM approach, $S(0 \neg t)$ and $S(t \neg 0)$, are not weighted according to their sample sizes. A symmetric mean is taken akin to a superlative index. But this is to confuse the use of symmetric mean when considering the weights of a price change, with a sample selection issue.

- The functional form is complicated by the use of actual values for weights. A simple ratio of arithmetic mean average prices between periods $t$ and 0 for a constant period 0 characteristic hedonic price index from a linear hedonic regression is given by:

(68).... $P_{H I D}^{0 t}=\frac{\frac{1}{N^{0}} \sum_{i \in N^{0}} \hat{p}_{i \mid z_{i}^{0}}^{t}}{\frac{1}{N^{0}} \sum_{i \in N^{0}} p_{i}^{0}}=\frac{\sum_{i \in N^{0}}\left(\frac{\hat{p}_{i \mid z_{i}^{0}}^{t}}{\hat{p}_{i \mid z_{i}^{0}}^{0}}\right) \hat{p}_{i|| z_{i}^{0}}^{0}}{\sum_{i \in N^{0}} p_{i \mid z_{i}^{0}}^{0}}=\frac{\sum_{i \in N^{0}}\left(\frac{\hat{p}_{i \mid z_{i}^{0}}^{t}}{\hat{p}_{i \mid z_{i}^{0}}^{0}}\right) \hat{p}_{i \mid z_{i}^{0}}^{0}}{\sum_{i \in N^{0}} \hat{p}_{i \mid z_{i}^{0}}^{0}} \neq \frac{\sum_{i \in N^{0}}\left(\frac{\hat{p}_{i \mid z_{i}^{0}}^{t}}{\hat{p}_{i \mid z_{i}^{0}}^{0}}\right) p_{i \mid z_{i}^{0}}^{0}}{\sum_{i \in N^{0}} p_{i}^{0}}$

\footnotetext{
56 The difference arises because Hill and Melser (2008, page 600) argue for the use of predicted values (double imputation) for the price change measurement but against the use of predicted values for weights due to a possible mis-measurement error for these predicted price levels. However, first the weights are relative values, not levels, and thus less prone to such error. Second, the omission of current period 0 (period $t$ ) weights for period $t$ (period 0$)$ observations which requires predicted values (prices) could be more problematic.
} 
a straightforward representation as a price (expenditure) weighted average of constant quality price changes (dual imputation) if predicted values are used as weights.

- HM's formulation omits a separate term $S(0 \cap t)$ but this is on the basis that there are usually relatively few such observations, though exceptions may exist such as for Tokyo apartments, Shimizu et al. (2010).

\section{F. Weights for the time dummy approach}

The time dummy hedonic price change estimates based on equations (8) (a linear functional form) and (9) (a log-linear functional form) are estimates of ratios of arithmetic and geometric mean prices respectively, controlling for (partial-out) changes in the quality mix. Of note, for both linear and log-linear functional forms, is that the quality-mix adjustment might have been valued at period 0 or at period $t(=1)$ characteristic prices, but in this time dummy formulation is constrained over the two periods to be identical, $\beta_{k}=\beta_{k}^{0}=\beta_{k}^{t=1}$.

The imputation approach, and by equivalence, the characteristics approach, have a major advantage over the time approach since they can readily facilitate the introduction of explicit weights at the level of the individual property. Unlike the hedonic imputation and characteristics approaches, the time dummy estimate of constant quality price change comes directly from the estimated coefficients of the regression itself. The introduction of explicit weights has to be undertaken as part of the estimation.

Diewert (2002 and 2005) in seminal papers on weighted aggregation in regression argued for a weighted least squares (WLS) estimator using expenditure shares as weights. He showed that in a model for a bilateral two-period aggregate price comparison with average expenditure shares $\left(w_{i, 0}+w_{i, t}\right) / 2$ used as weights in a WLS estimator, the estimated price change will be equivalent to the superlative Törnqvist index. ${ }^{57}$ Further contributions on developing (value-share) weighting systems in regression-based estimates of aggregate price change include Silver (2002), de Haan (2004), Diewert, Heravi and Silver (2009), de Haan (2004 and 2009), Ivancic, Diewert, and Fox (2009), and de Haan and Krsinich (2014), and for the cross country-product dummy approach, Diewert (2004 and 2005) and Rao (2005).

\section{Leverage effects and the need for outlier detection and robust estimators}

57 The Törnqvist index is given by $I_{T}^{0 \rightarrow t}=\prod_{i=1}^{N}\left(\frac{p_{i, t}}{p_{i, 0}}\right)^{\left(s_{i, 0}+s_{i, t}\right) / 2}$. See Diewert (1976 and 1978) for its superlative properties.

(continued...) 
Silver $(2002)^{58}$ raised a concern with influential observations. First, as outlined in more detail in Annex 2, there is the effect of an outlier on the estimated coefficients in a hedonic regression. In a time dummy regression a, for example, property price observation whose characteristics differ markedly from the mean of the transaction sample and whose price is not well predicted by the regression - has relatively large residuals - can have a weight/influence in determining the constant-quality price change that is markedly greater than its singular transaction price deserves. Moreover, even if it had a larger explicit expenditure weight attached to it using WLS, its overall influence would still be greater than that merited by its expenditure weight.

Following Davidson and MacKinnon (1993), we first note that an OLS vector of $\boldsymbol{\beta}$ estimates is a weighted average of the individual $\mathbf{p}$ elements, the prices of individual properties, (69).... $\hat{\boldsymbol{\beta}}=\left(\mathbf{X}^{\mathrm{T}} \mathbf{X}\right)^{-1} \mathbf{X}^{\mathrm{T}} \mathbf{p}$

where the matrix $\mathbf{X}$ are the explanatory variable and $\left(\mathbf{X}^{\mathbf{T}} \mathbf{X}\right)^{-1} \mathbf{X}^{\mathbf{T}} \mathbf{p}$ are the implicit weights given to the prices. Equation (61) clearly shows that the $\hat{\boldsymbol{\beta}}$ estimate is a weighted average of prices, $\mathbf{p}$. Consider also a WLS estimator where the explicit weights $\mathbf{W}$ are expenditure shares:

(70)... $\hat{\boldsymbol{\beta}}=\left(\mathbf{X}^{\mathrm{T}} \mathbf{W X}\right)^{-1} \mathbf{X}^{\mathrm{T}} \mathbf{W} \mathbf{p}$.

It is apparent from (69) and (70) that outliers with unusual values of $\mathbf{X}$ will have a stronger influence in determining $\hat{\boldsymbol{\beta}}$, than observations which are clustered in a group. In normal index number formulae, the weights given to price changes are expenditure shares, while in the hedonic framework in equation (1) the results from an expenditure share weighted hedonic regression will also be determined by the residuals and relative values of the $\mathbf{X}$ characteristics. An older property, for example, may have unusually poor quality characteristics, and an unusually low price given such characteristics, the relatively high residuals and leverage giving it undue influence in spite of the weights $\mathbf{W}$ in equation (70). Influence statistics are a method of discovering influential observations, or outliers. Measures of leverage and residuals are readily available in econometric software as are regression estimators robust to undue leverage. ${ }^{59}$ They are concerned with the detection of how different an observation is from the other observations in an equation's sample, the difference that a single observation makes to the regression results, and use of robust estimators as an alternative to OLS.

\footnotetext{
${ }^{58}$ Much of this is drawn from a 2002 unpublished mimeo by the author, Cardiff University.

${ }^{59}$ EViews, for example, provides least squares diagnostics for outlier detection, described in "Leverage Plots" on page 218, six diagnostic statistics/tests of the "Influence of an observation," page 220, and in Chapter 30 , page 387, "Robust least squares" details of three robust estimators one of which has as its focus outliers with high leverage. (EViews 9 User's Guide, Irvine CA: March 2015).
} 
The presence and effect of influential observations is not fatal to the use of WLS. A proposal would be to first examine all observations with high leverage, residuals, and influence and correct/delete those found to be the result of mis-measurement or being out of the scope of the study. However, since residuals are in turn based on a regression equation that may be influenced by outliers, care is necessary in the identification of outliers and alternative measures of influence and Belsley, Kuh, and Welsch (2005), Chatterjee and Hadi (1986), and Davidson and MacKinnon (1993) are instructive in this regard. Second, there would remain a problem with observations with relatively high weights and high influence values having to be downgraded. However, observations with high leverage may be unusual only because of shortfalls in the sampling of clusters in this characteristics space and the appropriate action is to take, where feasible, a larger sample. Third, there may be a set of observations that have very small weights and whose price changes are not dissimilar to other observations, but have relatively unusually high leverage. The regression should be run with and without these observations to validate their inappropriate influence and the observations deleted as appropriate. Fourth, there is a case for using a heteroskedastic-consistent covariance matrix estimator (HCCME). MacKinnon and White (1985) outline the HC2 estimator which replaces the squared OLS residuals $\hat{\mu}_{i}^{2}$ by a term that includes the leverage, and similarly the HC4 estimator proposed by Cribari-Neto (2004). ${ }^{60}$ The $i^{\text {th }}$ residual is inflated more (less) when $h_{i}$ is large (small) relative to the average of the $h_{i}$, which is $k / n$, see MacKinnon (2013). Finally, there is a very different approach due to Silver and Graf (2014) considered in the context of panel data for property price inflation. Included in the regression is a spatial autoregressive (SAR) term that aside from removing potential omitted-variable bias enables an innovative weighting system for the aggregate price change measure.

Yet WLS has a more conventional use in econometrics. A WLS estimator may be appropriate when the errors from estimated models are heteroskedastic. WLS can give more weight to observations with less conditional variance, thereby decreasing the sampling variance of the OLS estimator. An observation from a distribution with less conditional variance is considered to be more informative (in a predictive sense), than an observation from a distribution with a higher conditional variance. However, the use of WLS to introduce weights related to expenditure shares may conflict with a possible use as a more appropriate estimator when errors are heteroskedastic.

${ }^{60} \mathrm{HC} 2$ replaces the OLS residuals with $\frac{\hat{\mu}_{i}^{2}}{\left(1-h_{i}\right)}$ and HC4 with $\frac{\hat{\mu}_{i}^{2}}{\left(1-h_{i}\right)^{\delta}}$ where, $\delta_{i}=\min \left(4, n h_{i} k\right)$ and $n$ is the number of observations and $k$ the number of explanatory variables, $\hat{\mu}_{i}$ the residuals. MacKinnon (2013 notes that a few papers have taken different approaches. Furno (1996) uses residuals based on robust regression instead of OLS residuals in order to minimize the impact of data points with high leverage. Qian and Wang (2001) and Cribari-Neto and Lima (2010) explicitly correct the biases of various HCCMEs in the HCj series. The formulae that result are considered to generally appear to be complicated and perhaps expensive to program when $\mathrm{n}$ is large. 
Diewert, Heravi, and Silver (2009), following on from Silver and Heravi (2007b), have formally determined the factor distinguishing between the results of (adjacent period) timedummy and hedonic imputation hedonic indexes. It is not straightforward:

"An exact expression for the difference in constant quality log price change between the time dummy and imputation measures is also developed in section 4.3. It is found that in order for these two overall measures to differ, we require the following.

- Differences in the two variance covariance matrices pertaining to the model characteristics in each period.

- Differences in average amounts of model characteristics present in each period.

- Differences in estimated hedonic coefficients for the two separate hedonic regressions." (Diewert, Heravi, and Silver (2009, page 163).

While the extent of the difference can be calculated retrospectively, it will remain an empirical issue for the data set at hand. However, the hedonic time dummy approach can be a useful alternative measure that and may well have results that do not differ significantly from the imputation and characteristics counterparts. Notwithstanding this, the proposed measures in the final section of this paper are based on the hedonic imputation (and characteristics) approaches for the following reasons:

- The characteristic and imputations approaches provide the same result and have natural, albethey different, intuitions, a feature that strengthen the case for their use;

- The time dummy approach, while based on the reasonably intuitive indirect approach, can only be explained within the context of a regression equation;

- The difference between the time dummy and hedonic imputation approaches is not readily explained to the user.

- The hedonic imputation (and characteristics) approaches can, unlike the time dummy method, have explicit weights readily applied in an easy-to-compute and understand manner that can be easily interpreted in index number theory as a "quasi" hedonic superlative index and its difference from a hedonic superlative index readily computed, identified and understood.

- The hedonic imputation index can be easily segmented, subject to satisfactory sample sizes, into meaningful sub-strata.

\section{G. Stock weights}

The use of explicit weight provides flexibility to include stock or transaction weights depending on the purpose of the property price index (see, Fenwick (2013, 9.45-9.47). For stock weights a census of properties may provide data on the value of properties by type, including whether detached, brackets of size, number of bedrooms, post(zip)-code and so 
forth. To calculate a stock-weighted index the first step would be to define meaningful cells or sub-strata of housing - for example single-family 4+ bedroom row homes in Dupont Circle, Washington DC - for which stock weights and a meaningful sample of transactions exist, say for $j=1, \ldots, \mathrm{J}$ cells. The cells should be defined on as granulated a level as stock weights and constant-quality price changes permits and be exhaustive of all properties. The constant-quality price change measure may be restricted, if necessary, to the price change of a representative type of property. For each cell an aggregate measure of constant-quality price change is computed and the stock weights, $s_{j}^{0} / \sum_{j \in J^{0}} s_{j}^{0}$, applied.

For an arithmetic mean and linear hedonic form using constant-quality reference period transactions, as given by equation (), the weights applied respectively to the numerator and denominator in equation (68), are $s_{j}^{0} / \hat{p}_{j}$ and $\sum_{j \in J^{0}} s_{j}^{0} / \sum_{j \in J^{0}} \hat{p}_{j \mid z_{i}^{0}}^{0}$, where $\hat{p}_{j \mid z_{i}^{0}}^{0}=\sum_{i \in j} \hat{p}_{i \mid z_{i}^{0}}^{0}$ the index being:

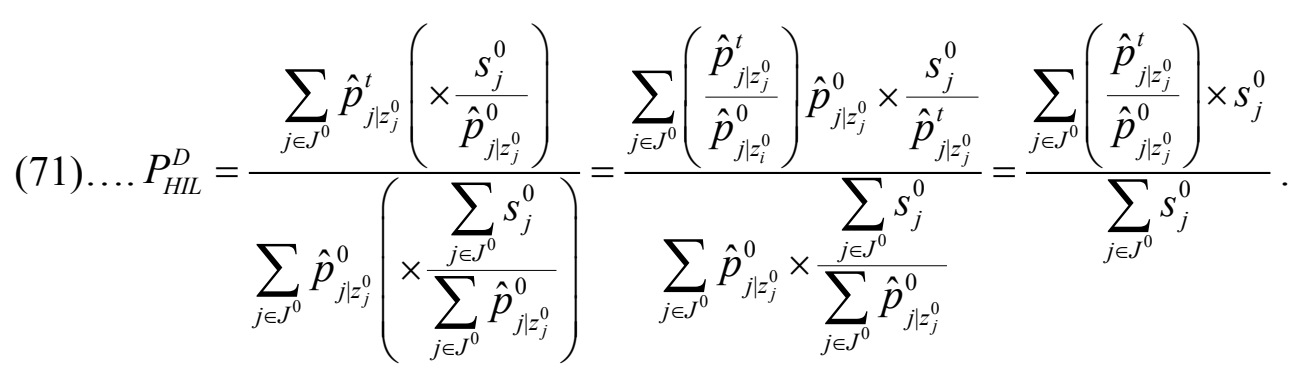

\section{HEDONIC PROPERTY PRICE INDEXES SERIES: PERIODIC REBASING, CHAINING AND ROLLING WINDOWS}

Throughout this work our comparisons over time are bilateral: a reference period is established denoted as period 0 for which prices are collected and compared in turn with successive current periods denoted as periods $t=1, \ldots, T$. The reference period may have the same periodicity as the successive periods of the index, say quarterly, 2015Q4=100.0 or be more firmly rooted, say $2015=100.0$. The fixed-base version of these indexes are estimated as constant-quality price changes between each period $t$ and its reference period: $P^{2015 \rightarrow 2016 Q 1}$; $P^{2015 \rightarrow 2016 Q 2} ; P^{2015 \rightarrow 2016 Q 3} ; P^{2015 \rightarrow 2016 Q 4} ; P^{2015 \rightarrow 2017 Q 1} ; \ldots \ldots . ., P^{2015 \rightarrow 2020 Q 1}$. Each bilateral index may use the fixed characteristic and transaction weights of either a reference period or current period, or symmetric mean of the two.

Table 2. Illustration of periodic linking

\begin{tabular}{|c|c|c|c|}
\hline & 2015=100.00 & 2016=100.00 & 2015=100.00 \\
\hline 2015 & 100.00 & & 100.00 \\
2016Q1 & 101.42 & & 101.42 \\
2016Q2 & 103.78 & & 103.78 \\
2016Q3 & 106.29 & & 106.29 \\
\hline
\end{tabular}




\begin{tabular}{|l|c|c|c|} 
2016Q4 & 108.85 & & 108.85 \\
2017Q1 & & 102.78 & $105.085 / 100.00 \times 102.78=108.01$ \\
2017Q2 & & 104.01 & $105.085 / 100.00 \times 104.01=109.30$ \\
\hline
\end{tabular}

\section{On periodic linking and chaining}

It is apparent that these bilateral comparisons would benefit from a periodic updating and linking of current period prices to the initial reference period. Table 2 illustrates this linking: 108.85 is the price index for a bilateral comparison between the reference period $2015=100.00$ and the current period, say 2016Q3; 102.78 is the index for a bilateral comparison between the reference period 2016=100.00 and the current period, 2017Q1; and so forth. The "links" are chained to form a continuous series from 2015=100.00 using 2016 annual averages as an overlap period. The 2016 overlap is $(101.42+103.78+106.29+108.85) / 4=105.085$ for $2015=100$ and 100.00 for $2016=100.00$.

This ratio is used to "up-rate" the $2016=100.00$ quarterly index figures to the $2015=100$ reference period, as shown in Table 2, to form a continuing $2015=100.00$ series, to be similarly linked in subsequent years.

A quarterly rolling window index (and similarly for a monthly index) is illustrated in Table 3. A time dummy hedonic regression would be estimated using data for 2015Q1 to Q4 with 2015Q1=100.00. In the first column of table 3, the index values for 2015Q2 to Q4 come directly from these hedonic estimates. A new regression is estimated using 4-quarters, but the first quarter of the previous sample (2015Q1) is dropped and a new quarter added (2016Q1); the index results are shown in Column 2. We keep the first 4 quarters, but for 2016Q1 use the price change from the new regression to continue the series in the last column, that is the 2016 Q 1 index is $87.0 \times(80.4 / 89.7)=78.0$, the 2016 Q 2 index $78.0 \times(82.7 / 80.8)=79.8$ and so forth.

Table 3. Rolling window regression example

\begin{tabular}{|l|c|c|c|c|c|c|c|c|}
\hline Period & $\begin{array}{c}\text { 2015Q1- } \\
\text { 2015Q4 }\end{array}$ & $\begin{array}{c}\text { 2015Q2- } \\
\text { 2016Q1 }\end{array}$ & $\begin{array}{c}\text { 2015Q3- } \\
\text { 2016Q2 }\end{array}$ & $\begin{array}{c}\text { 2015Q4- } \\
\text { 2016Q3 }\end{array}$ & $\begin{array}{c}\text { 2016Q1- } \\
\text { 2016Q4 }\end{array}$ & $\begin{array}{c}\text { 2016Q2- } \\
\text { 2017Q1 }\end{array}$ & $\begin{array}{c}\text { 2016Q3- } \\
\text { 2017Q2 }\end{array}$ & $\begin{array}{c}\text { 4-quarter } \\
\text { RW } \\
\text { 2015Q1:201 } \\
\text { 5Q4 =100 }\end{array}$ \\
\hline 2015Q1 & 100.0 & & & & & & & \\
2015Q2 & 95.9 & 100.0 & & & & & & \\
2015Q3 & 96.8 & 100.2 & 100.0 & & & & & 95.9 \\
2015Q4 & 87.0 & 89.7 & 90.8 & 100.0 & & & & 96.8 \\
2016Q1 & & 80.4 & 80.8 & 92.7 & 100.0 & & & 78.0 \\
2016Q2 & & & 82.7 & 93.5 & 100.7 & 100.0 & & 79.8 \\
2016Q3 & & & & 86.7 & 92.1 & 93.7 & 100.0 & 74.0 \\
2016Q4 & & & & & 91.7 & 91.5 & 95.4 & 73.8 \\
2017Q1 & & & & & & 84.9 & 90.3 & 68.5 \\
2017Q2 & & & & & & & 89.4 & 67.8 \\
\hline
\end{tabular}


A quarterly adjacent period index is a rolling window rebased each quarter, and similarly for a monthly index $;^{61}$ the window comprises only two periods, the current period and the period prior to it. A time dummy hedonic regression would be estimated using 2016Q1 and 2016Q2 data to provide an index for 2016Q2, with 2016Q1=100.00, and similarly for subsequent adjacent periods, linked together to form a chain as illustrated in Table 4, see also Diewert (2005b) and Triplett (2006).

${ }^{61}$ Griliches (1961), Triplett (2006) and Rambaldi and Fletcher (2014) describe the adjacent period approach as a special case of the rolling window one. We give prominence to it since current period quarter-on-quarter indexes are based on parameter estimates that directly relate to these periods. 
Table 4. Illustration of quarterly adjacent period chaining

\begin{tabular}{|c|c|c|c|c|c|c|}
\hline & \multicolumn{6}{|c|}{ Reference period $=100.00$} \\
\hline & 2016Q1 & 2016Q2 & 2016Q3 & 2016Q4 & 2017Q1 & 2016Q1=100.00 \\
\hline 2016Q1 & 100.00 & & & & & 100.00 \\
\hline 2016Q2 & 101.30 & 100.00 & & & & 101.30 \\
\hline 2016Q3 & & 101.4 & 100.00 & & & 102.72 \\
\hline 2016Q4 & & & 101.6 & 100.00 & & 104.36 \\
\hline 2017Q1 & & & & 101.86 & 100.00 & $104.36 / 100.00 \times 101.86=106.30$ \\
\hline 2017Q2 & & & & & 102.01 & $104.36 / 100.00 \times 102.01=108.44$ \\
\hline
\end{tabular}

The adjacent period method is reliable in the sense that individual quarter-on-quarter price changes are only determined by the data for these periods. It is a version of the rolling window approach that restricts the size of the window to two successive periods. Rolling windows of larger sizes, such as the 4-quarter example in Table 3, are advantageous when data are sparse and concern exists as to the robustness of regression estimates based on a series of hedonic regressions either due to specification or estimation, including sparse data, issues. However, the longer the window, the smoother will be the series and the longer the lag in tracking turns in the series. The adjacent-period rolling window if faithfully based on a sufficient sample size and well-specified hedonic regression should give timely information about changes in property price inflation that, while seemingly more volatile, are rightly so having not been subjected to what may be undue smoothing. ${ }^{62}$

\section{A PRACTICAL CHOICE OF FORMULA: EQUIVALENCES, INFREQUENT HEDONIC ESTIMATION, WEIGHTING, THIN MARKETS, AND THE INDIRECT APPROACH}

In this section we devise a new formula that benefits from (i) the equivalence results of previous sections to narrow down and consolidate the choice of formula; ${ }^{63}$ (ii) the innovative approach to introducing weights at the transaction level to property price changes; (iii) the use of dual imputations for price changes and imputations for weights; (iv) the introduction

\footnotetext{
${ }^{62}$ There is a case for using a Kalman Filter Smoother (Rambaldi and Fletcher, 2014). The Kalman Filter Smoother has been shown in some empirical work to produce relatively stable estimates that need only be estimated sporadically, not each period. Rambaldi and Fletcher (2014) use that, at least for the early period, are sparse and the rolling adjacent period window provides volatile estimates of the hedonic coefficients. It is argued that the indexes based on the Kalman Filter optimally weight current and past information while the rolling window constrains the estimation to the period of the window, two-periods in the case of the adjacent period window, used in the study.

${ }^{63}$ This benefits compilers in that the choice between the approaches and myriad methods of adopting them can be confusing and is unnecessary given the equivalences demonstrated. Our focus on the hedonic imputation method is because it provides a natural vehicle for introducing weights that does not distract from the characteristics approach, for which we showed a weighted equivalent exists.
}

(continued...) 
of substitution effects, the issue of sample selectivity and definition of target "quasi" and "full" hedonic superlative price indexes; (v) a best practice well-grounded practical formulation for suitable for property markets where properties are heterogeneous and transactions sparse - thin markets; ${ }^{64}$ and (vi) a formulation that does not require the regular estimation of a hedonic regression in every current period $t$ and rely on the vagrancies of its estimation and specification.

Proposals for this practical problem are:

\section{i. $\quad$ That we use formulations of hedonic approaches for which the imputation and characteristics approaches are equivalent. We have shown that for two reasonable hedonic specifications and the use of arithmetic means as aggregators of characteristics, the hedonic characteristics and imputation approaches, and indirect approaches to both, all yield the same result.}

As shown in the previous section The three approaches - characteristics, imputation, and time dummy - all measure the price change of a constant-quality set of characteristics, but have quite different and, a priori quite reasonable, intuitions. The characteristics approach is based on the change over time in the price of a constant set of average (property-price determining) characteristic values. The imputations approach is based on the change in the average (predicted) property prices in one period and the average (predicted) price of properties with the self-same characteristics in another. The indirect hedonic approach takes the change in prices, and adjusts (divides) this change by a measure of the change in the volume component of the quality churn. The results are reliant on, for a linear hedonic functional form, the hedonic characteristics index being based on arithmetic means of characteristics, and the hedonic imputation index taking the form of a ratio of arithmetic means. And for a log-linear hedonic functional form, the hedonic characteristics index is also based on arithmetic means of characteristics and the hedonic imputation index taking the form of a ratio of geometric means. Similar considerations are required for the indirect hedonic approach. This consolidates our choice of formula and its rationale from more than one perspective.

The time dummy approach estimates the change in average prices while controlling for changes in the quality-mix of the characteristics. We also show the time dummy approach has a direct conceptual correspondence to the indirect method and can be formulated as such.

\footnotetext{
64 There are other approaches to the problem of "thin" markets including (i) estimating a temporally aggregated price index for example, moving from a quarterly to a semiannual or annual index, Geltner (1993) and Bokhari and Geltner (2012); (ii) use of a time-series methodology, such as the Kalman Filter, including Goetzmann (1992), Schwann (1998), Francke and De Vos (2004), Francke (2008), and Rambaldi and Fletcher (2014); (iii) the inclusion of other related series as explanatory variables in thin markets, Baroni et al. (2007) and Schulz and Werwartz (2004), Thorsnes, P., \& Reifel, J. W. (2007); and (iv) Silver and Graf (2014) consider an improvement to the efficiency of the estimator using data on sample sizes.
} 
These results concerning equivalences were outlined in detail in Section III. We thus advocate the use of arithmetic means of characteristics as outlined in section II in the compilation of both linear and log-linear hedonic approaches for the equivalences to work.

\section{ii. $\quad$ That a current period t formulation be used since the hedonic regression need only be estimated for period 0}

If a constant current period quality formulation is used for either of the approaches considered above, the hedonic regression need only be estimated for period 0 , that is:

\section{Linear}

$(72 \mathrm{a}) \ldots \frac{\frac{1}{N^{t}} \sum_{i \in N^{t}} p_{i}^{t}}{\frac{1}{N^{t}} \sum_{i \in N^{t}} \hat{p}_{i \mid z_{i}^{t}}^{0}} \equiv \frac{\frac{1}{N^{t}} \sum_{i \in N^{t}} \hat{p}_{i \mid z_{i}^{t}}^{t}}{\frac{1}{N^{t}} \sum_{i \in N^{t}} \hat{p}_{i \mid z_{i}^{t}}^{0}}$

\section{Log-linear}

(72b) ... $\frac{\exp \left(\frac{1}{N^{t}} \sum_{i \in N^{t}} \ln p_{i}^{t}\right)}{\exp \left(\frac{1}{N^{t}} \sum_{i \in N^{t}} \ln \hat{p}_{i \mid z_{i}^{t}}^{0}\right)} \equiv \frac{\exp \left(\frac{1}{N^{t}} \sum_{i \in N^{t}} \hat{p}_{i \mid z_{i}^{t}}^{t}\right)}{\exp \left(\frac{1}{N^{t}} \sum_{i \in N^{t}} \hat{p}_{i \mid z_{i}^{t}}^{0}\right)}$

Note that actual values in the first term of equations (72a and b) are used in the numerators in contrast to the imputed values of period $t$ characteristics priced in period 0 , in the denominators. However, this is equivalent to a dual imputation because the average price equals the predicted price in an OLS regression. The measure is of the price change of a basket of constant current period $t$ characteristics, $z_{i}^{t}$, but only requires a hedonic regression for period 0 . Limiting the regression estimation to the reference period is a major advantage given the critical role that hedonic estimates play in real estate property price. Having to only estimate a hedonic regression for period 0 is a very attractive feature. Hedonic regression estimates are subject to the vagrancies of specification and estimation procedures, particularly in thin markets. A measure based on a well-grounded regression, especially one based on an extended reference period as outlined in (ii) below, in turn better grounds the index.

As explained in the previous section, the restricting of the sample of transactions to period $t$, in a price comparison between periods 0 and $t$, is more concerned with than sample selectivity bias than substitution bias. In the exploratory stage of calculating hedonic property 
price indexes current and reference period formulations can be calculated and estimates of sample selectivity bias derived and monitored.

\section{iii. $\quad$ That an extended-current period formulation be used since sparse data is less problematic}

A major problem in RPPI and especially CPPI estimation is that of sparse data on heterogeneous properties. However this can be alleviated by the use of an extended reference period, noted as a useful feature of property price index construction by de Haan and Diewert (2013). ${ }^{65}$ There may not be an adequate number of observations and/or variation in the characteristics of the sample of properties transacted in period 0 to enable reliable and pertinent estimates to be made of the coefficients of price-determining characteristics that define properties sold in period $t$. For example, there may a relatively large, recently-built retail property in a prime location (say postcode) sold in period $t$, but only a limited number of retail properties sold in period 0 all of which are much smaller, older, and located in poorer areas. The problem of sparse data prevents reliable estimates of the predicted price from a period 0 regression of the period $t$ characteristics. ${ }^{66}$ The current period formulation can go some way to solving the problem of sparse data simply by defining the reference period 0 , for example, for a quarterly series 2016Q1, 2016Q2 etc., to be an extended period of say a year with the index referenced as $2015=100.0$ and centered at mid-2015. As such, the period 0 regression will be more likely to better encompass the characteristics of period $t$ properties. It is worth noting that the Paasche direct hedonic characteristics and imputation indexes and the indirect counterparts all have this feature. The formulas using an extended reference period are:

\section{Linear}

$(73 \mathrm{a}) \ldots \frac{\frac{1}{N^{t}} \sum_{i \in N^{t}} p_{i}^{t}}{\frac{1}{N^{t}} \sum_{i \in N^{t}} \hat{p}_{i \mid z_{i}^{t}}^{e r}}=\frac{\frac{1}{N^{t}} \sum_{i \in N^{t}} \hat{p}_{i \mid z_{i}^{t}}^{t}}{\frac{1}{N^{t}} \sum_{i \in N^{t}} \hat{p}_{i \mid z_{i}^{t}}^{e r}}$

\footnotetext{
${ }^{65}$ Though de Haan and Diewert (2013) refer to it in the context of an advantage of the indirect method, similar such formulations and advantages apply to the direct imputation and characteristics approach.

${ }^{66}$ More formally, the width (standard error) of a prediction interval from a regression of $y$ on $x$, for a given value of say $x=x^{\prime}$, depends not only on the fit of the regression - the larger the sample size and dispersion of the explanatory variables, the smaller the interval - but also on the distance the given value of $x^{\prime}$ is from the sample mean $\bar{x}$. The prediction will be better for values of $x^{\prime}$ closer to $\bar{x}$ (Maddala and Lahiri, 2009).
} 


\section{Log linear}

$$
\ldots \frac{\exp \left(\frac{1}{N^{t}} \sum_{i \in N^{t}} \ln p_{i}^{t}\right)}{\exp \left(\frac{1}{N^{t}} \sum_{i \in N^{t}} \ln \hat{p}_{i \mid z_{i}^{t}}^{e r}\right)}=\frac{\exp \left(\frac{1}{N^{t}} \sum_{i \in N^{t}} \hat{p}_{i \mid z_{i}^{t}}^{t}\right)}{\exp \left(\frac{1}{N^{t}} \sum_{i \in N^{t}} \hat{p}_{i \mid z_{i}^{t}}^{e r}\right)}
$$

iv. $\quad$ That the index be appropriately weighted at the lower level: weighting, quasisuperlative indexes, and dual imputations

\section{Arithmetic implicit weights and quasi-Fisher indexes}

Weights are implicit in the functional form of the hedonic regressions and formula used to average the prices. Given a linear functional form for the hedonic regression underlying the (equivalent) characteristics and imputation approaches, the implicit weights given to each property's constant quality price change is the relative value of the property, a finding that holds for the direct and indirect approaches. However, for the log-linear functional form of the hedonic regression underlying the (equivalent) characteristics and imputation approaches, equal weight is given to each constant-quality price change rather than the more desirable transaction value. In section VI we outlined an approach to directly incorporating transaction value weights into a hedonic imputation, and thus characteristics, approach for the log-linear form. A linear/arithmetic index based on current period $t$ transactions is defined as:

$$
\text { (74).... } P_{H D C: z_{i}^{t}}^{0, t}=\frac{\frac{1}{N^{t}} \sum_{i \in N^{t}} p_{i}^{t}}{\frac{1}{N^{t}} \sum_{i \in N^{t}} \hat{p}_{i \mid z_{i}^{t}}^{0}}=\frac{\frac{1}{N^{t}} \sum_{i \in N^{t}} \hat{p}_{i \mid z_{i}^{t}}^{t}}{\frac{1}{N^{t}} \sum_{i \in N^{t}} \hat{p}_{i \mid z_{i}^{t}}^{0}}=\left[\frac{\sum_{i \in N^{t}} \hat{p}_{i \mid z_{i}^{t}}^{t}}{\sum_{i \in N^{t}} \hat{p}_{i z_{i}^{t}}^{t}\left(\frac{\hat{p}_{i \mid z_{i}^{t}}^{t}}{\hat{p}_{i \mid z_{i}^{t}}^{0}}\right)^{-1}}\right]^{-1}
$$

since for OLS: $\frac{1}{N^{0}} \sum_{i \in N^{0}} p_{i \mid z_{i}^{0}}^{0}=\frac{1}{N^{0}} \sum_{i \in N^{0}} \hat{p}_{i \mid z_{i}^{0}}^{0}$.

A quasi-Fisher price index using period 0 and period $t$ weights, but only price changes of the period $t$ sample of transactions, is given by:

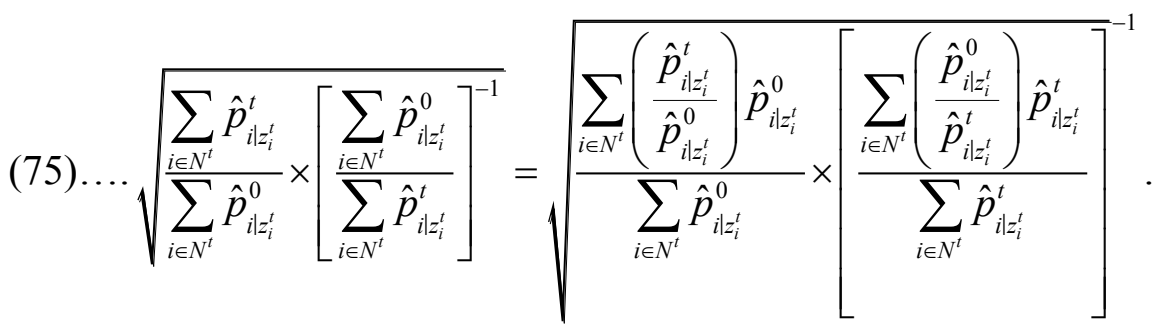


Again, since for OLS: $\frac{1}{N^{0}} \sum_{i \in N^{0}} p_{i \mid z_{i}^{0}}^{0}=\frac{1}{N^{0}} \sum_{i \in N^{0}} \hat{p}_{i \mid z_{i}^{0}}^{0}$; we do not need to estimate a hedonic regression for period $t$.

\section{Geometric explicit weights and quasi-Törnqvist indexes}

For the log-linear formulation, a hedonic quasi-Törnqvist imputation index is:

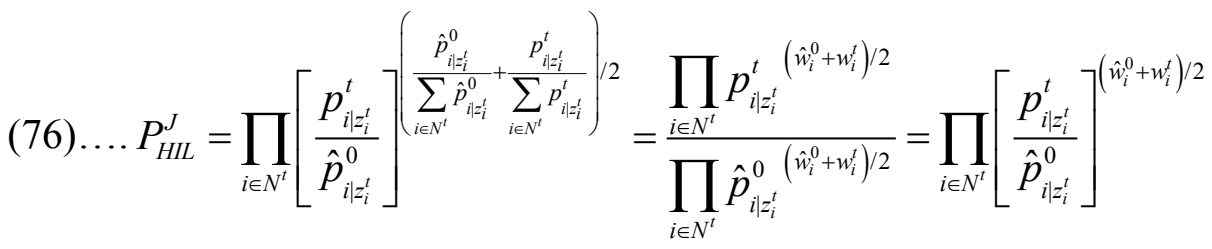

$$
\begin{aligned}
& =\exp \left(\sum_{i \in N^{t}}\left(\hat{w}_{i}^{0}+w_{i}^{t}\right) / 2\left[\ln p_{i \mid z_{i}^{t}}^{t}-\ln \hat{p}_{i \mid z_{i}^{t}}^{0}\right]\right)
\end{aligned}
$$

Now equation (76) differs from our Törnqvist imputation index in equation (59) in that because we are not running period $t$ hedonic regressions, there are no predicted period $t$ prices. Actual prices and weights are used for period $t$ and dual imputation for the (logarithm of the) price changes, are not possible. Workarounds are necessary to convert $w_{i}^{t}$ to $\hat{w}_{i}^{t}$ and $p_{i \mid z_{i}^{t}}^{t}$ to $\hat{p}_{i \mid z_{i}^{t}}^{t}{ }^{67}$

\section{v. $\quad$ That a workaround be applied to the log-linear case to (a) approximate predicted values of prices and weights using actual values and (b) form dual imputations}

An approximation for the predicted value of period $t$ weights is:

(77).... $\hat{w}_{i}^{* t}=\frac{p_{i}^{t}\left(\frac{\hat{p}_{i \mid z_{i}^{0}}^{0}}{p_{i}^{0}}\right)}{\sum_{i \in N^{t}} p_{i}^{t}\left(\frac{\hat{p}_{i \mid z_{i}^{0}}^{0}}{p_{i}^{0}}\right)}=\frac{w_{i}^{t}\left(\frac{\hat{p}_{i \mid z_{i}^{0}}^{0}}{p_{i}^{0}}\right)}{\sum_{i \in N^{t}} w_{i}^{t}\left(\frac{\hat{p}_{i \mid z_{i}^{0}}^{0}}{p_{i}^{0}}\right)}=\frac{w_{i}^{t} e_{i}^{o}}{\sum_{i \in N^{t}} w_{i}^{t} e_{i}^{o}}$ where $e_{i}^{o}$ is the error term from the

log-linear hedonic regression.

If the hedonic regression has a poor fit, especially for unusually high or low priced properties, actual values could be used for weights in both periods: $w_{i}^{* * \tau}=\left(w_{i}^{0}+w_{i}^{t}\right) / 2$.

Retrospective studies using $w_{i}^{t}, \hat{w}_{i}^{* t}$ and $\hat{w}_{i}^{* * t}$ should be undertaken to compare the difference in the results for the index.

\footnotetext{
${ }^{67}$ An alternative is to use actual values as weights for both periods 0 and $t$ as shown and discussed in section IVA.
} 
A workaround for the predicted value of period $\boldsymbol{t}$ prices for a dual imputation would be to use the indirect method:

(78) has integrity in the sense that the ratio of average actual prices between periods 0 and $t$ in the numerator is of actual values, while the ratio in the denominator is a dual imputation, of predicted prices. None of the terms require the estimation of a hedonic regression in period $t$. It does not lead to our desired hedonic quasi-Törnqvist index of equation (5), but should be a good approximation.

A reasonable stance is to accept equation (73) as is; the resulting index is an implied price index born out of appropriate measures of the change in actual prices divided by the overall change in characteristics volumes, the former comparing with actual prices and the latter measured as a dual imputation. We denote this as option A.

However, option B is to develop a workaround for using predicted instead of actual period $t$ price. An alternative formulation of the indirect method is to use:

$$
(74) \ldots P_{H I G L}^{J}=\frac{\left(\prod_{i \in N^{t}}\left(p_{i \mid z_{i}^{t}}^{t}\right)^{w_{i}^{0}}\right)}{\left(\frac{\prod_{i \in N^{0}}\left(p_{i \mid z_{i}^{0}}^{0}\right)^{w_{i}^{0}}}{\prod_{i \in N^{t}}\left(\hat{p}_{i \mid z_{i}^{t}}^{0}\right)^{w_{i}^{t}}}\right)}=\frac{\left(\frac{\exp \left(\sum_{i \in N^{t}} w_{i}^{t} \ln p_{i \mid z_{i}^{t}}^{t}\right)}{\exp \left(\sum_{i \in N^{0}} w_{i}^{0} \ln p_{i \mid z_{i}^{0}}^{0}\right)}\right)}{\left(\frac{\exp \left(\sum_{i \in N^{t}} w_{i}^{t} \ln \hat{p}_{i \mid z_{i}^{t}}^{0}\right)}{\exp \left(\sum_{i \in N^{0}} w_{i}^{0} \ln p_{i}^{0}\right)}\right)}=\frac{\exp \left(\sum_{i \in N^{t}} w_{i}^{t} \ln p_{i \mid z_{i}^{t}}^{t}\right)}{\exp \left(\sum_{i \in N^{t}} w_{i}^{0} \ln \hat{p}_{i \mid z_{i}^{t}}^{0}\right)}
$$

Note that the bottom term in the denominator is now an actual, rather than predicted transaction price. Again all terms can be calculated without estimating a hedonic regression for period $t$. The advantage of the above formulation is that it cancels out to a ratio of two terms, the meaningful price index, but that now the resulting index is a ratio of price changes, the average actual price in period $t$ of period $t$ characteristics in the numerator and the average predicted price in period 0 of period $t$ characteristics in the denominator. The disadvantage is that it is not a dual imputation. 
To ameliorate any bias from the single imputation in equation (73) we, as a work-around,

apply a correction to $p_{i \mid z_{i}^{t}}^{t}$ to approximate $\hat{p}_{i \mid z_{i}^{t}}^{t}$. Instead of using $\frac{\exp \left(\sum_{i \in N^{t}} w_{i}^{t} \ln p_{i}^{t}\right)}{\exp \left(\sum_{i \in N^{t}} w_{i}^{0} \ln \hat{p}_{i \mid z_{i}^{t}}^{0}\right)}$ from the right hand side of equation (74), we use an estimate of the predicted value in the numerator: (75).... $\hat{p}_{i \mid z_{i}^{t}}^{* t}=p_{i}^{t}\left(\frac{\hat{p}_{i \mid z_{i}^{0}}^{0}}{p_{i}^{0}}\right) \square \hat{p}_{i \mid z_{i}^{t}}^{t}$.

The direct dual imputation from equation (74) is thus:

$$
(76) \ldots \frac{\exp \left(\sum_{i \in N^{t}} w_{i}^{t} \ln p_{i \mid z_{i}^{t}}^{t}\left(\frac{\hat{p}_{i \mid z_{i}^{0}}^{0}}{p_{i}^{0}}\right)\right)}{\exp \left(\sum_{i \in N^{t}} w_{i}^{0} \ln \hat{p}_{i \mid z_{i}^{t}}^{0}\right)}=\frac{\exp \left(\sum_{i \in N^{t}} w_{i}^{t} \ln \hat{p}_{i \mid z_{i}^{t}}^{*}\right)}{\exp \left(\sum_{i \in N^{t}} w_{i}^{0} \ln \hat{p}_{i \mid z_{i}^{t}}^{0}\right)}
$$

A concern is that $\hat{p}_{i \mid z_{i}^{*}}^{* t}$ should have been estimated using the current period $t$ ratio of actual to predicted prices, rather than the period 0 ones in equation (74), that is:

(77) $\hat{p}_{i \mid z_{i}^{t}}^{* * *_{t}}=p_{i \mid z_{i}^{t}}^{t}\left(\frac{\hat{p}_{i \mid z_{i}^{t}}^{t}}{p_{i}^{t}}\right)=\hat{p}_{i \mid z_{i}^{t}}^{t}$.

However, this requires a hedonic regression estimated for period $t$. Some simple tests on retrospective data should help with the choice between options $\mathrm{A}$ and $\mathrm{B}$, and for option $\mathrm{B}$, using the (indirect) price index in equation (74) or the (direct) price index, with an adjustment for double imputation, in equation (75).

Such tests may be based on estimating indexes from retrospective data for which period $t$ can hedonic regressions can be reliably estimated using $\left(\hat{p}_{i \mid z_{i}^{*}}^{* t}\right.$ and $\left.\hat{p}_{i \mid z_{i}^{*}}^{* * t}\right)$ in equations (75 and 78) and comparing this with the results from using equation (59) that benefits from a period $t$ estimated hedonic regression. If the differences are relatively small over time, then the adjustment may be used. ${ }^{68}$

\footnotetext{
${ }^{68} \mathrm{We}$ note here that a further development would be to use a mid-period valuation of the characteristics. At first this has little meaning, because the characteristics do not change. The sample is of a set of transactions in period $t$ whose self-same characteristics are valued in period 0 . However, if we apply period 0 weights to the characteristic values and period $t$ weights for period $t$ average characteristic values, then a mid-period
} 


\section{vi. $\quad$ That an indirect approach be used}

The indirect approach takes the change in prices, as in equation (78), and divides this by the change in quality-mix, equation (79), to derive a measure of the change in constant quality price change, equation (80), that is:

(78).... $\frac{\frac{1}{N^{t}} \sum_{i \in N^{t}} p_{i}^{t}}{\frac{1}{N^{0}} \sum_{i \in N^{0}} p_{i}^{0}}=\frac{\frac{1}{N^{t}} \sum_{i \in N^{t}} \hat{p}_{i \mid z_{i}^{t}}^{t}}{\frac{1}{N^{0}} \sum_{i \in N^{0}} \hat{p}_{i \mid z_{i}^{0}}^{0}}$ is the change in average (actual equal to predicted, for OLS)

prices; and

(79).... $\frac{\frac{1}{N^{t}} \sum_{i \in N^{t}} \hat{p}_{i \mid z_{i}^{t}}^{0}}{\frac{1}{N^{0}} \sum_{i \in N^{t}} \hat{p}_{i \mid z_{i}^{0}}^{0}}$ is the change in the quality-characteristics value at constant period 0

prices.

Since $\frac{1}{N^{t}} \sum_{i \in N^{t}} p_{i}^{t}=\frac{1}{N^{t}} \sum_{i \in N^{t}} \hat{p}_{i \mid z_{i}^{t}}^{t}$ for OLS, equation (79) divided by equation (78) equals:

$(80) \ldots \frac{\left[\frac{\frac{1}{N^{t}} \sum_{i \in N^{t}} \hat{p}_{i \mid z_{i}^{t}}^{t}}{\frac{1}{N^{0}} \sum_{i \in N^{0}} \hat{p}_{i \mid z_{i}^{0}}^{0}}\right]}{\left[\frac{\frac{1}{N^{t}} \sum_{i \in N^{t}} \hat{p}_{i \mid z_{i}^{t}}^{0}}{\frac{1}{N^{t}} \sum_{i \in N^{t}} \hat{p}_{i \mid z_{i}^{0}}^{0}}\right]}=\frac{\frac{1}{N^{t}} \sum_{i \in N^{t}} \hat{p}_{i \mid z_{i}^{t}}^{t}}{\frac{1}{N^{t}} \sum_{i \in N^{t}} \hat{p}_{i \mid z_{i}^{t}}^{0}}$

characteristic average value is meaningful. Advantages are outlined in Okamoto (2001). Diewert (2004, 15.4915.53), Hill (1998), and Hill (1990) and Baldwin (1990, 255-256), cited by Diewert (2004). Using the

characteristics approach based on average (weighted) mean characteristic values, a constant quality mid-period characteristic value index can be devised and calculated. There would be the need for issues and workarounds to be considered as to the use of imputations, but these could be resolved. Further details are from the author. 
And for a log-linear form:

$(81) \ldots\left[\frac{\exp \left(\frac{1}{N^{t}} \sum_{i \in N^{t}} \ln \hat{p}_{i \mid z_{i}^{t}}^{t}\right)}{\exp \left(\frac{1}{N^{t}} \sum_{i \in N^{t}} \ln \hat{p}_{i \mid z_{i}^{0}}^{0}\right)}\right] / \exp \left(\sum_{k=0}^{K}\left(\bar{z}_{k}^{t}-\bar{z}_{k}^{0}\right) \ln \hat{\beta}_{k}^{t}\right)=\frac{\exp \left(\frac{1}{N^{t}} \sum_{i \in N^{t}} \ln \hat{p}_{i \mid z_{i}^{t}}^{t}\right)}{\exp \left(\frac{1}{N^{t}} \sum_{i \in N^{t}} \ln \hat{p}_{i \mid z_{i}^{t}}^{0}\right)}$

is the constant (period $t$ )-quality price index.

Since the indirect approach (equation (81)) provides the same result as the direct one, an obvious question is: why we propose switching to the indirect one?

First, the indirect method is phrased to follow the intuition of the problem at hand. A change in average prices is affected by a change in the quality mix of properties transacted each period. Thus the need to identify price-determining characterizers and measure changes in their average values, for example, on average, number of bedrooms, number of bathrooms, square footage of lot, square footage of property, proportion in a specific postcode and so forth. We take measures of changes in the average quantities of such characteristics to correct for the change in the quality mix. The change in each characteristic's average quantity is valued (weighted) using the estimated valuations from a period 0 hedonic regression that explains price variation in terms of its price-determining characteristics. A weak point of the intuition for the direct approach, at least to the lay user, is that the essence of the measure is the change in the marginal valuations of the characteristics from the estimated parameters of hedonic regressions.

Second, the indirect formulation provides additional information: it takes the change in average transactions prices, divides this by the explicitly-measured change in characteristic mix via an identifiable measure of such changes. The constant-quality property price index has an analytical decomposition as the change in price adjusted by the change in the qualitymix of properties sold. The direction and extent of average price change, for example, going into, during, and coming out of recessions can be analyzed in terms of the its constituent product of quality mix and raw price change. Indeed, we can decompose the change in total value of properties transacted to be the product of the change in the number of properties transacted and changes in the average prices, and the change in average price to be the product of the quality-adjusted and the change in the volume of quality:

(82) $\ldots . \Delta$ Value $=\Delta P \times \Delta$ Number .

and

(83) $\ldots \Delta P=\Delta P^{\text {const-qual }} \times \Delta$ Volume $^{\text {quality }}$. 


\section{vii. Segmentation and periodic updating of weights}

The proposed formulas are for individual segments of properties, say terraced houses in a major city. The index of price change for an individual segment can be aggregated with other segments, say by location and then by type to form a national index. The weights might be stock or transaction-value weights depending on purpose, Fenwick (2013). An advantage of the hedonic imputation quasi-superlative formulation is that for each transaction in period $t$ there is a repeat valuation in period 0 . Thus, sample sizes permitting, more granular results within any segment can be given, depending on user needs.

The quasi-superlative formulation recommended here requires that only a reference period hedonic regression be estimated. However, as with the rebasing of any price index number, the estimated coefficients might soon become out of date. How "soon" is soon is an empirical matter readily tested by estimating a pooled regression over a number of time periods, testing for the constancy of the estimated coefficients over time and if failing, ascertaining the magnitude of the change. Quarterly or monthly hedonic property price indexes might require an updating of the reference period hedonic regression every two or three years, or possibly annually. 


\section{SUMMARY}

For the hard problem of properly measuring RPPIs countries generally have available to them only secondary data sources: from land registries/notaries, lenders, realtors, buyers, and builders. Further, transactions of properties are infrequent and properties are heterogeneous. Measures of average property price change can be confounded by changes in the quality-mix of properties transacted between the two periods compared. Hedonic regressions have been advocated as the primary method for adjusting measured price change for the change in the quality-mix of transactions. De Haan and Diewert (2013) outline the three main approaches to using hedonic regressions for this purpose, for which there are many forms, including different forms of weights, sample selection, imputations, aggregators, direct and indirect methods and no straightforward guidelines.

First, we demonstrate equivalencies between the approaches for quite straightforward formulations of hedonic methods to narrow down the choice among formulas. We show that the hedonic characteristics and imputations approaches give the same result as long as we stick to a what are quite reasonable formulations of these methods. This is a major plus in harmonizing and justifying hedonic methodologies.

Second, we devise an easily applicable and innovative form of weighting for these property price indexes and, there from, derive quasi-superlative and superlative formulations of these hedonic indexes that improve on those in the literature.

Third, arising from these derivations, we develop well-grounded practical measures of hedonic property price inflation that are (i) suitable for thin markets and sparse data, (ii) not subject to the vagrancies of the periodic estimation of hedonic regressions, (iii) benefit from the innovative weighting system along with (iv) a "quasi" superlative formulation that should take account of much of any substitution bias at this level (and does not require re-estimation of the hedonic regression), ${ }^{69}$ and (v) has a justification on an intuitive level from both the imputation and characteristics hedonic approaches, and (vi) can be readily segmented into sub-aggregates.

\footnotetext{
${ }^{69}$ The "quasi" superlative formulation is tightly phrased as a component of a hedonic superlative index and its implicit assumptions are quite reasonable and easily testable using retrospective data.
} 


\section{ANNEX A. DIFFERENCE BETWEEN HEDONIC ARITHMETIC AND GEOMETRIC MEAN PROPERTY PRICE INDEXES}

Following Silver and Heravi (2007b), consider a sample Dutot index, $P_{D}$, in equation (A1), as a ratio of two sample arithmetic means of prices. The sample Dutot is a consistent, but not unbiased, estimator of the ratio of population means, the population Dutot index,

(A1) $\ldots I_{D}=\frac{\mathrm{E}\left[p^{t}\right]}{\mathrm{E}\left[p^{0}\right]}=\frac{\mu^{t}}{\mu^{0}}$

The sample hedonic geometric Laspeyres-type index, $P_{J}$, in equations (A2), is a ratio of the exponents of two sample means of log prices and is a consistent estimator of the population hedonic geometric Laspeyres-type index,

(A2) $\ldots I_{J}=\frac{\exp \left[\mathrm{E}\left[\log \left(p^{t}\right)\right]\right]}{\exp \left[\mathrm{E}\left[\log \left(p^{0}\right)\right]\right]}=\frac{\exp \left(\eta^{t}\right)}{\exp \left(\eta^{0}\right)}=\exp \left(\eta^{t}-\eta^{0}\right) \quad$ where

$\eta^{t}=\mathrm{E}\left[\log \left(p^{t}\right)\right]$ and $\eta^{0}=\mathrm{E}\left[\log \left(p^{0}\right)\right]$

Since the exponential function cannot be taken through expected values:

(A6)... $\mu^{\tau} \equiv \mathrm{E}\left[p^{\tau}\right] \neq \exp \left[\mathrm{E}\left[\log \left(p^{\tau}\right)\right]\right]=\exp \left(\eta^{\tau}\right) \quad$ for $\tau=0, t$

and by Jensen's inequality:

(A7) $\ldots \mu^{\tau} \equiv \mathrm{E}\left[p^{\tau}\right]>\exp \left[\mathrm{E}\left[\log \left(p^{\tau}\right)\right]\right]=\exp \left(\eta^{\tau}\right) \quad$ for $\tau=0, t$

As such the numerator of $I_{D}$ will exceed the numerator of $I_{J}$, as will the denominator, making it impossible to determine which effect will dominate, without making a further distributional assumption.

We introduce the distributional assumption:

(A8) $\ldots . \log \left(p^{\tau}\right) \square \operatorname{Normal}\left(\eta^{\tau}, \varepsilon_{\tau}^{2}\right) \quad$ for $\quad \tau=0, t$.

It follows from the properties of a lognormal distribution that: 
(A9)..... $\mu^{\tau}=\exp \left(\eta^{\tau}+\varepsilon_{\tau}^{2} / 2\right) . \quad$ for $\tau=0, t$.

Substituting $\mu^{\tau}$, for $\tau=0, t$, in equation (A1) by equation (A6) and using equation (A2) gives a relationship between the population Dutot and Hedonic geometric Laspeyres-type indexes in terms of the difference in the variances of log-prices between periods 0 and $t$ :

$$
(\mathrm{A} 10) \ldots . . I_{D}=\frac{\mu^{t}}{\mu^{0}}=\frac{\exp \left(\eta^{t}+\varepsilon_{t}^{2} / 2\right)}{\exp \left(\eta^{0}+\varepsilon_{0}^{2} / 2\right)}=I_{J} \cdot \frac{\exp \left(\varepsilon_{t}^{2} / 2\right)}{\exp \left(\varepsilon_{0}^{2} / 2\right)}=I_{J} \cdot \exp \left[\left(\varepsilon_{t}^{2}-\varepsilon_{0}^{2}\right) / 2\right]
$$

It is apparent from equation (A10) that as product heterogeneity and price dispersion decreases, so too will the difference between the two indexes. The above exposition carries over to indexes that control for observable product heterogeneity through hedonic regressions. Consider a regression, using data on $m=0, \ldots, M$ matched models for periods $\tau=0, t$, of the $\log$ of price, $\ln p_{m}^{\tau}$, on a dummy variable $D^{t}$ which takes the value of 0 in period $t$ and zero in a base period 0 , and on $k=2, \ldots, K$ quality characteristics, $z_{k m}^{\tau}$ :

$(\mathrm{A} 11) \ldots \ldots \ln p_{m}^{\tau}=\beta_{0}+\beta_{1} D^{t}+\sum_{k=2}^{K} \beta_{k} z_{k m}^{\tau}+u_{m}^{\tau}$

where $u_{m}^{\tau}$ is assumed to be normally distributed with mean and variance $\delta^{\tau}$ and $\xi_{\tau}^{2}$ respectively. The hedonic (quality-adjusted) estimated geometric Laspeyres-type index is given by:

$(\mathrm{A} 12) \ldots P_{J}^{*}=\exp \left(\hat{\beta}_{1}\right)$

which, since matched models are used, is equal to the hedonic geometric Laspeyres-type index in equation (A2). However, the Dutot index failed the commensurability test and is thus itself determined by the extent of price dispersion. A consistent estimator of the hedonic (quality-adjusted) Dutot index is given by:

$(\mathrm{A} 13) \ldots . \hat{I}_{D}^{*}=\exp \left(\hat{\beta}_{1}\right) \cdot \exp \left[\left(\xi_{t}^{2}-\xi_{0}^{2}\right) / 2\right]=P_{J}^{*} \cdot \exp \left[\left(\xi_{t}^{2}-\xi_{0}^{2}\right) / 2\right]$

where the * denotes heterogeneity-adjusted and where $\xi_{\tau}^{2}$, for $\tau=0, t$, are the variances of the residuals of observations in periods 0 and $t$ respectively. Thus the difference between the hedonic geometric Laspeyres-type index and the Dutot hedonic price index is related to the change in the variance of the residuals over time. If $\left(\hat{\xi}_{t}^{2}-\hat{\xi}_{0}^{2}\right)<\left(\varepsilon_{t}^{2}-\varepsilon_{0}^{2}\right)$ (from (A11) and (A7) respectively) then the discrepancy between the Dutot and hedonic geometric Laspeyres- 
type indices in (00) will be greater than the discrepancy between the heterogeneity-controlled Dutot and the hedonic geometric Laspeyres-type index in (A00). Note that first, for $\tau=0, t$, as $\hat{\xi}_{\tau}^{2} \rightarrow 0, P_{D}^{*} \rightarrow P_{J}^{*}$. Second, $\left(\hat{\xi}_{t}^{2}-\hat{\xi}_{0}^{2}\right)<\left(\varepsilon_{t}^{2}-\varepsilon_{0}^{2}\right)$ if the hedonic regression controls for the same proportion of price variation in each period, that is $\hat{\xi}_{\tau}^{2}=\delta_{\tau} \varepsilon_{\tau}^{2}$ for $\tau=0, t$ where $\delta_{0}=\delta_{t}<1$. Minimizing dispersion from product heterogeneity should account for some of the difference between the Dutot and hedonic geometric Laspeyres-type indexes. 


\section{ANNEX B. OUTLIERS AND LEVERAGE EFFECTS ON COEFFICIENT ESTIMATES}

We consider the effect of an outlier on the hedonic estimates. This is largely based on Davidson and MacKinnon (1993).

Consider the effect of adding a, for simplicity, single unusual observation belonging to a different data generating process to an OLS hedonic regression. We compare $\hat{\boldsymbol{\beta}}$ with $\hat{\boldsymbol{\beta}}^{(\mathrm{t})}$ where the latter is an estimate of $\boldsymbol{\beta}$ if OLS was used on a sample omitting the new $t^{\text {th }}$ observation. Distinguish between the leverage of the $t^{\text {th }}$ observation, $h_{t}$ and its residual $\hat{u}_{t}$. The leverage for observation $t$ is given by:

(B1).... $h_{t}=\mathbf{X}_{\mathbf{t}}\left(\mathbf{X}^{\mathbf{T}} \mathbf{X}\right)^{-1} \mathbf{X}_{\mathbf{t}}^{\mathbf{T}} \mathbf{p} \quad$ where $0 \leq h_{t} \leq 0$

and the difference between the hedonic coefficients with the $t^{\text {th }}$ observation respectively omitted and included by:

(B2) $\ldots \hat{\boldsymbol{\beta}}^{(\mathrm{t})}-\hat{\boldsymbol{\beta}}=-\left(\frac{1}{1-h_{t}}\right)\left(\mathbf{X}^{\mathrm{T}} \mathbf{X}\right)^{-1} \mathbf{X}_{\mathbf{t}}^{\mathrm{T}} \hat{\mu}_{t}$

where $h_{t}$ and $\hat{\mu}_{t}$ are relatively large the effect of the $t^{\text {th }}$ observation on at least some of $\hat{\boldsymbol{\beta}}$ is likely to be substantial. Thus high leverage $h_{t}$ only potentially affects $\hat{\boldsymbol{\beta}}$, it also requires that $\hat{\mu}_{t}$ is not close to zero. It follows that including the $t^{\text {th }}$ observation in the regression affects the fitted value for that observation by:

(B3) $\ldots . . \mathbf{X}^{\mathrm{T}} \hat{\boldsymbol{\beta}}=\mathbf{X}^{\mathrm{T}} \hat{\boldsymbol{\beta}}^{(\mathrm{t})}+\left(\frac{h_{t}}{1-h_{t}}\right) \hat{\mu}_{t}$

and therefore the influence, or the change in the $t^{\text {th }}$ residual by including the $t^{\text {th }}$ observation is given by:

(B4)...- $\left(\frac{h_{t}}{1-h_{t}}\right) \hat{\mu}_{t}$

It can be shown that $h_{t}$ must on average equal $k / n$ where there are $k$ explanatory variables and $n$ observations. If all $h_{t}$ were equal to $k / n$ then every observation would have the same leverage. We can thus explore on an empirical basis the values of $h_{t}, \hat{\mu}_{t}$, $-\left(\frac{h_{t}}{1-h_{t}}\right) \hat{\mu}_{t}$ when estimating hedonic regressions. 


\section{ANNEX C. EQUATING AN ESTIMATED COEFFICIENT ON A TIME DUMMY FROM A LOG-LINEAR HEDONIC MODEL TO THE GEOMETRIC MEAN OF THE PRICE CHANGES ${ }^{70}$}

A similar finding for a linear hedonic regression equating to an arithmetic mean naturally follows. We use the formulation in Silver and Hearvi (2005), due originally to Triplett and McDonald (1977). Consider a log-linear time dummy hedonic regression for which there are only two periods so $T=2$ and we assume that the models are matched in each of the two periods so that $S(0)=S(2)$ and $N(1)=N(2) \equiv M$ so that the same $M$ models are available in each period.

Hence the model characteristics are the same in each, i.e. we have:

$z_{m t k}=z_{m k}$ say, for $t=0,2, m=0, \ldots, M$ and $k=0, \ldots K$.

With these restrictions the least squares estimates for the unknown parameters are denoted by $\alpha_{1}^{*}$ and $\alpha_{2}^{*}$ and $\beta_{k}^{*}$ for $k=0, \ldots K$.

Define price levels for periods 0 and $2, P_{0}$ and $P_{2}$ respectively, in terms of the least squares estimates for $\alpha_{1}$ and $\alpha_{2}$ as follows:

(C1)... $\ln P_{1} \equiv \alpha_{1}^{*} ; \ln P_{2} \equiv \alpha_{2}^{*}$.

Hence the logarithm of the price index going from period 0 to 2 is defined as (C2)... $\ln P_{2} / P_{1} \equiv \alpha_{2}^{*}-\alpha_{1}^{*}$.

A property of least squares regression estimates is that the column vector of least squares residuals is orthogonal to each column vector of exogenous variables (this follows a. technique of proof used by Diewert (2000). Using this property for the first two columns of exogenous variables corresponding to the time dummy variables leads to the following two equations:

$$
\sum_{m=1}^{M} \ln p_{m 1}=M \alpha_{1}^{*}+\sum_{m=1}^{M} \sum_{k=1}^{K} z_{m k} \beta_{k}^{*}
$$

(C4) $\sum_{m=1}^{M} \ln p_{m 2}=M \alpha_{2}^{*}+\sum_{m=1}^{M} \sum_{k=1}^{K} z_{m k} \beta_{k}^{*}$;

Divide both sides of (C3) and (C4) by $M$ and solve the resulting equations for the least squares estimates, $\alpha_{1}^{*}$ and $\alpha_{2}^{*}$. Substituting these expressions for $\alpha_{1}^{*}$ and $\alpha_{2}^{*}$ into (C2) leads to the following formula for the log of the hedonic price index:

\footnotetext{
${ }^{70}$ Though see Kennedy (1980) and Giles (2011) for an adjustment.
} 
(C5) $\ln P_{2} / P_{1}=\alpha_{2}^{*}-\alpha_{1}^{*}=(1 / M) \sum_{m=1}^{M} \ln \left[p_{m 2} / p_{m 1}\right]$.

Taking exponents of both sides of (C5) shows that the hedonic model price index going from period 0 to 2 under the above matched model conditions is equal to the equally weighted geometric mean of the $M$ model price relatives, which would be a conventional matched model statistical agency estimate of the price index for this elementary group of commodities. 


\section{References}

Adelman, Irma and Zvi Griliches, 1961. On an index of quality change. Journal of the American Statistical Association, 56, 295, 535-548.

Baldwin, Andrew 1990. Seasonal baskets in consumer price indexes, Journal of Official Statistics, 6 ,3, September, 251-273.

Balk, Bert M. 1983. Does there exist a relation between inflation and relative price change variability? The effect of the aggregation level, Economic. Letters 13, 2-3, 173-180.

Balk, Bert M. 2005. Price indexes for elementary aggregates: The sampling approach, Journal of Official Statistics, 21, 4, 675-699.

Balk, Bert M. 2008. Price and Quantity Index Numbers, Cambridge: Cambridge University Press.

Baroni, M., Barthélémy, F., \& Mokrane, M. 2007. A PCA repeat sales index for apartment prices in Paris, Journal of Real Estate Research 29, 137-158.

Belsley, David A., Edwin Kuh, and Roy E. Welsch 2005. Regression diagnostics: Identifying influential data and sources of collinearity, vol. 571. John Wiley \& Sons.

Berndt, Ernst R. 1991. The practice of econometrics: classic and contemporary Reading, Massachusetts: Addison Wesley.

Berndt, Ernst R., and Zvi Griliches 1993. Price indexes for microcomputers: An exploratory study. In Price measurement and their uses, ed. Murray F. Foss, Marilyn E. Manser, and Allan H. Young, 63-93. Studies in Income and Wealth 57. Chicago: University of Chicago Press.

Berndt, Ernst R., Zvi Griliches, and Neal. J. Rappaport. 1995. Econometric estimates of different approaches to estimating hedonic price indexes for personal computers in the 1990s. Journal of Econometric, 68, 1, 243-268.

Berndt, Ernst R., and Neal J. Rappaport 2001. Price and quality of desktop and mobile personal computers: A quarter-century historical overview. American Economic Review 91, 2, 268-273.

Bokhari, Sheharyar and David Geltner 2012. Estimating real estate price movement for highfrequency tradable indexes in a scarce data environment, Journal of Real Estate Finance and Economics, 45, 2, 522-543.

Case, Bradford, Henry O. Pollakowski and Susan M. Wachter, 1991 On Choosing Among House Price Index Methodologies, Real Estate Economics, 19, 3, 286-307, September.

Cassel, E. and Mendelsohn, R. 1985. The choice of functional forms for hedonic price equations: comment. Journal of Urban Economics, 18, 2, 135-142. 
Chatterjee, Samprit and Ali S. Hadi 1986. Influential observations, high leverage points, and outliers in linear regression, Statistical Science, 1, 3, August, 379-393.

Can, Ayse, 1992. Specification and estimation of hedonic housing price models, Regional Science and Urban Economics, 22, 3, 453-474, August. Cochran, W.G. 1977. Sampling Techniques, 3rd edition. New York: John Wiley and Sons.

Coulson, E. 2008. Monograph on hedonic estimation and housing markets, Department of Economics, Pennsylvania State University. http://grizzly.la.psu.edu/ ecoulson/hedonicmonograph/monog.htm.

Cribari-Neto, F., and M. G. A. Lima 2010. Approximate inference in heteroskedastic regressions: A numerical evaluation, Journal of Applied Statistics, 37, 4, 591-615, April.

Dalèn, Jorgen 1992. Computing elementary aggregates in the Swedish consumer price index. Journal of Official Statistics, 8, 2, 129-147.

Dalèn, J. and E. Ohlsson 1995. Variance Estimation in the Swedish Consumer Price Index, Journal of Business \& Economic Statistics, July 1995, 13, 3.

Davidson R., and J.G. MacKinnon 1993, Estimation and Inference in Econometrics, Oxford: Oxford University Press.

Diewert, W. Erwin 1976. "Exact and Superlative Index Numbers," Journal of Econometrics, 4, 2, 115-145.

Diewert, W. Erwin 1978. "Superlative Index Numbers and Consistency in Aggregation," Econometrica, 46, 883-900.

Diewert, W. E. 2003a. Hedonic regressions: A review of some resolved issues. Paper presented at the Seventh Meeting of the Ottawa Group. 27- 29 May, Paris.

Diewert W. Erwin 2003b. Hedonic regressions: A consumer theory approach. In Scanner data and price indexes, ed. Mathew Shapiro and Rob Feenstra, 317-48. Studies in Income and Wealth, vol. 61. Chicago: University of Chicago Press.

Diewert W. Erwin 2004. The economic approach to index number theory. In International Labor Office op. cit., chapters 7 and 8.

Diewert, W. Erwin 2005a. Weighted country product dummy variable regressions and index number formulae, Review of Income and Wealth, 51, 561-70.

Diewert, W. Erwin 2005b. Adjacent period dummy variable hedonic regressions and bilateral index number theory, Annales d'Économie et de Statistique, 79/80, Contributions in memory of Zvi Griliches, July/December, 759-786.

Diewert, W. Erwin, Jan de Haan and Rens Hendriks 2011. Hedonic regressions and the decomposition of a house price index into land and structure components, Department of Economics Discussion Paper 11-01, The University of British Columbia. 
Diewert, W. Erwin, Saeed Heravi, and Mick Silver 2009. Hedonic imputation indexes versus time dummy hedonic indexes. In W. Erwin Diewert, John Greenlees, and Charles R. Hulten eds. Price Index Concepts and Measurement, NBER, Chicago: University of Chicago Press, 278-337.

Diewert, W. Erwin, and Chihiro Shimizu 2013. A conceptual framework for commercial property price indexes, Department of Economics Discussion Paper 13-11, The University of British Columbia.

Diewert, W. Erwin and Chihiro Shimizu 2015. Residential property price indexes for Tokyo, Macroeconomic Dynamics, 19, 8, December, 1659-1714.

Dorfman, A. H., Lent, J., Leaver, S. G., and E.Wegman 2006. On sample survey designs for consumer price indexes, Survey Methodology, December, 32, 2, 197-216.

Eurostat, European Union, International Labor Organization, International Monetary Fund, Organisation for Economic Co-operation and Development, United Nations Economic Commission for Europe, The World Bank 2013. Handbook on Residential Property Prices Indices (RPPIs), Luxembourg, European Union.

Feenstra, R. C. 1995. Exact hedonic price indexes. Review of Economics and Statistics,77, 4, 634-53.

Fenwick, David 2013. Uses of residential property price indices, In Eurostat et al. 2013 op. cit., chapter 2.

Fisher, Jeffrey D., David M. Geltner and R. Brian Webb, 1994. Value indices of commercial real estate: A comparison of index construction methods, Journal of Real Estate Finance and Economics, 9, 137-164.

Francke, M.K. (2008). The hierarchical trend model. In T. Kauko and M. Damato, editors, Mass Appraisal Methods; An International Perspective for Property Valuers, 164180 ,

Wiley-Blackwell RICS Research, 2008.

Francke, M. K. and G. A. Vos 2004. The hierarchical trend model for property valuation and local price indices, Journal of Real Estate Finance and Economics, 28, 179-208.

Friedman, Milton 1977. Nobel Lecture: Inflation and Unemployment, Journal of Political Economy, 85, June, 451-72.

Furno, M. 1996. Small sample behavior of a robust heteroscedasticity consistent covariance matrix estimator, Journal of Statistical Computation and Simulation, 54, 105-128.

Geltner, David 1993. Temporal aggregation in real estate return indices, Journal of the American Real Estate and Urban Economics Association 21, 2, 141-166.

Goetzmann, W. N. 1992. The accuracy of real estate indices: Repeat sale estimators. Journal of Real Estate Finance and Economics, 5, 5-53. 
Giles, David E. 2011. Interpreting dummy variables in log-linear regression models: exact distributional results, University of Victoria, Department of Economics, Econometrics Working Paper EWP 1101, January.

de Gregorio, Carlos 2012. Sample size for the estimate of consumer price subindices with alternative statistical designs, Rivesta di Statistica Ufficiale N. 1/2012, Istituto Nazionale di Statistia 19.

Griliches, Z. 1961. Hedonic price indexes for automobiles: An econometric analysis of quality changes. Government Price Statistics: Hearings before the Subcommittee on Economic Statistics of the Joint Economic Committee. 87th Cong., January 24, 1961.

Griliches, Z. 1964. Notes on the measurement of price and quality changes. In Models of income determination, 381-418. NBER Studies in Income and Wealth, vol. 28. Princeton, NJ: Princeton University Press.

Griliches, Zvi, 1971. Hedonic price indexes revisited: Some notes on the state of the art. In Price indexes and quality change, editor, Z. Griliches, 3-15. Cambridge, MA: Harvard University Press.

Griliches, Zvi. 1988. Postscript on hedonics. In Technology, education, and productivity, editor, Zvi Griliches, 119-22. New York: Basil Blackwell.

de Haan, Jan 2004a. Direct and indirect time dummy approaches to hedonic price measurement, Journal of Economic and Social Measurement, 29, 4, 427-443.

de Haan, Jan 2004b. The time dummy Index as a special case of the imputation Törnqvist index, Paper presented at the eighth meeting of the Ottawa Group, 23-25, August 2004, Helsinki, Finland.

de Haan, Jan 2009. Comment on "Hedonic imputation versus time dummy hedonic indexes" and Diewert, Erwin W., "Response” to Jan de Haan's comment in Diewert, Heravi, and Silver (2009) op. cit.

de Haan, Jan2010. Hedonic price indexes: A comparison of imputation, time dummy and 'repricing' methods, Jahrbücher für Nationalökonomie und Statistik / Journal of Economics and Statistics, 230, 6.

de Hann, Jan and W. Erwin Diewert 2013a. Hedonic regression methods. In Eurostat et al. (2013) op. cit., chapter 5.

de Hann, Jan and W. Erwin Diewert 2013b, Repeat sales methods. In Eurostat et al. (2013) op. cit., chapter 6.

de Haan, Jan, and Yunlong Gong 2014. Accounting for spatial variation of land prices in hedonic imputation house price indexes. Paper presented on December 5, 2014 at the 14th annual international workshop of the Economic Measurement Initiative of the Centre for Applied Economics, University of New South Wales, Australia. 
de Haan, Jan and Frances Krsinich 2014. Scanner data and the treatment of quality change in nonrevisable price indexes, Journal of Business \& Economic Statistics 32, 3, 341358.

de Haan, Jan, E. Opperdoes, and C. Schut 1997. Item sampling in the consumer price index: a case study using scanner data, Paper presented at the Joint ECE/ILO meeting of the Group of Experts on Consumer Price Indices, Working Paper n.1, Geneva 24-27 November.

Halvorsen, R. and H.O. Pollakowski 1981. Choice of functional form for hedonic price equations, Journal of Urban Economics, 10, 1, 37-49.

Hansen, James 2009. Australian house prices: A comparison of hedonic and repeat-sales measures, Economic Record, 85, 269, 132-145, June.

Hill, Robert J. 2013. Hedonic price indexes for residential housing: a survey, evaluation and taxonomy, Journal of Economic Surveys, 27, 5, 879-914, December.

Hill, Robert J. and D. Melser 2008. Hedonic imputation and the price index problem: An application to housing, Economic Inquiry, 46, 593-609.

Hill, Robert J. and Michael Scholz 2013. Incorporating Geospatial Data in House Price Indexes: A Hedonic Imputation Approach with Splines, EMG Workshop, University of New South Wales, Sydney, 28-29 November 2013.Hill, T. Peter 1998. The measurement of inflation and changes in the cost of living, Statistical Journal of the United Nations ECE, 15, 37-51.

Igan, Deniz and Prakash Loungani, 2012. Global housing cycles, IMF Working Paper Series WP12/217 August.

Ioannidis, Christos and Mick Silver 1999. Estimating hedonic indices: An application to U.K. television sets. Zeitschrift fur Nationalokonomie (Journal of Economics) 69, 1, 7094.

International Labor Office (ILO), International Monetary Fund, Organisation for Economic Co-operation and Development, Statistical Office of the European Community, United Nations and World Bank 2004. Consumer Price Index Manual: Theory and Practice, Geneva: International Labor Office.

Kennedy, Peter, E. 1980. Estimation with correctly interpreted dummy variables in semilogarithmic equations, American Economic Review 70, 4, 800.

Konus A. 1924. A misunderstanding in index-number theory: The true Konus condition on cost-of-living index numbers and its limitations, translated in Econometrica, 7, 1, January, 1939, 10-29.

MacKinnon, James G. 2013. Thirty years of heteroscedasticity-robust inference. In Chen, Xiaohong and Norman R. Swanson (Editors), Recent Advances and Future Directions in Causality, Prediction, and Specification Analysis: Essays in Honor of Halbert L. White Jr., New York: Springer. 
Maddala, G.S. and Kajal Lahiri, 2009. Introduction to Econometrics, John Wiley: Chichester, West Sussex.

Muellbauer, John and Anthony Murphy 2008. Housing markets and the economy: the assessment, Oxford Review of Economic Policy 24, 1, 1-33.

Okamoto, Masato 2001. Midpoint-year basket index as a practical approximation to a superlative index, Paper presented at the Sixth Meeting of the International Working Group on Price Indices, Canberra, Australia, 2-6 April 2001.

Pace, R. Kelley and James P. LeSage 2004. Special issue: Spatial statistics and real estate, Journal of Real Estate Finance and Economics, 29, 2.

Pakes A., 2003 A reconsideration of hedonic price indexes with an application to PCs, The American Economic Review, 93, 5, December, 1576-1595.

Qian, L. and S. Wang 2001. Bias-corrected heteroscedasticity robust covariance matrix (sandwich) estimators," Journal of Statistical Computation and Simulation, 70, 161174.

Rambaldi, A.N. and C.S. Fletcher 2014. Hedonic imputed price indexes: the effects of econometric modeling choices, The Review of Income and Wealth 60, s423-s448.

Rambaldi, A. N. and D. S. P. Rao, 2011. Hedonic predicted house price indices using timevarying hedonic models with spatial autocorrelation, School of Economics Discussion Paper 432, School of Economics, University of Queensland.

Rambaldi, A. N. and D. S. P. Rao, 2013. Econometric modeling and estimation of theoretically consistent housing price indexes, WP04/2013 in CEPA Working Papers Series, School of Economics, University of Queensland.

Rao, D. S. P. 2005. On the equivalence of weighted country product (CPD) method and the Rao system for multilateral price comparisons, Review of Income and Wealth, 4, $570-580$.

Rosen, S. 1974. Hedonic prices and implicit markets: Product differentiation and pure competition. Journal of Political Economy 82:34-49.

Peter J. Rousseeuw 1984. Least Median of Squares Regression, Journal of the American Statistical Association, 79, 388, December, 870-880.

Reinsdorf, Marshall 1994. New Evidence on the Relation between Inflation and Price Dispersion, American Economic Review. 84, June, 720-731.

Schwann, G. M. 1998. A real estate price index for thin markets, Journal of Real Estate Finance and Economics, 16, 269-87.

Schulz, Rainer and Axel Werwatz 2004. A state space model for Berlin house prices: estimation and economic interpretation, The Journal of Real Estate Finance and Economics, 28, 1, 37-57. 
Shiller, Robert J. 1991. Arithmetic repeat sales price estimators, Journal Housing Economics, $1,1,110-126$.

Shiller, Robert J. 1993. Measuring asset values for cash settlement in derivative markets: hedonic repeated measures indexes and perpetual futures, Journal of Finance 48, 3, 911-931.

Shiller, Robert J. 2014. S\&P Dow Jones Indices: S\&P/Case-Shiller Home Price Indices Methodology McGraw Hill Financial, July. http://us.spindices.com/index-family/realestate/sp-case-shiller.

Shimizu, C., K. G. Nishimura and T. Watanabe 2010. Housing prices in Tokyo: A comparison of hedonic and repeat sales measures, Journal of Economics and Statistics, 230, 6,

$792-813$.

Silver, Mick 1999. An evaluation of the use of hedonic regressions for basic components of consumer price indices, The Review of Income and Wealth, 45, 1, 41-56.

Silver, Mick 2004. Quality change and hedonics. In International Labor Office, International Monetary Fund, Organisation for Economic Co-operation and Development, Statistical Office of the European Community, United Nations and World Bank, Consumer Price Index Manual: Theory and Practice, Geneva: International Labour Office, chapter 20.

Silver, Mick 2011. House price indices: does measurement matter? World Economics, 12, 3, July-Sept.

Silver, Mick 2013. Understanding commercial property price indexes, World Economics 4, 3, September, 27-40.

Silver, Mick 2015. The degree and impact of differences in house price index measurement, Journal of Economic and Social Measurement, 39, 305-328.

Silver, Mick 2016. Real-estate price indexes, availability, importance, and new developments, Reality, Data, and Space, International Journal of Statistics and Geography, 7, 1, January-April.

Silver, Mick and Brian Graf 2014. Commercial property price indexes: problems of sparse data, spatial spillovers, and weighting, IMF Working Paper WP/14/72, Washington DC, April.

Silver, Mick and Saeed Heravi 2001a. Scanner Data and the Measurement of Inflation, Economic Journal, 111, 472, 383-404, June.

Silver M. and Saeed Heravi 2001b. Quality adjustment, sample rotation and CPI practice: an experiment," presented at the Sixth Meeting of the International Working Group on Price Indices, Canberra, Australia, April 2-6. 
Silver, Mick and Saeed Heravi 2003. The measurement of quality-adjusted price changes. In Robert C. Feenstra and Matthew D. Shapiro, editors, Scanner Data and Price Indexes, NBER: University of Chicago Press.

Silver, Mick and Saeed Heravi 2005. A failure in the measurement of inflation: results from a hedonic and matched experiment using scanner data, Journal of Business and Economic Statistics, 23:5, 269-281.

Silver, Mick and Saeed Heravi 2007a. Different approaches to estimating hedonic indexes. In Ernst R. Berndt and Charles R. Hulten, editors, Hard-to-Measure Goods and Services: Essays in Honor of Zvi Griliches, NBER: Chicago: University of Chicago Press.

Silver, Mick and Saeed Heravi 2007b. The difference between hedonic imputation indexes and time dummy hedonic indexes, Journal of Business and Economic Statistics, 252 , 239-246, April 2007.

Silver, Mick and Saeed Heravi 2007b. Why elementary price index number formulas differ: price dispersion and product heterogeneity, Journal of Econometrics 140, 2, 874-83, October.

Silver, Mick and Christos Ioannidis 2001. Inter-country differences in the relationship between relative price variability and average prices, Journal of Political Economy 109,2 , 355-374, April.

Sirmans S., L. MacDonald, D. Macpherson and E. Zietz 2006. The value of housing characteristics: A metaanalysis," The Journal of Real Estate Finance and Economics 33, 215-240.

Thorsnes, P., \& Reifel, J. W. 2007. Tiebout dynamics: Neighborhood response to a central city/ suburban house-price differential. Journal of Regional Science 47, 693-719.

Triplett, Jack 2006. Handbook on Hedonic Indexes and Quality Adjustments in Price Indexes Special Application to Information Technology Products: Special Application to Information Technology Products. OECD Publishing.

Triplett, Jack E. 1987. Hedonic functions and hedonic indexes. In The New Palgrave: A Dictionary of Economics, first edition. Editors: John Eatwell, Murray Milgate and Peter Newman, Palgrave Macmillan, UK, The New Palgrave Dictionary of Economics Online, Palgrave Macmillan. December 2005.

Triplett, Jack E. and Richard J. McDonald 1977. Assessing the quality error in output measures: the case of refrigerators, Review of Income and Wealth 23, June, 137-56.

Van Garderen, K. J. and C. Shah 2002. Exact interpretation of dummy variables in semi logarithmic equations, Econometrics Journal 5, 149-159. 